\title{
Properties and Interactions of Oral Structures and Restorative Materials
}

J. A. Tesk

J. M. Antonucci

J. W. Stansbury

S. M. Keeny

K. Asaoka

J. Code

G. Schumacher

U.S. DEPARTMENT OF COMMERCE

Technology Administration

National Institute of Standards

and Technology

Materials Science and Engineering Laboratory

Polymers Division

Dental and Medical Materials

Gaithersburg, MD 20899

Prepared for.

National Institute of Dental Research

Bethesda, MD 20892

Annual Report for Period

October 1, 1991 to September 30, 1992

Issued May, 1993

Interagency Agreement

Y01-DE30001 


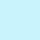




\section{Properties and Interactions of Oral Structures and Restorative Materials}

\author{
J. A. Tesk \\ J. M. Antonucci \\ J. W. Stansbury \\ S. M. Keeny \\ K. Asaoka \\ J. Code \\ G. Schumacher
}

U.S. DEPARTMENT OF COMMERCE

Technology Administration

National Institute of Standards

and Technology

Materials Science and Engineering Laboratory

Polymers Division

Dental and Medical Materials

Gaithersburg, MD 20899

Prepared for:

National Institute of Dental Research

Bethesda, MD 20892

Annual Report for Period

October 1, 1991 to September 30, 1992

Issued May, 1993

Interagency Agreement

Y01-DE30001

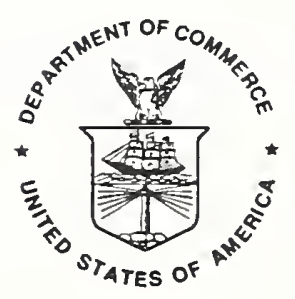

U.S. DEPARTMENT OF COMMERCE Ronald H. Brown, Secretary

NATIONAL INSTITUTE OF STANDARDS AND TECHNOLOGY

Raymond G. Kammer, Acting Director 


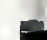


TABLE OF CONTENTS. . . . . . . . . . . . . . . . . . . . . . i ABSTRACT. . . . . . . . . . . . . . . . . . . . . . . iv STATEMENT OF WORK. . . . . . . . . . . . . . . . . . . . vi-xiii

PART I - IMPROVEMENT OF DENTAL COMPOSITES, SEALANTS, CEMENTS AND ADHESIVE MATERIALS (Antonucci, Stansbury, Liu, Keeny, Matsuya, Kikuchi). • . . . . . . . . . . . . . . 1

A. Improvement of Dental Resin Systems. . . . . . . . . . 2

A. 1 Monomers which Polymerize with Expansion. . . . 2

A. 2 Lactone Monomers. . . . . . . . . . . . . 11

A.3 Low Surface Energy Monomers. . . . . . . . . . 11

A.4 Cyclopolymerizable Monomers. . . . . . . . . . . 11

A.7 Synthesis, Characterization and Evaluation of Multifunctional Silane Agents. . . . . . . . 34

B. Improvement of Filler systems for Composites and Cements. . . . . . . . . . . . . . . . 38

D. New Resin Systems and Pretreatment Techniques for Bonding to Dentin . . . . . . . . . . . . . 38

E. Improvement of Dental Cements. . . . . . . . . . 55

F. Fluorescent Probes for Assessing the Cure of Dental Composites and the Effectiveness and Durability of Coupling Agents. (A PILOT EXPLORATION TO DEMONSTRATE FUTURE APPLICABILITY IN DENTAL MATERIALS) • • • • • 57

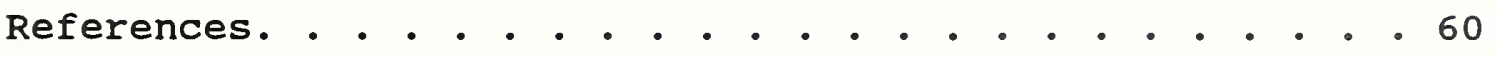

PART II - WEAR RESISTANCE AND DURABILITY ASSESSMENT OF DENTAL COMPOSITE RESTORATIVES AND RELATED MATERIALS (KeenY, Antonucci, Stansbury) . . . . . . . . . . . 70

A. Round-Robin Wear and Chemical Degradation Study of Posterior Composites. . . . . . . . . . . . . . . 0 
Summary • • • • • • • • • • • • • • • • • • • • •

References. • . . . . . . . . . . . . . . . . 79

PART III - DENTAL ALLOYS, CERAMICS, METROLOGY AND ANALYSES (Tesk, Asaoka, Kelly). . . . . . . . . . . 83

A. Stress in Prosthetic and Restorative Systems (Porcelain-Metal Thermo-mechanical Compatibility) . . 84

References. . . . . . . . . . . . . . . . . . 92 ADDENDUM:

Publications. . . . . . . . . . . . . . . . . 93

Preprints and Reports. . . . . . . . . . . . . . . . 93

Manuscripts in Press. . . . . . . . . . . . . . 95

Submitted to Journal or Under Review. . . . . . . . . 95

Invited Talks. . . . . . . . . . . . . . . . 95

Contributed Talks. . . . . . . . . . . . . . . . 96

Patents. . . . . . . . . . . . . . . . . 97

American Dental Association Publications. . . . . . . 98

American Dental Association Manuscripts Submitted

to Journal or Under Review . . . . . . . . . . . . . 99

NIDR Research Papers. . . . . . . . . . . . . 101 
The headings and subheadings of the annual report retain their designations from the original proposal. Since some sections of that proposal were deleted or reorganized into other sections, gaps appear in the numbering system for the annual report. The following sections from the original proposal were deleted or reorganized with the consequence that no technical report is given or required for these sections:

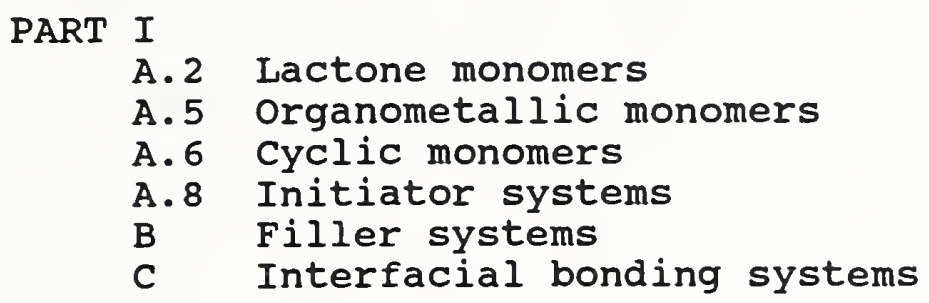

\author{
PART II \\ Phases I-IV, and VI \\ PART III \\ B. 1 Bonded systems \\ B.2 Diametral tensile strength \\ B.3 Clinical performance \\ C Superstrong prostheses
}

NOTE: Certain commercial materials and equipment are identified in this article to specify the experimental procedures. In no instance does such identification imply recommendation or endorsement by the National Institute of standards and Technology or that the materials and equipment identified are necessarily the best available for the purpose. 
The research program described herein is designed to achieve a number of objectives leading to improved dental restorative materials, techniques and applications of dental materials science for improved delivery of health care. The bulk of the research is related in one manner or another to dental composites, cements, adhesives, and sealants. composite research focuses on improvements through the development of more durable resin matrices, stronger and more durable coupling between fillers and resins, and defining the best overall combination of components, including curing systems, for improved performance of composites. This work has moved swiftly toward a major emphasis on the synthesis and applications of monomers which reduce polymerization shrinkage through the use of expanding monomers (or monomers which undergo much less shrinkage than conventional resin-matrix monomers).

Research on cements, adhesives and sealants employs many of the same methods as for composites but with further attention to adhesion to dentin and enamel. Analytical techniques include infrared (IR) spectroscopy, chromatography, x-ray analysis, nuclear magnetic resonance, hardness and tensile testing, and shrinkage dilatometry. A new effort involves a study aimed at the use and further development of fluorescent dye spectroscopy for analysis of processes such as curing, applying coupling agents and monitoring the degradation of bonding between fillers and resin matrices; this application holds promise for farreaching results.

Studies on the wear and durability of dental materials are conducted to complement the generic developmental work on composites, cements, adhesives and sealants. The wear work is to help guide further improvements in materials.

A second distinct area of effort focuses on dental alloy and ceramic systems. Weibull statistics, computer modeling, and finite element stress analysis are employed for the determination of the strengths of ceramic and ceramic-metal systems as affected by processing parameters, thermo-mechanical properties, and relative material thicknesses.

This program was divided in Three Basic Parts for FY 1991; in FYs 92 and 93, Part II on Wear Resistance is subsumed into Part I, Improvement of Dental Composites, Sealants, Cements and Adhesive Materials. 
"The activity covered by this agreement consists of work which requires the definition of measurement methods, materials property data, and standards of basic scientific and engineering units, and the application of primary standards to insure equity and comparability in U.S. commerce, international trade, and technical activities. As such it complies with OMB Circular A76, Revised under paragraph 5f ("Activities classified as Government responsibilities or are intimately related to the public interest")."

NO HUMAN SUBJECTS ARE INVOLVED IN THIS RESEARCH 
PART I. - Improvement of Dental Composites, Sealants, Cements, and Adhesive Materials

The overall objective of Part $I$ is to enhance the in vivo properties, especially durability and performance, of resin-based and related dental materials (composites, sealants, adhesives, cements, etc.).

A. Improvement of Dental Resin Systems

The primary focus of section $A$. of Part I is the development of new types of monomer systems that yield highly converted, stable polymers that have experienced slight or zero contraction or even a slight expansion on polymerization. In addition, monomers that are designed to enhance interfacial bonding within composites, and to tooth structure, will be synthesized.

This work will proceed as outlined:

A.1 Monomers which Polymerize with Expansion

Phase I:

Consists of several distinct, independent approaches primarily related to the synthesis of new monomers for double ring-opening polymerization.

Phase II:

Characterization of the new spiro monomers (e.g. IR, NMR), studies of their polymerization behavior and evaluation of polymer and copolymer properties will be performed.

Phase III:

The most promising spiro monomers will be used to formulate dental resin systems and composites which will be evaluated for polymerization shrinkage, mechanical strength, wear, water uptake, resistance to simulated oral fluids and adhesion potential. 


\section{A. 4 Cyclopolymerizable Monomers}

Phase I:

Consists of several distinct, independent approaches primarily related to the synthesis of cyclopolymerizable monomers and study of the cyclopolymerization process.

\section{Phase II:}

Characterization of the new monomers (e.g. IR, NMR), studies of their polymerization behavior and evaluation of polymer and copolymer properties will be performed.

Phase III:

The most promising new monomers will be used to formulate dental resin systems and composites which will be evaluated for polymerization shrinkage, mechanical strength, wear, water uptake, resistance to oral fluids and adhesion potential.

A.7 Synthesis, Characterization and Evaluation of Multifunctional Silane Agents

Phase I:

Evaluation of previously synthesized silane agent derived from the reaction of 3isocyanatopropyltriethoxysilane and 2,2-bis [p-2-(hydroxy-3'-methacryloxypropoxy) phenyl]propane (BIS-GMA).

Phase II:

Multifunctional silane agents based on a polyfluorinated polyol (PFP).

Phase III:

Double ring-opening silanes.

B. Improvement of Filler Systems for Composites and Cements

D. New Resin systems and Pretreatment Techniques for Bonding to Dentin

Phase I: 
Pretreatments of dentin.

Phase II:

Synthesis, characterization and evaluation of new surface-active monomers based on $\alpha-$ bromomethylacrylate.

Phase III:

Synthesis, characterization and evaluation of new surface-active monomers.

Phase IV:

Synthesis, characterization and evaluation of new surface-active monomers from trimellitic anhydride chloride.

Phase V:

Does not exist due to typographical error in original proposal.

Phase VI:

Synthesis, characterization and evaluation of fluorinated surface-active monomers.

Phase VII:

Synthesis, characterization and evaluation of the surface-active monomers based on $\mathrm{N}-\mathrm{t}-$ butylaminoethylmethacrylate.

Phase VIII:

Investigate the self-curing mechanism of carboxylic acid monomers and aryl amines.

E. Improvement of Dental Cements

The goal is to reduce their propensity to brittle failure and hydrolytic degradation, and enhance their biocompatibility and adhesion to tooth structure by changes in their structure and/or composition.

Phase I:

Develop new types of hybrid cement-composites based on polyelectrolyte cements plus water soluble monomers capable of cyclopolymerization. 
Phase II:

Develop new types of hybrid cement-composites based on modified water soluble polymers.

Phase III:

Develop new calcium phosphate cements based on the apatite-forming reaction of dicalcium phosphate and tetracalcium phosphate using aqueous solutions of phytic acid or derivatives as the reaction media.

Phase IV:

Develop new polyelectrolyte cements from the cyclic polymers or copolymers of acrylic or methacrylic anhydride.

F. Fluorescent Probes for Assessing the Cure of Dental Composites and the Effectiveness and Durability of Coupling Agents. (A PILOT EXPLORATION TO DEMONSTRATE FUTURE APPLICABILITY IN DENTAL MATERIALS)

There are two primary objectives to this part of the proposal with one underlying common theme i.e., to improve properties of dental composite resins and resin-based cements by monitoring the degree of cure and the quality of the interfacial bond within composites through the application of NIST's fluorescent dye technology.

The first objective is to use cure-sensitive fluorescent dyes for making definitive measurements of the curing in composites and cements, thereby leading to improved resin formulations and initiator systems. It can be foreseen that this technology could also be useful for the American dental industry (research and product quality assurance) and might even find its way into the practicing dentist's office.

The second objective is to use fluorescent dyes for quantitative measurements of the effectiveness of various methods for applying a variety of coupling agents to filler substrates, and for determining the degradation resistance of the coupling agent-to-filler bond. This work can be extended to degradation of the interfacial bond between the resin matrix and the coupling agent-filler system. Here too, the potential application as a measurement technique in the clinical evaluation of composites, and the extension to use in dental practice, are reasonable possibilities. 
The following work plan is envisioned:

CURING TECHNOLOGY

Phase I: (Pilot)

Develop dye systems which are physically and chemically compatible with dental monomers.

Phase II: (Pilot)

Correlate fluorescent dye measurements with those from IR spectroscopy for quantitative assessment of degree of cure via fluorescence (use neat resins, then composites and cements).

Phase III:

(a) Use fiber waveguides for excitation of fluorescence in standardized forms of dental composite to determine: degree of cure and depth of cure as functions of the curing system (composite, initiator, method of initiation, etc.).

(b) Use the technique as research tool for developments in other sections of Part I of the proposal.

Phase IV:

(a) Evaluate the degree of cure (in vitro) within simulated composite restorative fillings:

(1) degree of cure.

(2) depth of cure.

(b) Evaluate the cure of resin based cements under crowns, around inlays and with fixed partial dentures.

Phase V:

Explore techniques, including hardwares, for applying the technology for use in the dental clinic for control of degree of cure and determination of depth of cure.

COUPLING-AGENTS

Phase I: (Pilot) 
Use flat plates of composite filler material (quartz, fused silica, etc.) for evaluation of efficiency of attachment (by measurement of dye fluorescence):

(1) technique variation.

(2) coupling-agent chemistry.

Phase II:

For the most promising systems from Phase I, evaluate stability of attachment to plates:

(1) water, various $\mathrm{pH}$ levels.

(2) other food simulating liquids.

Phase III:

(a) Prepare dental composites with filler employing best coupling-agents from Phase II.

(b) Cure prepared composites between glass plates, mylar etc. to produce high degrees of cure. Then remove covering and expose composite to degradation environment.

(c) Debonding should yield a shift in the fluorescence color (wavelength). Upon successful demonstration of technique, use in other sections of Part I and promote for use by American industry.

Phase IV:

Using suitable filters, etc. conduct in vitro simulation of clinical examination of composite resin fillings exposed to wear in a degradation environment to determine potential use for:

(1) clinical evaluation of composites.

(2) diagnosis of failing composites in dental practice.

PART II. Wear Resistance and Durability Assessment of Dental Composite Restoratives and Related Materials

The general objective of this project is to develop a fundamental basis for enhancing the durability of dental composite restoratives and related materials. The approach is to define and delineate critical wear mechanisms applicable to the in vitro wear of these materials. For this work two classical pin and disc wear apparatuses will be employed: (1) a first generation unit, (I), which bathes specimens with flowing water and; (2) a second generation unit, (II), for which the bathing medium can be chosen from 
a variety of food simulating liquids (including water) with the capability for providing constant exposure to the specimen. Various ancillary methods of degradative analyses will be employed. This project consists of the following phase:

Phase V: This phase has two components

A. Round-Robin Wear and Chemical Degradation study of Posterior Composites

B. Complete Construction of the Modified Wear Testing Apparatus

PART III. Dental Alloys, Ceramics, Metrology and Analyses

A. Stress in Prosthetic and Restorative Systems (Porcelain-Metal Thermo-mechanical Compatibility)

The objectives of this work are to make viscoelastic calculations of transient and residual stresses which develop in ceramic-metal systems as functions of processing, materials, and geometrical (dimensional) parameters.

Phase I:

For the viscoelastic models of porcelain and porcelainmetal slabs developed for ceramic-metal systems during the previous term of the interagency agreement: vary the coefficients of thermal expansion, $\alpha_{1}, \alpha_{2}, \alpha_{3}$ of metal, opaque and body porcelains, respectively, to determine how stresses change at the porcelain body surface, body-opaque interface and opaque-metal interface. Each $\alpha$ will be varied from a low to high value while holding the others constant. Other effects such as body, opaque and metal thicknesses, porcelain viscosities and activation energies will also be explored. Other geometry models such as shells or cylinders will be considered.

Phase II:

After one complete series of Phase I simulations at one cooling rate, several additional complete series will be run with the cooling rate as the variable.

Phase III:

Develop charts, figures and empirical formulae etc., useful for depiction of effects of $\alpha^{\prime} s$, and cooling rates etc. 
Phase IV:

For porcelain-metal systems, calculate stress relaxations at fixed temperatures or temperature ramps as functions of holding or cooling conditions. Vary the relative porcelain viscosities to determine trends which can be useful in design of more desirable stressstate systems.

Phase V:

For alloy systems which undergo phase transformations develop models which incorporate effects of phase transformations into viscoelastic calculations of stress as affected by such transformations under a variety of cooling regimens. 



\section{Overview}

The quest for durable, esthetic, adhesive and biocompatible materials suitable for the restoration of lost tooth structure has long challenged dental materials researchers. A significant step toward the realization of this goal was the development of resin-based dental composites which overcame many of the shortcomings of the silicate cements (purely inorganic composites) and unfilled resin restoratives (purely organic composites based on methyl methacrylate and its polymers). The synthesis of 2,2-bis[p-2'-(hydroxy-3'methacryloxypropoxy) phenyl]propane (BIS-GMA), by Bowen, ushered in the modern era of resin-based dental composite restorative materials and also other resin-based dental materials $[1,2]$. The essential components of dental composites are: (1) a resin system comprising one or more vinyl monomers which on polymerization forms the matrix or continuous phase, (2) reinforcing fillers such as radiopaque glasses, quartz, minerals, ceramics, organic and hybrid organic-inorganic powders of various sizes, size distributions, and shapes form the dispersed phase, (3) an interfacial phase for bonding the continuous and dispersed phases, derived from vinyl silanes, titanates, zirconates, i.e., coupling agents, (4) a polymerization initiator system effective under ambient conditions, and (5) stabilizers for optimizing storage stability and also preserving the chemical stability of the hardened restoration [3-25].

Unlike glass ionomer cements that bond to tooth structure, current resin-based composites are non-adhesive in nature. However, the acid-etch technique usually provides an effective micromechanical mechanism for bonding dental composites to enamel $[26,27]$. Bonding to dentin is a more challenging problem but recent developments have resulted in effective coupling agents for this substrate as well. [28-38] Efforts to enhance the durability and range of applications (e.g., posterior as well as anterior fillings) of dental composites include: optimization of the types, sizes, shapes and volume of the dispersed phase, reductions in the solubility parameter, residual vinyl unsaturation, and polymerization shrinkage of the resin phase and the development of more effective interfacial bonding phases [39-70].

Dental sealants have similar compositions and chemistry but are unfilled or only lightly filled and usually contain a higher proportion of diluent monomer(s). Resin-based systems also are widely used in other applications (e.g., adhesives, core build-up and crown and bridge materials, laminating veneers, impression, denture and maxillofacial materials. 
Dental cements, which also have a composite nature, find use in a wide variety of dental applications. In restorative dentistry they are employed as temporary, intermediate, and (in the case of glass ionomer cements) permanent filling materials. Their chemistry of hardening involves a series of acid-base reactions involving ion-exchanges that result in the development of a matrix into which are imbedded partially reacted basic filler particles. An ion-exchange mechanism involving polyelectrolyte cements (e.g., glass ionomer) and mineralized tissue also may explain their adhesion to tooth structure [71-83].

Two types of dental cements can be distinguished depending on their water content: (1) those that are aqueous based (e.g., zinc phosphate, polycarboxylate, glass ionomer) in which water plays a role both in their setting and in the development of their molecular and micro structures, and (2) those that are relatively non-aqueous in nature (e.g., zinc oxide-eugenol (ZOE), ethoxybenzoic acid (EBA), hexyl vanillate-EBA, dimer acid, etc.), although catalytic amounts of water or other polar compounds (e.g., acetic acid) are needed to activate the acid-base reactions and to achieve clinically acceptable setting times.

Basically this section is divided into three areas of research:

I. Improvement of Dental Resin Systems for Composites and Sealants.

(Synthesis, Characterization, Formulation and Evaluation)

II. Bonding of New Resin Systems to Tooth structure. (Synthesis, Characterization, Formulation and Evaluation)

III. Improvement of Dental Cements.

(Synthesis, Characterization, Formulation and Evaluation)

I. Improvement of Dental Resin systems for composites and sealants

Objective

The goal of this research task is to enhance the durability of dental composite, sealant, cement and adhesive materials through the use of low-shrinking, but highly thermosetting and stable resins. 
A.1. Monomers that Polymerize with Expansion

\section{Background}

A variety of material deficiencies have been attributed to the volume contraction associated with the polymerization of dental resins in composite and adhesive applications $[1,2]$. These deficiencies arise from the generation of stresses which are of sufficient magnitude to cause defects within the resin matrix and debonding at the interfaces [3-5]. These complications undermine performance and often restrict those situations for which composites and other related dental resin materials can be considered.

One approach toward minimizing the extent of polymerization shrinkage in resins is to incorporate spiro orthocarbonate monomers into formulations with conventional dimethacrylate comonomers. The oxaspiro monomers can undergo double ringopening polymerization wherein two bonds are broken for each new bond formed. The result is an expansion in volume that can be applied to counter the volume contraction connected with the methacrylate component of the polymerization.

These early results led to the development of free-radicalpolymerizable, asymmetric spiro orthocarbonate monomers $[6,7]$ which can have melting points below room temperature depending on substituent and ring size considerations. Liquid oxaspiro monomers were substituted in place of the dimethacrylate diluent monomer in dental composite formulations [8]. These experimental materials provided reduced polymerization shrinkage values along with a corresponding increase in the adhesion.

\section{PROGRESS REPORT}

During this reporting period, progress was made in the following areas:

b) Synthesis of modified ring-opening monomers.

d) Synthesis of 2-methylene spiro monomers.

f) Polymerizable chain transfer agents.

g) Spiro monomers based on large rings.

h) N-containing spiro monomers.

The results represent work in Phase I (monomer synthesis) designated (I), Phase II (characterization and polymerization of new monomers), designated (II), and Phase III (formulation and evaluation of experimental resins), designated (III), which pertain to the individual sections of the work plan.

b) Modified ring-opening monomers. 
In the previous annual report, the synthesis of a hydroxylfunctionalized spiro monomer was outlined (Scheme 1, [page 17]). The hydroxyl substituent gives access to a number of derivatives which can expand the potential applications of the ring-opening monomers. Compounds $1 \mathrm{a}$ and $1 \mathrm{~b}$ can be used in polymerizations in their underivatized states as a polar ringopening monomer. Some polymerization studies have been done in this manner. The hydroxyl groups have also been reacted with hexamethylene diisocyanate (scheme 2) to yield the viscous bis(spiro) diurethane monomer 2 (I). Evaluation of this crosslinkable ring-opening monomer remains to be completed.

The synthesis of a methacrylate derivative (3, scheme 3 ) was also described in the previous report. The multifunctional nature of monomer 3 allows crosslinked polymers to be formed in concert with ring opening and minimizes concerns of single ring opening with elimination of a cyclic carbonate fragment. This elimination pathway, which also serves to cleave two bonds per monomer addition, can be a significant pathway in both free radical and cationic polymerizations of oxaspiro monomers $[9,10]$. The results of polymerization studies with 3 and the evaluation of dental resins incorporating the spiromethacrylate monomer are reported here.

Polymerization studies involving radical and cationic polymerization of monomer 3 are summarized in Table 1 (II). A complex structure is proposed for the free radically produced polymer of 3 as a result of multiple polymerization pathways. Segments based on polymerization via non-ring opening, double ring opening and single ring opening with elimination are shown in scheme 4. Comparisons of the cationic polymerizations of monomer 3 and the model compounds 4 and 5 ( $\mathrm{Table} 2$ ) demonstrate advantages in terms of reactivity, rate of polymerization and crosslink formation to result from incorporation of the vinyl ether-type double bond in the ringopening monomer. Polymers of 3 obtained from the cationic or mixed cationic/free radical polymerization modes showed essentially complete ring opening as determined by the appearance of linear and cyclic carbonate absorption bands at approximately 1750 and $1800 \mathrm{~cm}^{-1}$, respectively, in the IR.

The degree of conversion results (Table 3 ) for the photopolymerized, unfilled (ethoxylated bisphenol A dimethacrylate) resin films demonstrate that high conversions of both the methacrylate and spiro vinyl groups can be achieved (III). The combination of UVI and BME in a mixed initiator system provided the optimum conversions observed for both the methacrylate and spiro vinyl groups (approximately $85 \%$ in each case). The comparable polymerization efficiencies of the spiro vinyl and methacrylate groups may allow higher proportions of the ring opening oxaspiro monomer to be utilized in the resin 
composition which should permit greater control of the polymerization shrinkage.

Table 1

Influence of Initiators on Polymerization of Spiro-methacrylate 3

\begin{tabular}{|c|c|c|c|c|c|}
\hline \multirow[b]{2}{*}{ Initiator } & \multirow[b]{2}{*}{ Abbrev } & \multirow{2}{*}{$\begin{array}{l}\text { Mode of } \\
\text { action }\end{array}$} & \multicolumn{2}{|c|}{ Conversion } & \multirow{2}{*}{$\begin{array}{l}\text { Ring } \\
\text { opening }\end{array}$} \\
\hline & & & $\mathrm{MA}$ & SV & \\
\hline $\begin{array}{c}\text { azobis (isobutyro- } \\
\text { nitrile) }\end{array}$ & AIBN & $\begin{array}{l}\text { radical } \\
\text { thermal }\end{array}$ & good & fair & fair \\
\hline $\begin{array}{l}\text { di-tert-butyl } \\
\text { peroxide }\end{array}$ & DTBP & $\begin{array}{l}\text { radical } \\
\text { thermal }\end{array}$ & good & fair & poor \\
\hline camphorquinone & $C Q$ & $\begin{array}{l}\text { radical } \\
\text { photo }\end{array}$ & good & fair & fair \\
\hline $\begin{array}{c}\text { benzoin methyl } \\
\text { ether }\end{array}$ & BME & $\begin{array}{l}\text { radical } \\
\text { photo-UV }\end{array}$ & excel & good & good \\
\hline $\begin{array}{c}\text { boron trifluoride } \\
\text { etherate }\end{array}$ & BTFE & cationic & poor & excel & excel \\
\hline $\begin{array}{c}\text { 4-diazo-N, } N- \\
\text { diethyl-aniline } \\
\text { fluoroborate }\end{array}$ & DDFB & $\begin{array}{l}\text { radical/ } \\
\text { cationic }\end{array}$ & poor & excel & excel \\
\hline $\begin{array}{l}\text { Cyracure UVI- } 6974 \\
\text { (UV initiator for } \\
\text { cycloaliphatics) }\end{array}$ & UVI & $\begin{array}{l}\text { radical/ } \\
\text { cationic } \\
\text { photo-UV }\end{array}$ & fair & excel & excel \\
\hline
\end{tabular}

$\mathrm{MA}=$ methacrylate double bond; $S V=$ spiro vinyl double bond. 
Table 2

$$
\text { Polymer Characteristics }
$$

\begin{tabular}{cccc} 
& \multicolumn{4}{c}{ Monomers } \\
\cline { 2 - 4 } $\begin{array}{c}\text { Initiator } \\
\text { type }\end{array}$ & SOCM & Soc acetate & Non-vinyl SOCM \\
& $(3)$ & $(4)$ & $(5)$ \\
\hline
\end{tabular}

Free radical

crosslinked

mostly spiro

slight DRO

moderate SRO/E

shrinkage 9-11\% soluble

mainly spiro

slight DRO

moderate SRO/E crosslinked mainly spiro some acrylate slight DRO slight SRO/E

Cationic

crosslinked

no spiro

mainly DRO

slight SRO/E

very reactive

shrinkage $2-3 \%$ soluble

no spiro

mainly DRO

slight SRO/E

very reactive crosslinked

no spiro mainly SRO/E moderate DRO less reactive

DRO = double ring opening.

$\mathrm{SRO} / \mathrm{E}=$ single ring opening with elimination. 
Table 3

Degree of Conversion of Photo-polymerized 3/EBPAD Resins ${ }^{\circ}$

\begin{tabular}{|c|c|c|c|c|}
\hline \multirow[b]{2}{*}{ Initiator } & \multirow[b]{2}{*}{ Wtq of resin } & \multirow[b]{2}{*}{ Cure conditions } & \multicolumn{2}{|c|}{ Conversion ${ }^{\dagger}, q$} \\
\hline & & & MA & SV \\
\hline$C Q /$ EDMAB $^{\ddagger}$ & $0.2 / 0.8$ & blue light/40 s & 77 & 53 \\
\hline $\mathrm{CQ} / \mathrm{EDMAB}$ & $0.2 / 0.8$ & sunlamp/5 min & 41 & 50 \\
\hline CQ/EDMAB / UVI & $0.2 / 0.8 / 1.5$ & sunlamp/5 min & 77 & 71 \\
\hline$C Q / E D M A B / D D F B$ & $0.2 / 0.8 / 0.5$ & sunlamp/5 min & 23 & 29 \\
\hline BME & 0.7 & $\begin{array}{c}\operatorname{sun} l a m p / 5 \\
1 \mathrm{hin}\end{array}$ & $\begin{array}{l}73 \\
85\end{array}$ & $\begin{array}{l}33 \\
48\end{array}$ \\
\hline BME/UVI & $0.7 / 1.5$ & $\begin{array}{c}\text { sunlamp } / 5 \mathrm{~min} \\
1 \mathrm{~h}\end{array}$ & $\begin{array}{l}81 \\
87\end{array}$ & $\begin{array}{l}83 \\
84\end{array}$ \\
\hline
\end{tabular}

- Resin = spiro monomer 3 + ethoxylated bisphenol $\mathrm{A}$ dimethacrylate in a $26.6: 73.4$ weight ratio.

$+\mathrm{MA}=$ methacrylate double bond; $\mathrm{SV}=$ spiro vinyl double bond.

F EDMAB = ethyl 4-N,N-dimethylaminobenzoate.

d) 2-Methylene spiro monomers.

Our experience with a variety of free radical polymerizable spiro monomers has indicated that the 2-methylene spiro orthocarbonates, with the exocyclic vinyl group adjacent to one of the spiro-fused oxygens, provide relatively good reactivities and ring-opening efficiencies by free radical polymerization. In order to minimize concerns of single ring-opening polymerization accompanied by elimination of a cyclic carbonate by-product, attempts have been made to synthesize difunctional spiro monomers. This would greatly reduce the likelihood of nonbound elimination products in the polymer network. Another incentive for the use of difunctional ring-opening monomers is crosslink formation on polymerization. This will give rigidity to the polymers which otherwise are often viscous oils. It may also allow greater percentages of the ring-opening monomers to be formulated with conventional monomers to achieve less shrinkage (or more expansion) without significant reductions in mechanical strength properties.

To this end, synthetic methods to prepare tetraols capable of forming the difunctional monomers are being evaluated (I). A tetraol with 1,3-diol groups at each end would be preferred since the resulting 6-membered rings that would be formed in the monomer should polymerize with less elimination than that associated with 5-membered rings 
originating from 1,2-diol groups. Schemes 5-7 show the approaches that have been examined thus far. In all cases, some success has been achieved, although none of these procedures is completely satisfactory at this stage.

In some cases, monofunctional model monomers have been synthesized and evaluated (I, II). For example, diol 9 (Scheme 8) was prepared as the monofunctional model of tetraol 6. Diol 9 was then converted to the spiro monomer 10 , which has a melting point of $78-79^{\circ} \mathrm{C}$. Since the analogous difunctional monomer based on tetraol 6 would be expected to have a significantly higher melting point due to greater symmetry and molecular weight, it would likely be difficult to incorporate into resin formulations at reasonably high concentrations. Therefore, a method of adding asymmetry or flexible units into the spacer group between spiro end units would appear desirable. With this in mind, diol 11 (Scheme 9) was synthesized by the same procedure devised to produce tetraol 8 . The model spiro monomer 12 was obtained and characterized. This monomer has an oxygen in the side chain for greater flexibility; however, the melting point was still around $65^{\circ} \mathrm{C}$, probably as a result of the two 5-membered rings in the spiro system. Synthesis of a similar monofunctional model compound (13, scheme 10) with a 6-membered spiro ring is currently in progress.

\section{f) Polymerizable chain transfer agents.}

The use of benzyl disulfide as a potential initiator for ring-opening polymerization was investigated (II). The disulfide was added to a vinyl-substituted spiro monomer and heated to thermally cleave the disulfide bond. This did not result in any ring opening or polymerization. The monomer/disulfide mixture was then modified by the addition of azobis(isobutyronitrile) (AIBN) as a free radical initiator. Upon heating to generate the radical species, polymerization occurred; however, the amount of ring opening observed in the polymer did not appear any greater than that seen in the monomer/AIBN control polymerization.

\section{g) Spiro monomers based on large rings ( $>8$-membered rings).}

For a homologous series of cyclic compounds, there is an optimum ring size in terms of stability of the system. In our efforts to achieve the double ring-opening polymerization of spiro monomers, we would prefer to utilize ring systems that are inherently strained in order to favor the ring cleavage process. As seen in the unsubstituted hydrocarbon series listed in Table 4, the 6-membered ring 
structure of cyclohexane represents the energy minimum while above or below this ring size, the relative ring strain increases. While the 3 - and 4-membered rings possess a large amount of potential energy that could be directed toward ring-opening processes, ring-opening polymerization involving small rings results in greater shrinkage (or less expansion) than when larger rings are opened. In Table 5, the relative strain energies of 1,3-dioxa-heterocyclic compounds demonstrate that only an 8-membered ring system is required to introduce a significant amount of ring strain. Therefore our efforts in this area were directed toward the synthesis of an 8-membered ring fused to an exomethylenesubstituted 5-membered ring through the tetraoxaspiro linkage (I).

The synthesis devised to accomplish this utilized homophthalic anhydride which was opened to the acid-ester and then reduced to the benzo-substituted diol 14 (Scheme 11). The benzo-group was desired to provide some hydrolytic stability to the monomer as well as stiffness and stabilization to the resulting polymer. The 1,5-diol was converted to spiro orthocarbonate 15 by standard procedures except that the reaction was run somewhat more dilute than usual. The crude product mixture was fractionated by column chromatography to cleanly yield the spiro monomer which was thoroughly characterized by ${ }^{1} \mathrm{H}$ and ${ }^{13} \mathrm{C}$ NMR as well as IR spectroscopy. In spite of the increased strain associated with this monomer, it appears to be stable under normal handling conditions. The larger ring size offers a number of possible configurations which probably helps depress the melting point below room temperature. The bond angles in the 8-membered ring should be significantly distorted from normal valence bond angles. This distortion may be further magnified by the constraints imposed by the spiro center. with the knowledge that a spiro orthocarbonate containing an 8-membered ring can be synthesized and isolated, the procedure will be scaled-up and the polymerization behavior of the monomer investigated. 
Table 4

Heats of Polymerization of Cycloalkanes (strain energies)

\begin{tabular}{ccc}
\hline \hline Cycloalkane & $\begin{array}{c}\text { Ring size } \\
-\left(\mathrm{CH}_{2}\right)_{\mathrm{n}}^{-}\end{array}$ & $\begin{array}{c}-\Delta \mathrm{H}, \mathrm{Ring} \text { strain } \\
\text { energy }(\mathrm{kJ} / \mathrm{mol})\end{array}$ \\
\hline cyclopropane & $\mathrm{n}=3$ & 112 \\
cyclobutane & 4 & 105 \\
cyclopentane & 5 & 21.7 \\
cyclohexane & 6 & -2.93 \\
cycloheptane & 7 & 21.3 \\
cyclooctane & 8 & 34.7 \\
cyclononane & 9 & 46.8 \\
cyclodecane & 10 & 48.1 \\
cycloundecane & 11 & 45.1 \\
cyclododecane & 12 & 14.2 \\
\hline
\end{tabular}

Table 5

Heats of Polymerization of 1,3-Dioxacycloalkanes (strain energies)

\begin{tabular}{ccc}
\hline \hline Heterocycle & $\begin{array}{c}\text { Ring size } \\
-\mathrm{OCH}_{2} \mathrm{O}\left(\mathrm{CH}_{2}\right)_{\mathrm{n}}\end{array}$ & $-\Delta \mathrm{H}, \begin{array}{c}\text { strain energy } \\
(\mathrm{kJ} / \mathrm{mol})\end{array}$ \\
\hline 1,3-dioxolane & 5 & 25.9 \\
$1,3-$ dioxane & 6 & 0.0 \\
1,3 -dioxepan & 7 & 19.6 \\
$1,3-$ dioxocane & 8 & 53.5 \\
\hline
\end{tabular}


h) Nitrogen-containing spiro monomers.

The substitution of a nitrogen atom in place of one of the spiro-fused oxygens in the ring-opening monomers would be desirable since a urethane linkage could be formed upon ring opening. This group is of lower energy than a carbonate group and therefore, would provide more driving force for the ring opening to proceed. In addition, the urethane group may have somewhat greater hydrolytic stability than the carbonate functionality.

Several attempts have been made to prepare spiro monomers that incorporate an aminoalcohol into one of the rings (I). Those aminoalcohols investigated for this purpose (Figure 1) were either primary or secondary amines which had a 1,2- or 1,3-orientation between the hydroxyl and amino groups. All these attempted reactions (generalized in Scheme 12) resulted in very complex product mixtures. In several cases, there was significant carbonyl formation which indicates that the desired reaction may have occurred, but the spiro product was not sufficiently stable under the reaction conditions. Those reactions which utilized a secondary amine appeared to be more favorable. Further efforts will be directed toward the use of other secondary aminoalcohol starting materials and milder reaction conditions.

\section{A.2. Lactone Monomers}

This area of research was eliminated from our work plan. A paper summarizing our prior findings on this subject was published.

\section{A.3. Low Surface Energy Monomers}

(Relevant portions of this originally proposed section are now incorporated into section A.4, part d).

\section{A.4. Cyclopolymerizable Monomers}

\section{Background}

An amine-catalyzed reaction with formaldehyde has previously been used to convert acrylates to difunctional monomers (Scheme 13) and diacrylates to multifunctional oligomers (Scheme 14). This reaction transforms the isolated acrylate double bonds into paired 1,6-diene configurations. The resulting compounds can undergo efficient cyclopolymerization, which is desirable since high conversion can be achieved along with significantly reduced shrinkage $[11,12]$. The difunctional monomers are essentially ether-fused dimethacrylates, termed oxybismethacrylates, with the ester groups located 
externally. This ester functionality can be varied to significantly alter the properties of the monomers and their corresponding polymers [13]. The 1,6-diene configuration in the monomer gives access to an intramolecular cyclization pathway for polymerization. Depending on the polymerization conditions, linear polymer can be formed exclusively via cyclopolymerization or crosslinked polymer can be obtained by a combination of the 1,6-cycloaddition and 1,2-addition polymerization modes (Scheme 15).

\section{Progress Report}

During this reporting period, progress was made in the following areas:

c) Polymerization shrinkage of oxybismethacrylates.

d) Synthesis of fluorinated 1,6-dienes.

e) Aldehyde insertion reactions of related compounds.

i) Synthesis of water soluble monomers.

The results represent work in Phase I (monomer synthesis), designated (I), Phase II (characterization and polymerization of new monomers), designated (II), and Phase III (formulation and evaluation of experimental resins), designated (III) which pertain to the individual sections of the work plan.

\section{c) Polymerization shrinkage of oxybismethacrylates.}

Separate studies of oxybismethacrylate difunctional monomers and multifunctional oligomers have shown reduced shrinkage attributed to the cyclopolymerization process. Therefore, the logical progression of this work would combine the low viscosity difunctional oxybismethacrylate monomer as a reactive diluent for the viscous multifunctional oligomer to yield a low-shrinking, all cyclopolymerizable resin. This could be done by synthesizing and isolating the respective components separately and then combining them in a resin formulation.

Alternatively, in this study, the synthesis and formulation of an essentially all cyclopolymerizable dental resin was reduced to a convenient single-step process (I, III). A series of reactions with incremental changes in the ethyl acrylate (EA; Scheme 16) to ethoxylated bisphenol A diacrylate (EBPAD) ratio directly supplied cyclopolymerizable resins with a broad range of properties (Table 6). Analogous reactions with EA or EBPAD alone provided the boundary extremes for comparison. Analysis of the resins by NMR showed no unreacted acrylate groups (II). The difunctional monomer 16 produced from $E A$ serves as reactive diluent for the viscous multifunctional oligomer 17 which results from EBPAD. The EA reaction product also becomes 
incorporated into the oligomer as end-cap units and thereby limits the extent of oligomerization. Thus, resin viscosity and average molecular weight of the oligomeric component of the resin were inversely related to the amount of EA used in the reaction. Through the choice of reactant identity and ratio, this simple technique provides ready access to a variety of cyclopolymerizable resins for composite and other applications. The series of resins will be polymerized and evaluated with regard to mechanical strength, shrinkage and degree of conversion.

Table 6

\begin{tabular}{||l|l|l|l|l|l|l|l|l|l||}
\hline & \multicolumn{7}{|c|}{ EA/EBPAD Composition in Reaction } \\
\hline $\begin{array}{l}\text { Mole } \\
\text { ratio }\end{array}$ & $100 \% / 0$ & $20 / 1$ & $8 / 1$ & $4 / 1$ & $2 / 1$ & $1 / 1$ & $1 / 2$ & $1 / 5$ & $0 / 100 \%$ \\
\hline $\begin{array}{l}\text { Vinyl } \\
\text { equiv }\end{array}$ & $100 \% / 0$ & $10 / 1$ & $4 / 1$ & $2 / 1$ & $1 / 1$ & $1 / 2$ & $1 / 4$ & $1 / 10$ & $0 / 100 \%$ \\
\hline \hline & Incorporation of starting Materials in Resin (EA/EBPAD) \\
\hline $\begin{array}{l}\text { Mole } \\
\text { ratio }\end{array}$ & $100 \% / 0$ & $18 / 1$ & $6 / 1$ & $4 / 1$ & $2 / 1$ & $1 / 1$ & $1 / 4$ & $1 / 6$ & $0 / 100 \%$ \\
\hline
\end{tabular}

\section{d) Synthesis of fluorinated 1,6-dienes.}

The combination of hydrocarbon acrylate esters with paraformaldehyde in the presence of 1,4diazabicyclo $[2,2,2]$ octane (DABCO) yields the cyclopolymerizable 1,6-diene as the main product. Depending on the ester functionality, the reaction can also produce a 1,4-diene condensation product in concentrations ranging from 0 to approximately 15\%. The use of fluorinated acrylate esters in the aldehyde insertion reaction with DMSO as solvent was found to result in predominantly 1,4-diene products due to the electronegativity of the ester group. As reported in the previous annual report, the diacrylate of hexafluorobisphenol $A$ was synthesized and subjected to the standard aldehyde insertion reaction conditions (Scheme 17). The result was the multifunctional oligomer 18 which had internal diene linkages in a 2.1 to 1 ratio favoring the 1,4- over the 1,6-diene. The oligomer had an average of approximately five repeat units per oligomer chain. This type of fluorinated oligomer would be expected to provide a highly crosslinked, hydrophobic matrix. 
A visible light activated composite formulation comprised of equal amounts of 18 and hexamethylene dimethacrylate with 5 parts of silanized glass filler was evaluated (III). The resulting diametral tensile strength of $48 \pm 1.4 \mathrm{Mpa}$ for the cured composite is relatively good for a material with a significant fluorine content.

Other fluorinated acrylates (Figure 2) were prepared from the corresponding fluoro-alcohols or diols (I). The aldehyde insertion reaction with acrylates 19 and 20 failed to yield any isolable product although complete utilization of the starting material occurred. There was little indication of vinyl groups in the product mixture. Therefore, work with these acrylates was discontinued. The results obtained when the pentafluorobenzyl acrylate 21 was subjected to the $\mathrm{DABCO} /$ paraformaldehyde reaction were somewhat surprising. While highly fluorinated acrylates generally produce a 1,4diene as the major component of the reaction, there was very little of this type of product present in the crude reaction mixture. Instead, the vast majority of product obtained was the 1,6-, 1,8- and 1,10-diene structures (Scheme 18) that are more common from the hydrocarbon acrylate starting materials. These various compounds were isolated by HPLC. This approach appears to be an excellent method for producing highly fluorinated monomers which should efficiently cyclopolymerize.

\section{e) Aldehyde insertion reactions of related compounds.}

Previously monofunctional acrylates have been converted to difunctional cyclopolymerizable monomers and diacrylates to multifunctional oligomers, the latter with several sites capable of cyclopolymerization along the oligomer backbone. In the current work, a triacrylate starting material was used in the DABCO-catalyzed reaction with paraformaldehyde (I). If this reaction is allowed to proceed too far, an insoluble, crosslinked gel results. However, if the reaction conditions are kept to approximately $85^{\circ} \mathrm{C}$ for $4-8 \mathrm{~h}$ in DMSO, then a soluble, three dimensional multifunctional oligomer 22 can be isolated (Scheme 19). Under these conditions, virtually all the acrylate groups are converted either to the $\alpha$-hydroxymethyl acrylate end groups or to ether-linked 1,6-diene linkages. The NMR analysis of the product indicates an average molecular weight of $>2000$ with 15-20 functional groups. The oligomer has a large number of hydroxymethyl-substituted reactive end groups which make the material very hydrophilic. 
i) Synthesis of water soluble monomers.

Since the ester groups can be varied in the cyclopolymerizable monomers, the functionality can be tailored to fit specific application needs. One application of the cyclopolymerizable monomers would be for water soluble or water dispersible monomers for use as crosslinkable modifying agents for hybrid cement composites and polymeric calcium-phosphate cements as described in Part I.E. (Phase I) of the proposal. The synthesis of the cyclopolymerizable monomers shown in Figure 3 was included in the previous annual report. These monomers were polymerized and the degree of water uptake of the resulting crosslinked polymers was determined (Figure 4) (II). The addition of approximately 10 mole $z$ of the monofunctional tetrahydrofurfuryl $\alpha$-hydroxymethylacrylate, which is quite polar and water soluble, had a profound effect on the degree and rate of water uptake in the corresponding polymer (Figure 5). The PEG 400 oligomer was water soluble while the PEG 200 oligomer could readily be dispersed in water but did not have appreciable solubility. None of the cyclopolymerized samples was water soluble. Due to the fairly high crosslink density of the polymers, none of these samples showed significant swelling on water storage. However, there were significant changes in the polymer physical properties between the dry and fully hydrated states. The flexural moduli, as determined from the 3-point bending test, are shown in Table 7. A value of approximately 3 Gpa was obtained for an unfilled Bis-GMA/TEGDMA $(7: 3)$ polymer control which was stored $24 \mathrm{~h}$ in water prior to testing.

Table 7

\begin{tabular}{|c|c|c|}
\hline Polymer & $\begin{array}{l}\text { Flexural } \\
\text { dry }\end{array}$ & $\begin{array}{c}\text { Modulus, MPa } \\
\text { wet }\end{array}$ \\
\hline THF-OBM & $2996 \pm 60$ & $1119 \pm 112$ \\
\hline THF-OBM / $\alpha-\mathrm{HMA}$ & $1811 \pm 20$ & $N / A^{\circ}$ \\
\hline PEG 200 & $1995 \pm 53$ & $N / A^{\circ}$ \\
\hline PEG 400 & $\mathrm{~N} / \mathrm{A}^{*}$ & $N / A^{*}$ \\
\hline
\end{tabular}

- $N / A=$ specimen was too flexible to allow a meaningful measurement of modulus by this technique.

References

[1] Verzijden, C.W.D.J.M., Feilzer, A.J., Creugers, N.H.J., and Davidson, C.L. The influence of polymerization shrinkage of 
resin cements on bonding to metal. J. Dent. Res. 71:410$413,1992$.

[2] Davidson, C.L., Van Zeghbroeck, L., and Feilzer, A.J. Destructive stresses in adhesive luting cements. J. Dent. Res. $70: 880-882,1991$.

[3] Feilzer, A.J., DeGee, A.J., and Davidson, C.L. Setting stress in composite resin in relation to configuration of the restoration. J. Dent. Res. 66:1636-1639, 1987 .

[4] Feilzer, A.J., DeGee, A.J., and Davidson, C.L. Quantitative determination of stress reduction by flow in composite restorations. Dent. Mater. 6:167-171, 1990 .

[5] Zindan, 0., Gomez-Marin, O., and Tsuchiya, T. A comparative study of the effects of dentinal bonding agents and application techniques on marginal gaps in class $\mathrm{V}$ cavities. J. Dent. Res. 66:716-721, 1987.

[6] Endo, T. and Bailey, W.J. Synthesis and radical ringopening polymerization of spiro o-carbonates. J. Polym. Sci., Polym. Chem. Ed. 13:2525-2530, 1975.

[7] Stansbury, J.W. and Bailey, W.J. Synthesis of monomers that polymerize with expansion in volume. J. Dent. Res. 65:219, Abst. No. $452,1986$.

[8] Stansbury, J.W. and Bailey, W.J. Evaluation of spiro orthocarbonate monomers capable of polymerization with expansion as ingredients in dental composite materials. In: Progress in Biomedical Polymers, C.G. Gebelein and R.L. Dunn, Eds., New York: Plenum Press, pp. 133-139, 1990.

[9] Stansbury, J.W. Synthesis and evaluation of new oxaspiro monomers for double ring-opening polymerization. J. Dent. Res. 71:1408-1412, 1992 .

[10] Sakai, S., Fujinami, T., and Sakurai, S. Cationic ringopening polymerization of spiro-orthocarbonates. J. Polym. sci., Polym. Lett. Ed. 11:631-633, 1973.

[11] Butler, G.B. Perspectives in cyclopolymerization. In: Proceedings of the International symposium on Macromolecules, E.B. Mano, Ed., New York: Elsevier Scientific Publishing Co., pp 57-76, 1975.

[12] Stansbury, J.W. Cyclopolymerizable monomers for use in dental resin composites. J. Dent. Res. 69:844-848, 1990. 
[13] Stansbury, J.W. Difunctional and multifunctional monomers capable of cyclopolymerization. Macromolecules 24:20292035, 1991. 
Scheme 1

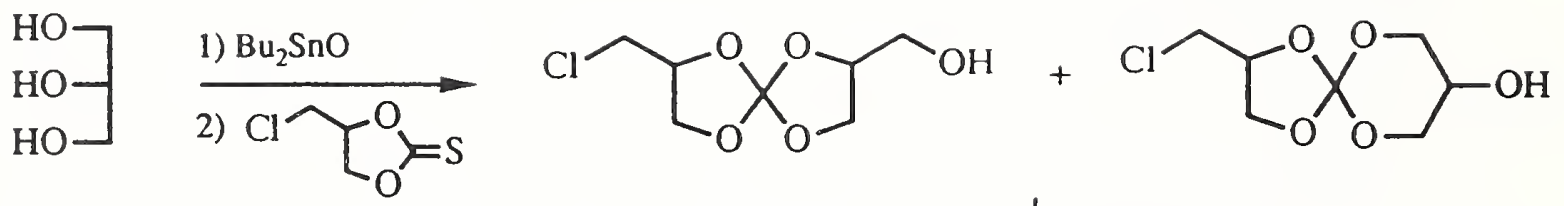

$$
\begin{aligned}
& \lceil\mathrm{KOtBu}
\end{aligned}
$$

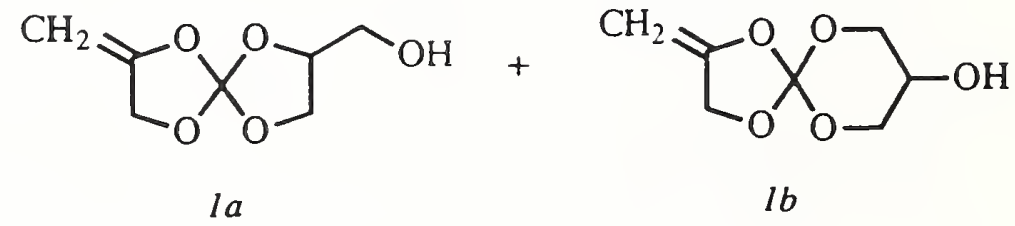

Scheme 2

$$
\underset{\mathrm{O}}{\mathrm{C}} \stackrel{\mathrm{OCN}-\left(\mathrm{CH}_{2}\right)_{6}-\mathrm{NCO}}{\mathrm{O}}
$$

Scheme 3

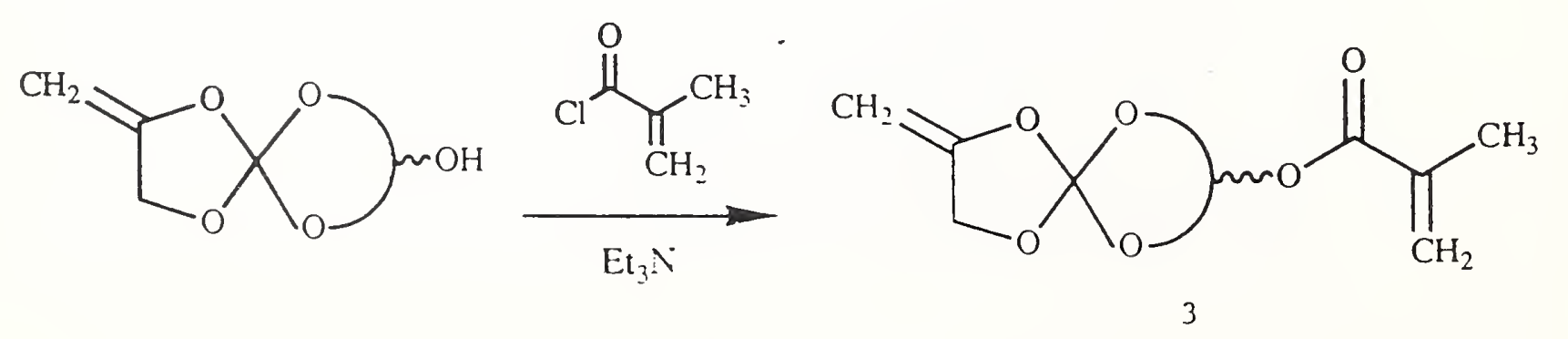




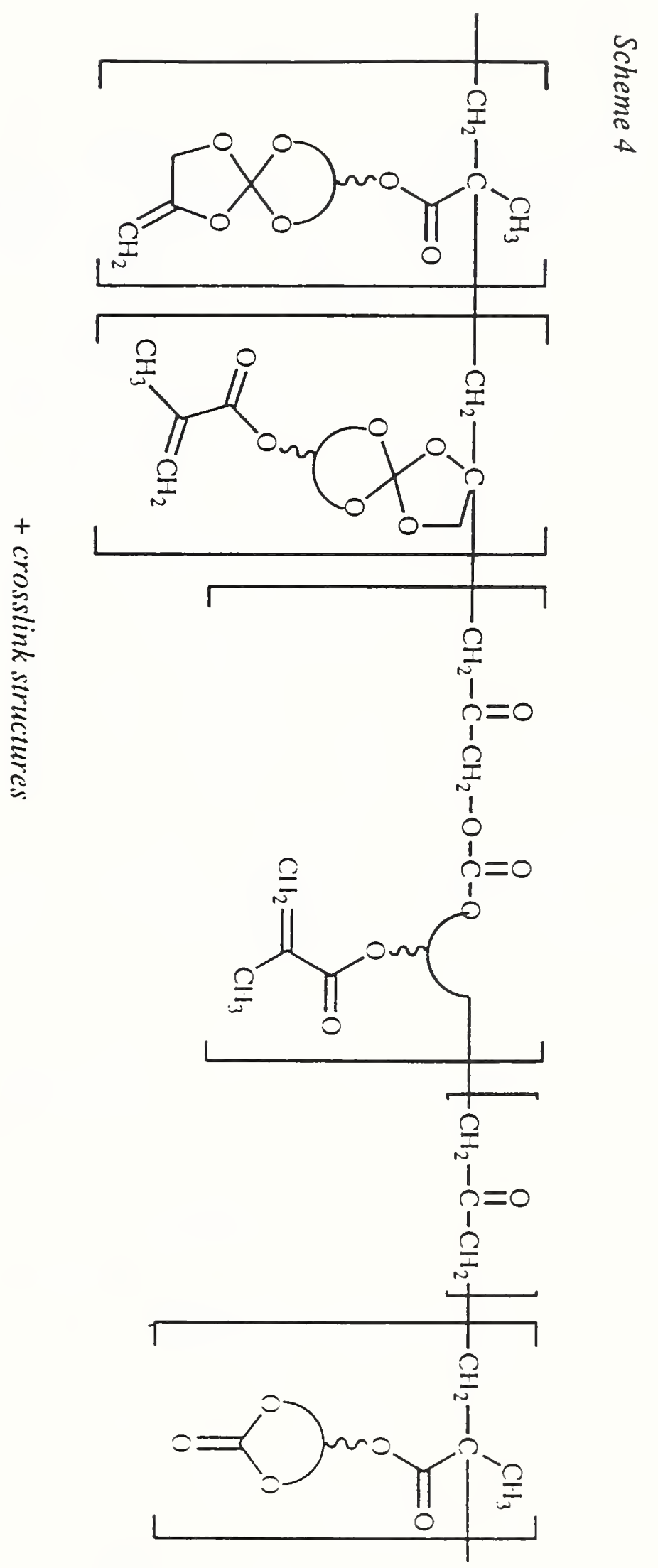


Scheme 5

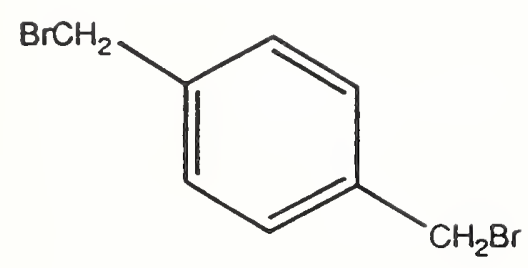

$$
+\stackrel{\mathrm{CH}_{2}}{\mathrm{CO}_{2} \mathrm{Et}} \underset{\text { 2) } \mathrm{LAH}}{\stackrel{\mathrm{OO}_{2} \mathrm{NaOEt}}{\longrightarrow}}
$$

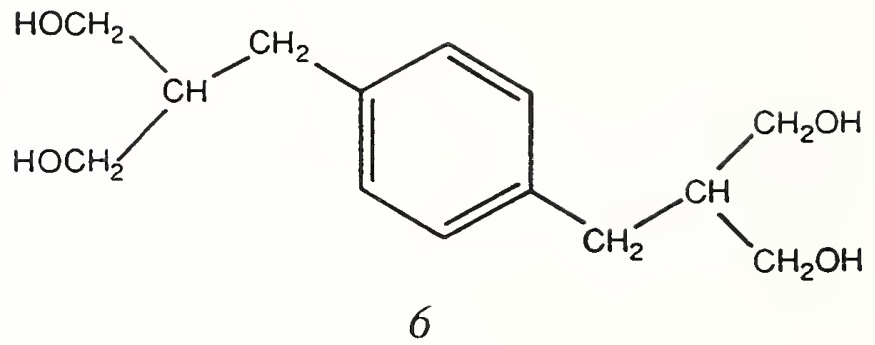

Scheme 6
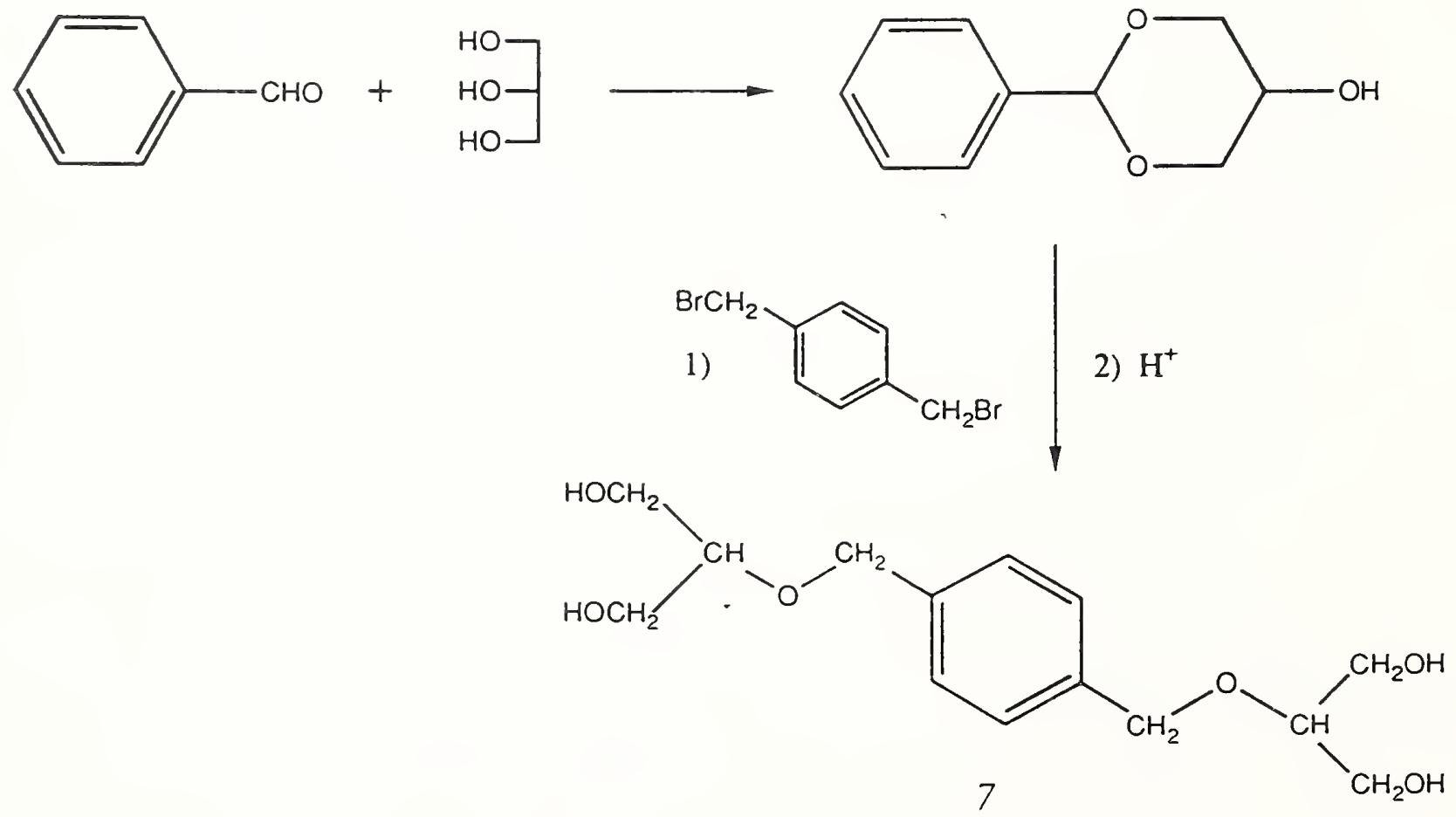
Scheme 7

<smiles>CC(C)(c1ccc(OCC(O)CO)cc1)c1ccc(OCC(O)CO)cc1</smiles> 
Scheme 8

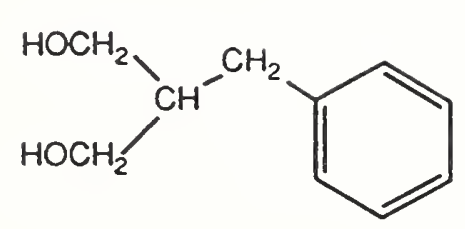

9
1) $\mathrm{Bu}_{2} \mathrm{SnO}$

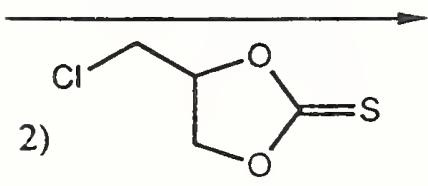

3) $\mathrm{KOtBu}$

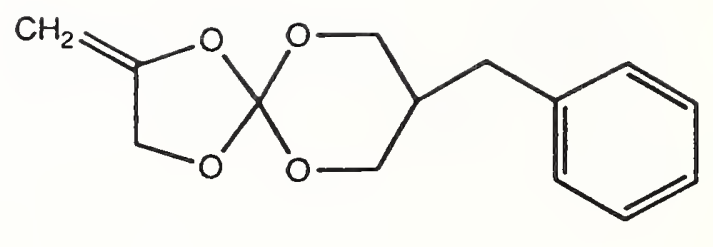

10

Scheme 9<smiles>OCC(O)COc1ccccc1</smiles>

11

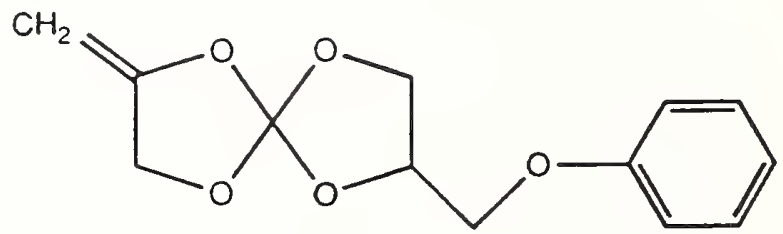

12

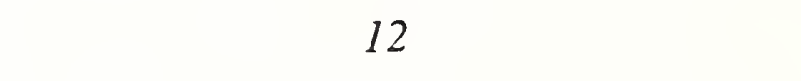

Scheme 10

$\mathrm{HOCH}_{2}$

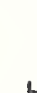

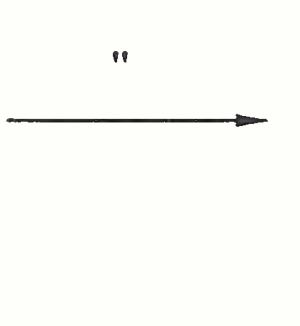


Scheme 11<smiles>O=C1Cc2ccccc2C(=O)O1</smiles>
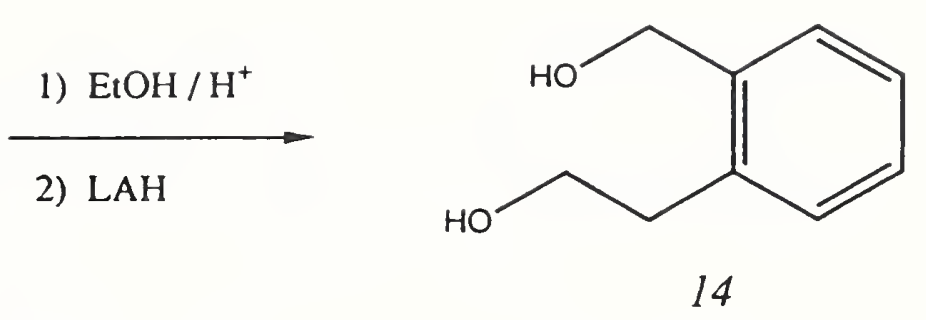

1) $\mathrm{Bu}_{2} \mathrm{SnO}$

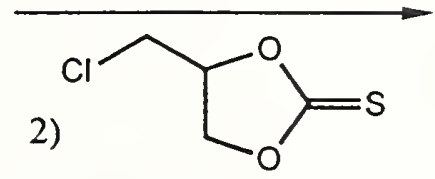

3) $\mathrm{KOtBu}$

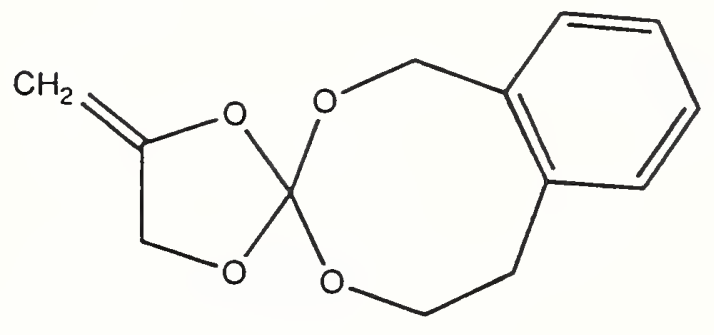

15 
Figure 1<smiles>Nc1ccccc1CO</smiles><smiles>OCCNCCO</smiles>

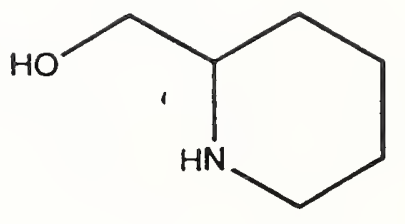

Scheme 12

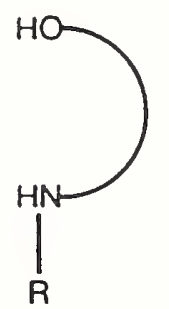

1) $\mathrm{Bu}_{2} \mathrm{SnO}$

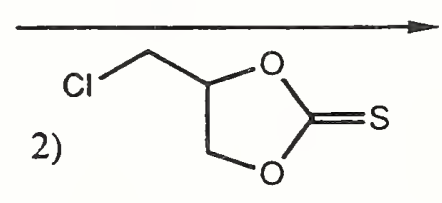

3) $\mathrm{KOtBu}$

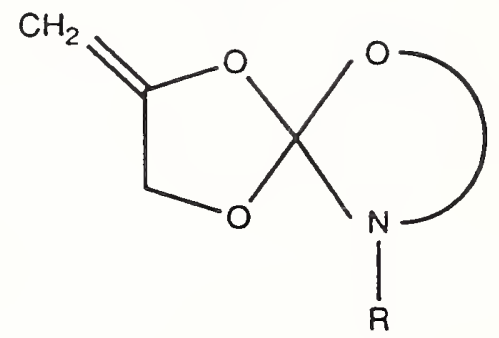

$$
\begin{array}{r}
R=H, \text { alkyl } \\
\text { or aryl }
\end{array}
$$

polymerize<smiles>[R]N(CCCCC(C)(C)C)C(=O)OCC(=O)CC(C)(C)C</smiles> 
Scheme 13<smiles>[R]OC(=C)C=O</smiles><smiles>O=C(O)COCCO</smiles><smiles>[R]OC(=O)C(=C)COCC(=C)C(=O)O[R]</smiles>

Scheme 14

paraformaldehyde<smiles>C=CC(=O)O[R]OC(=O)C(=C)C</smiles>
DABCO

1) $80^{\circ} \mathrm{C} / 28 \mathrm{~h}$

2) precipitate from methanol

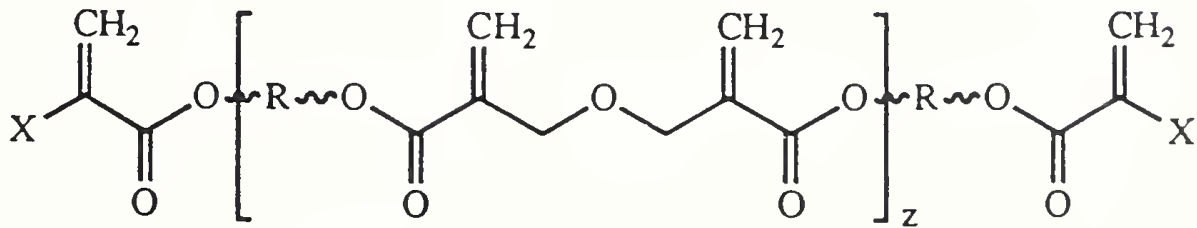

$\mathrm{X}=-\mathrm{H}$ and/or $-\mathrm{CH}_{2} \mathrm{OH}$<smiles>[R]#CC(C)(C)COc1ccc(C(C)(C)c2ccc(C(C)OCCC(C)(C)C)cc2)cc1</smiles> 
Scheme 15<smiles>[R]OC(=O)C(=C)COCC(=C)C([R])=O</smiles>

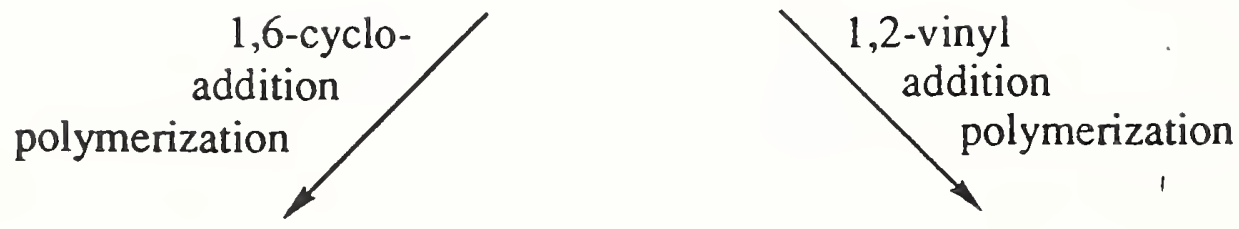

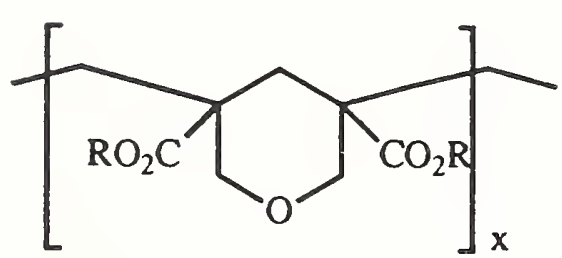

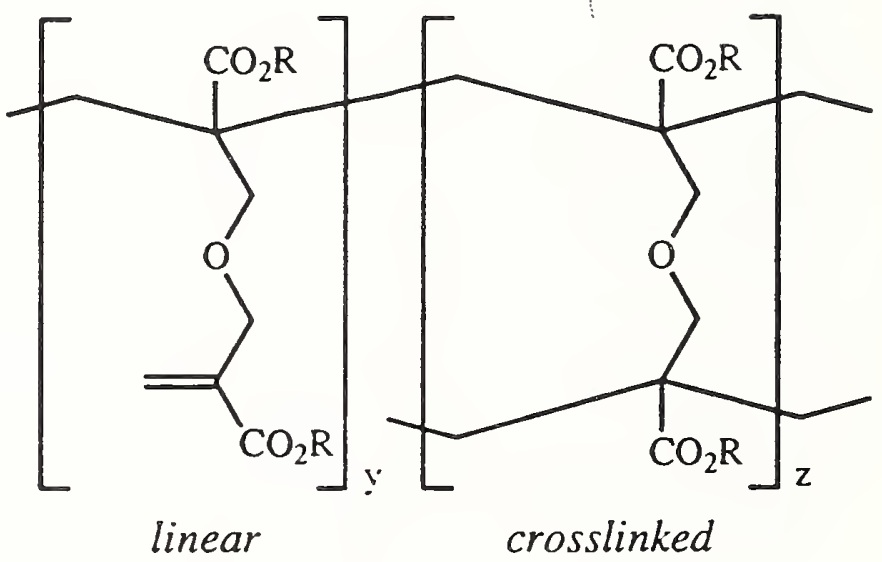




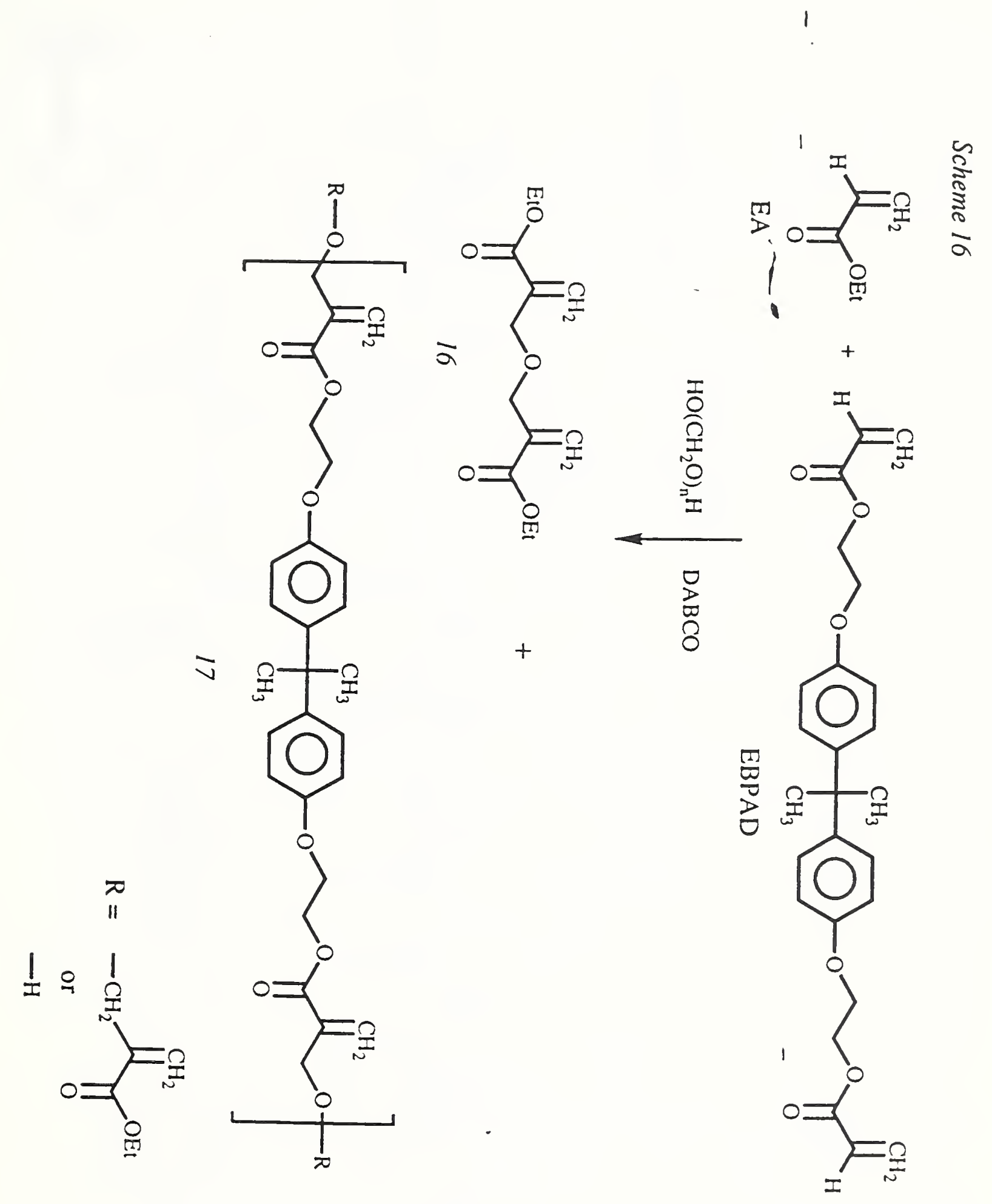



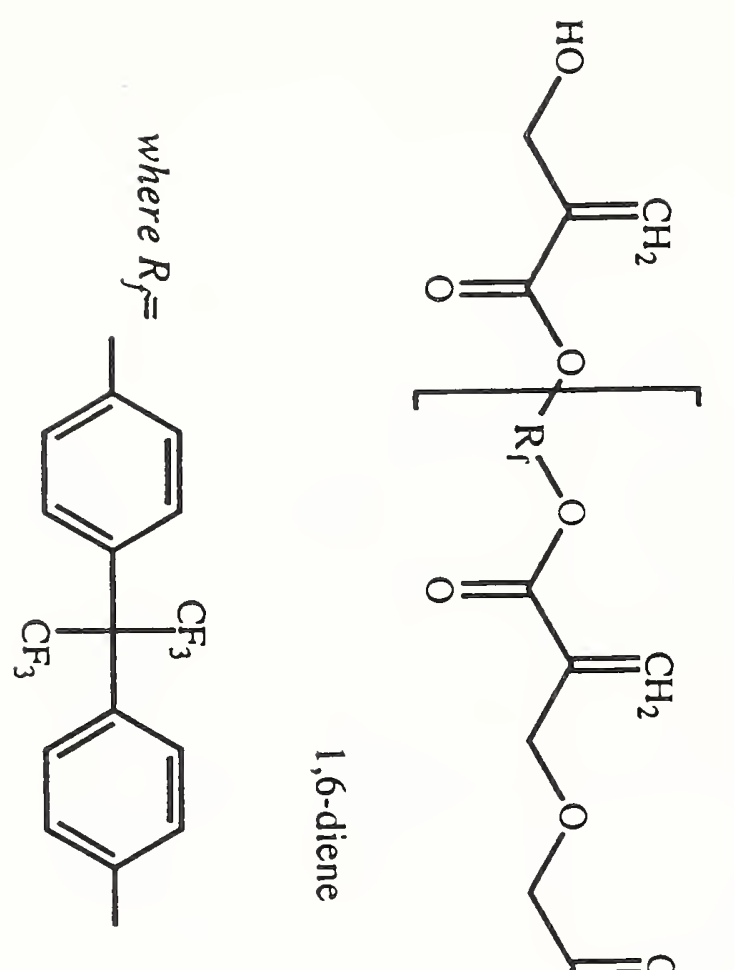

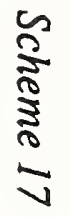
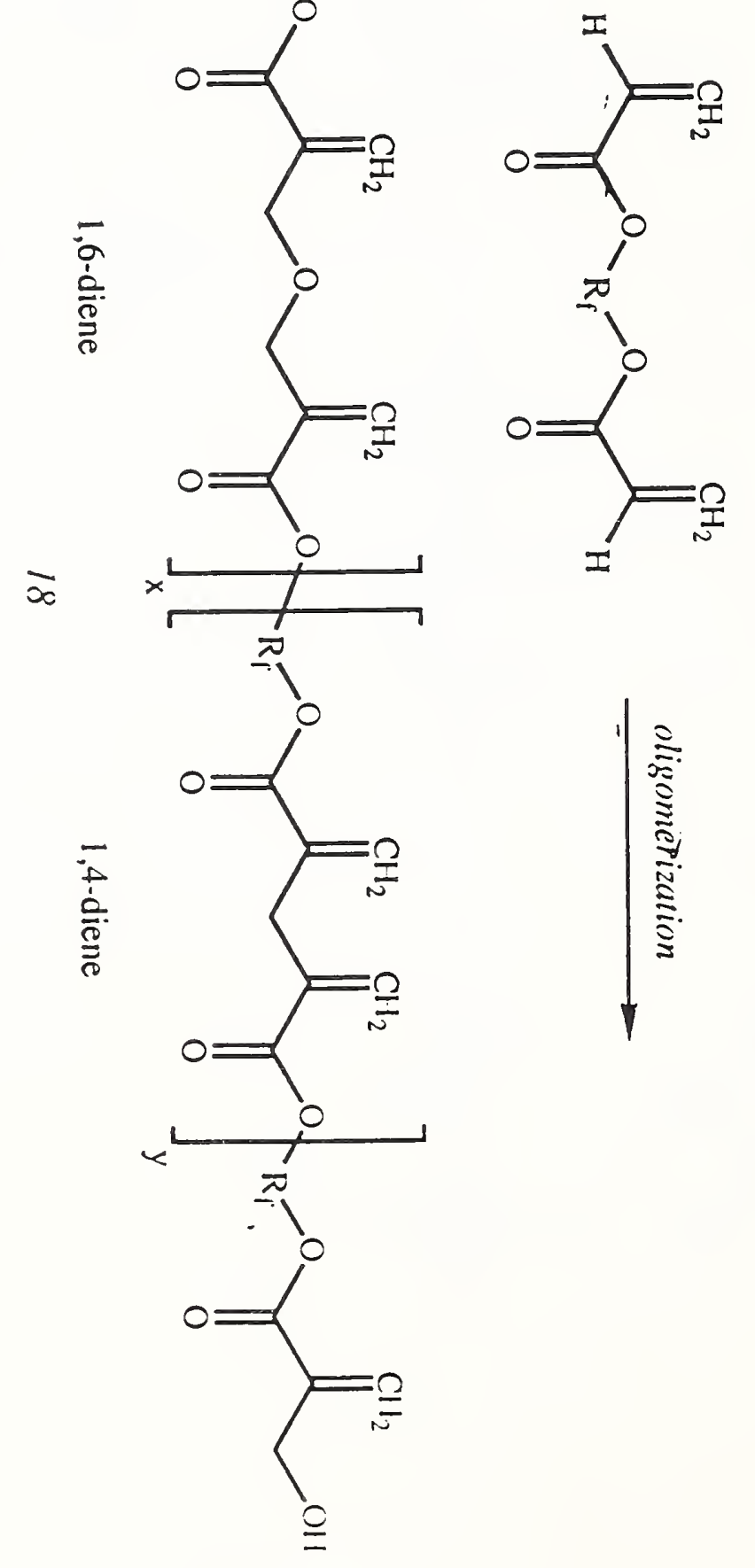
Figure 2<smiles>C=CC(=O)OC(c1ccccc1)(c1ccccc1)C(F)(F)F</smiles>

19<smiles>C=C(C)C(=O)OC(c1ccc(C(C(F)(F)F)(C(F)(F)F)C(F)(F)F)cc1)(C(F)(F)F)C(F)(F)F</smiles>

20<smiles>C=C(C)C(=O)OCc1c(F)c(F)c(F)c(F)c1F</smiles>

21

Scheme 18<smiles>C=C(C)C(=O)OCc1c(F)c(F)c(F)c(F)c1F</smiles><smiles>O=C(O)OCOCCO</smiles>

21<smiles>C=C(CCOCC(=C)C(=O)OCc1c(F)c(F)c(F)c(F)c1F)C(=O)OCc1c(F)c(F)c(F)c(F)c1F</smiles> 


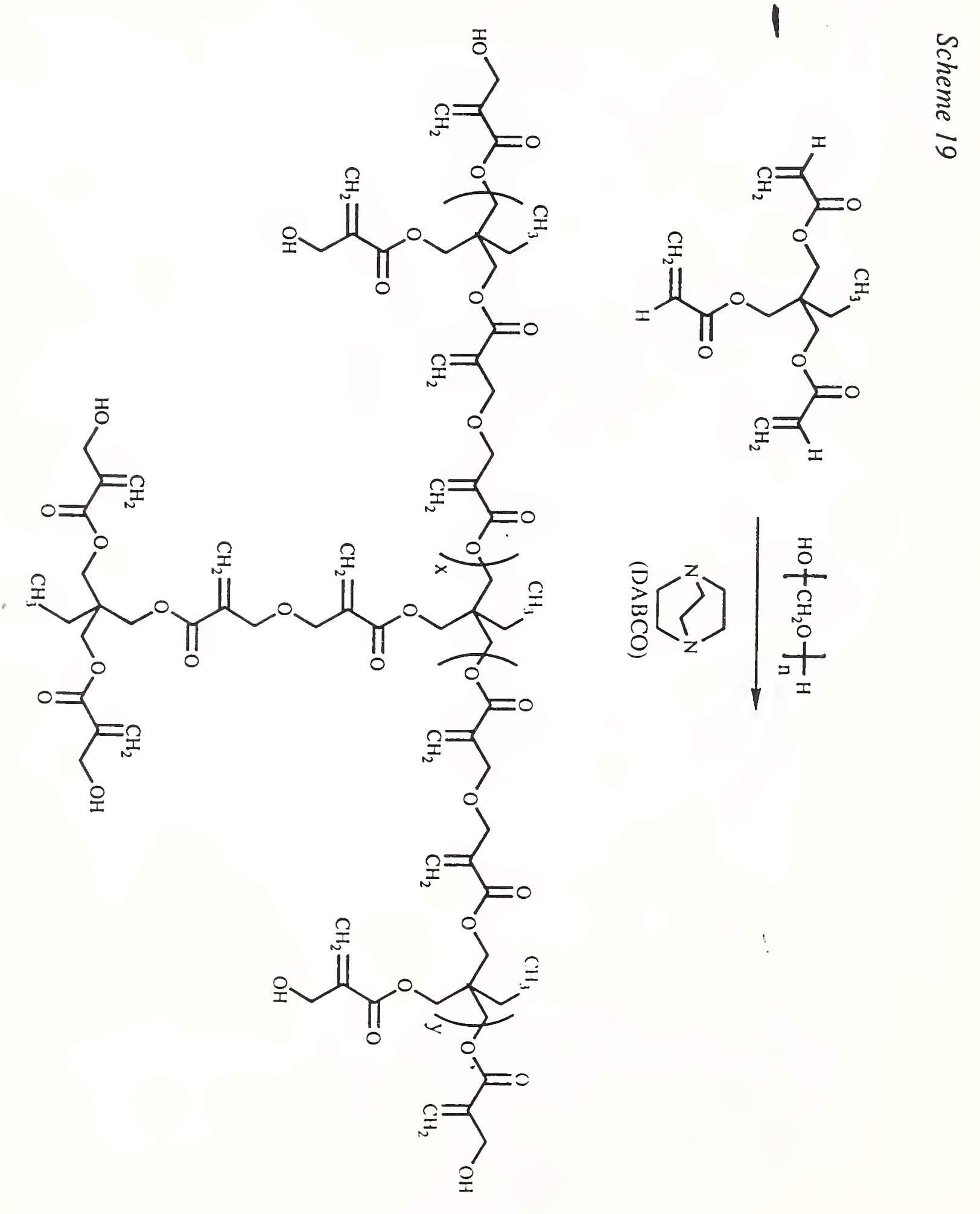


Figure 3<smiles>C=C(COCC(=C)C(=O)OCC1CCCO1)C(=O)OCC1CCCO1</smiles><smiles>C=C(COCC(=C)C(=O)OCC1CCCO1)C(=O)OCC1CCCO1</smiles>

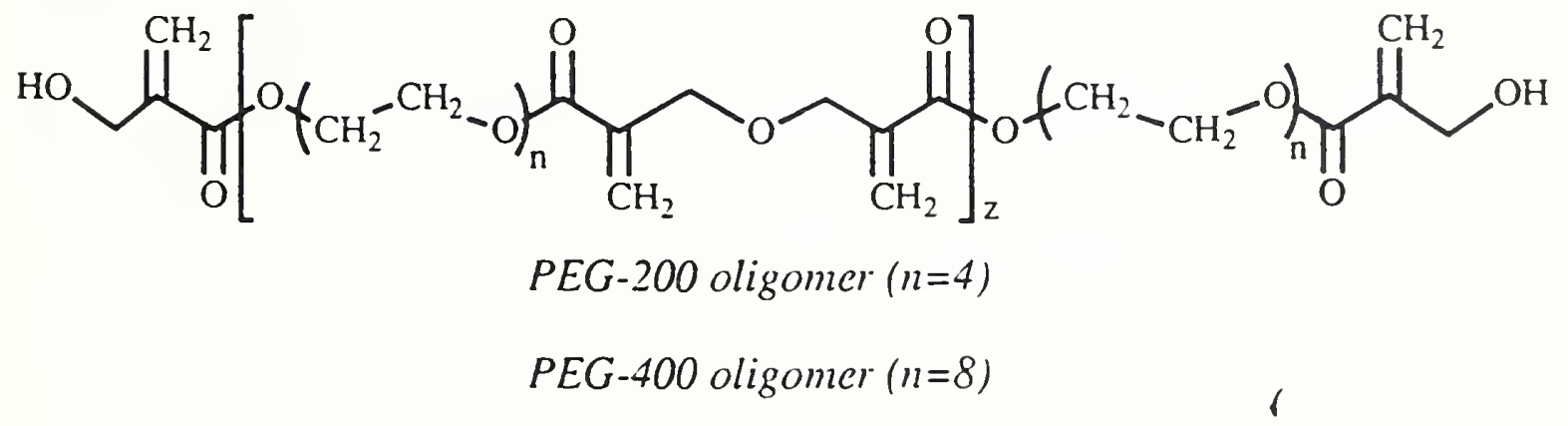<smiles>C=C(COCC(=C)C(=O)OCCO)C(=O)OCCO</smiles> 
Long term water uptake of cyclopolymers

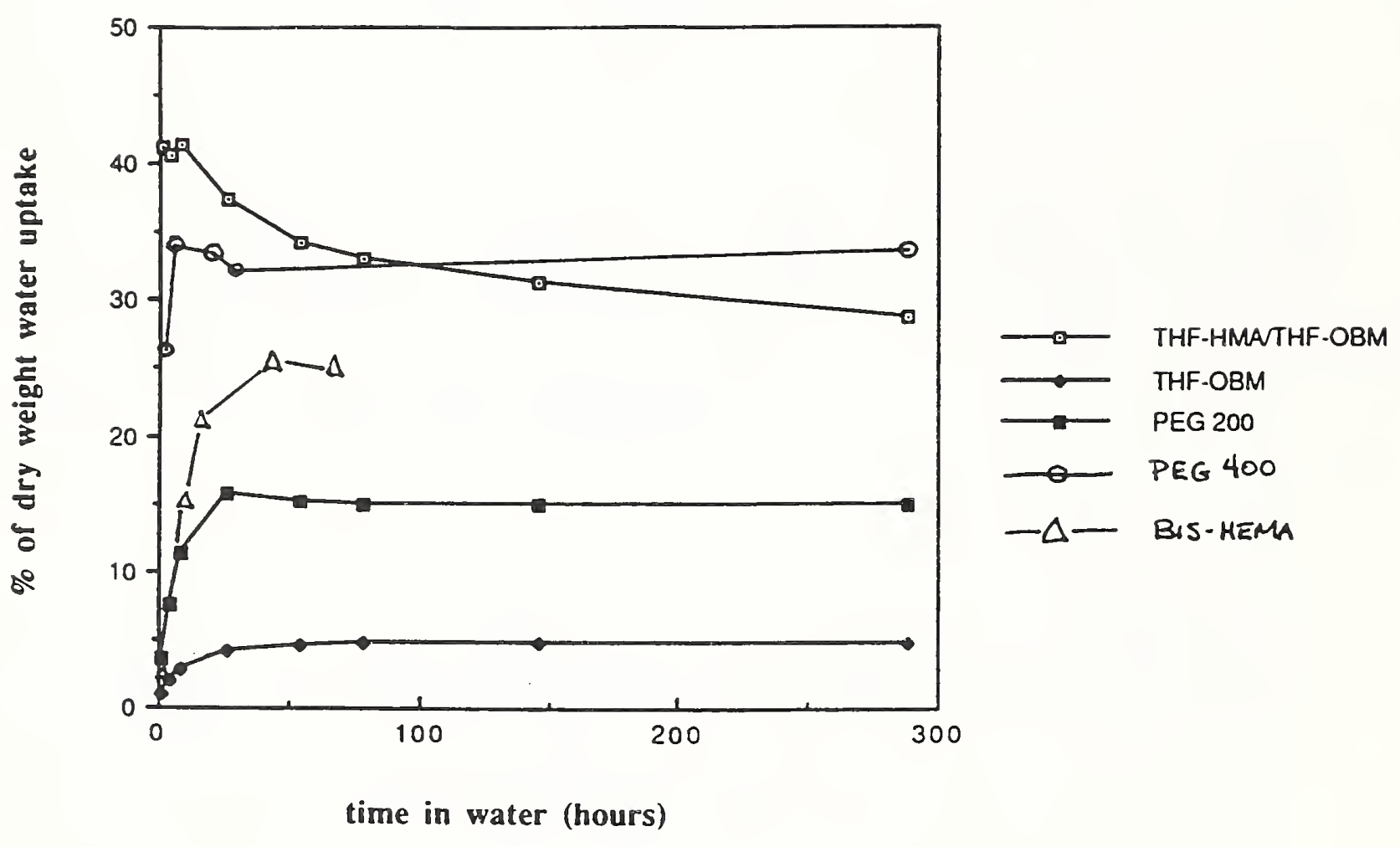

Figure 4 
Short-term Water Uptake of Poly (THF-HMA/THF-OBM)

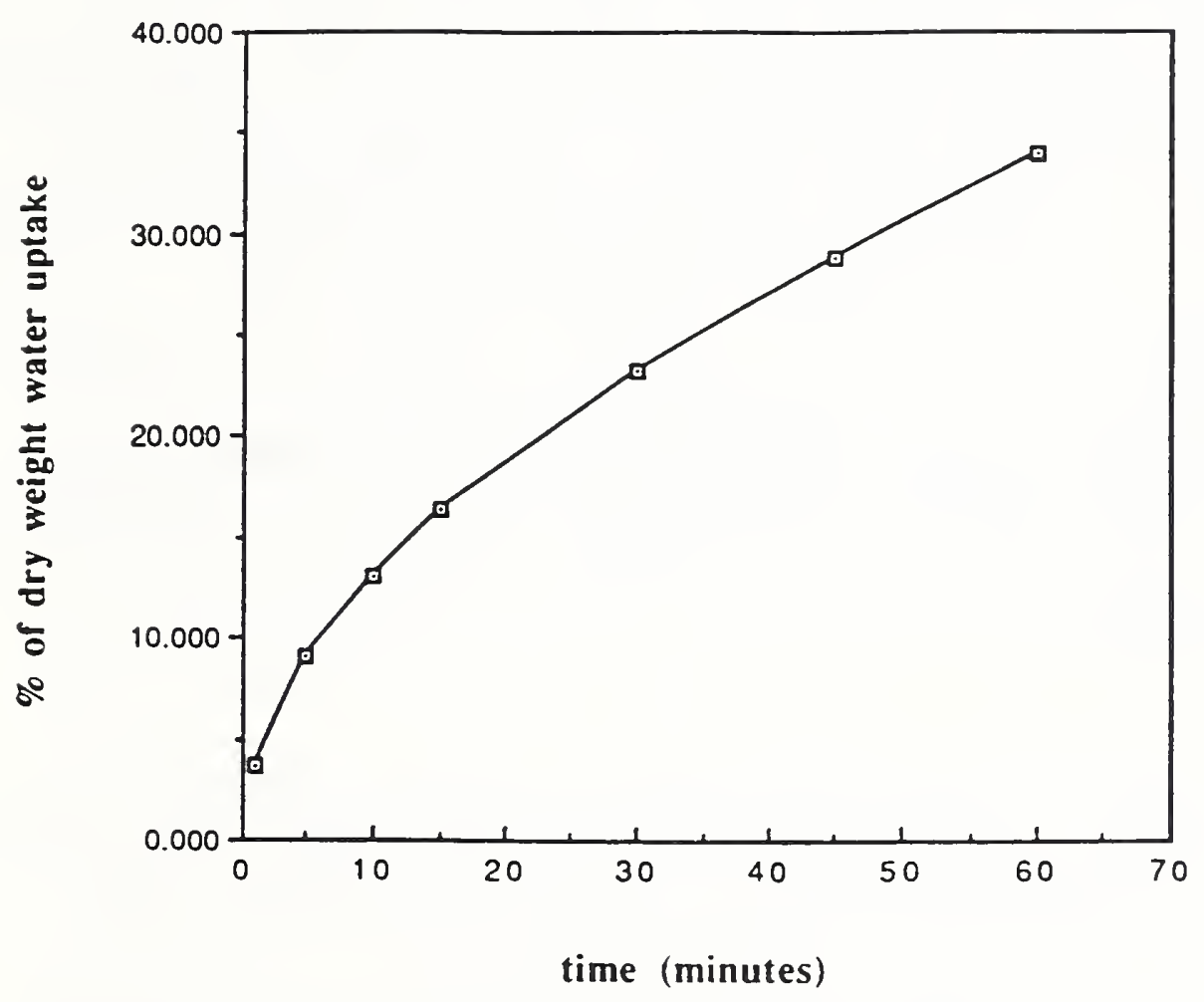

Figure 5 
A.7 Synthesis, Characterization and Evaluation of Multifunctional Silane Agents

\section{Background}

The weakest link in silane treated siliceous composites is the oxane bond that forms between the silane agent and the silanol groups on the filler surface. The oxane bond that forms between the coupling agent (e.g. A-174) and the mineral phase is vulnerable to hydrolysis, especially if it is not completely formed [92]. The extent of copolymerization of the resin system with the coupling agent also is an important factor in determining the durability of the interphase as is the nature of the filler, its size, surface area, topography, shape, etc. The objective of this section is to develop coupling agents and methods of surface modification that will improve the quality of the interfacial bonding phase in composites and thereby enhance their durability.

An ancillary part of this study is to develop methods suitable for the evaluation of the efficacy of the silane coupling agent and the silanization technique. (see section F.)

\section{PROGRESS REPORT}

\section{Phase I}

Evaluation of a multifunctional, crosslinkable silane agent derived from the reaction of 3-isocyanatopropyltriethoxysilane and BIS-GMA $\left(2,2-b\right.$ is $\left[p-2^{\prime}-\left(\right.\right.$ hydroxy- $3^{\prime}-$ methacryloxypropoxy) phenyl] propane).

A new batch of the multifunctional, crosslinkable silane coupling agent derived from BIS-GMA and 3-isocyanatopropyltriethoxysilane $[93,94]$ was prepared and characterized. An evaluation of this multifunctional silane agent will be reported in Phase II.

As mentioned in our last report we had the privilege of having Dr. Kikuchi of Nihon University as a guest scientist. Dr. Kikuchi's interests are in composites, mechanical methods for evaluating the efficacy of silanization techniques and the effects of water exposure and flaws on the mechanical properties of composites. Consequently, we are collaborating on several projects that are designed to elucidate the quality of interfacial bonding in resin based dental materials. One such project involves a comparison of the diametral tensile strength and the uniaxial tensile strength as a method for assessing the effects of coupling 
agents in both macro- and microfilled composites [95-99]. We reported the results of this study in our last report.

In this report the results of a second project which were presented at the 1992 IADR are summarized below and in Table $1-4$.

Resin based composites, originally developed as esthetic filling materials for anterior teeth and other low stress applications, are increasingly being used in high stress bearing situations, e.g. inlays, onlays, posterior

restoratives. In order to better assess the capabilities of the rapidly growing number of newly improved composites for these and other uses, it is necessary to use tests that will accurately characterize their strength and durability, at least in vitro.

There exists some concern about the suitability of the diametral compression test as a method for determining the tensile strength of polymer based dental composites. Previous studies using commercial dental composites (hybrid, macro- and microfilled materials) indicated that the uniaxial tensile strength (UTS), obtained from a pure tensile pull test on dumbbell shaped specimens, and the diametral tensile strength (DTS), obtained from compressing cylindrical specimens on their sides, can be either similar or divergent [96-99].

A comparative study of the tensile strengths of several experimental, visible light-cured, macrofilled, composites was performed using the uniaxial tension and diametral compression tests. Specific goals included: 1) comparing their diametral tensile strengths and their uniaxial tensile strengths, 2) determining the effect of prolonged water immersion on UTS and DTS, and 3) measuring the effect of flaws on UTS, DTS and compressive strength (CS). Composites were prepared from two mixtures of BIS-GMA/TEGDMA

(triethyleneglycol dimethacrylate) ( $7 / 3$ and $1 / 1$ by wt), activated with 0.2 wto camphorquinone and 0.8 wto ethyl 4$\mathrm{N}, \mathrm{N}$-dimethylaminobenzoate, and 83.3 wt $\%$ of a macrosized (ca $44 \mathrm{~mm})$ glass filler. Composite specimens were polymerized by visible light irradiation. Both silanized (S) and unsilanized (US) glass fillers were used in the preparation of composite pastes. Flaws were introduced by vigorous mixing of degassed, silanized composite pastes for 1 or 3 minutes prior to irradiation. For the unmixed s composites, UTS was significantly greater than DTS $(7 / 3,78 \mathrm{vs} .53 \mathrm{MPa}$; $1 / 1,86$ vs. $51 \mathrm{MPa}$ ). Comparison of S vs. Us composites, showed UTS to be a more sensitive indicator of the interfacial effects of the coupling agent than DTS; 7/3, UTS $S$ vs. US ( 78 vs. $23 \mathrm{MPa})$, DTS S vs. US (53 vs. $24 \mathrm{MPa}) ; 1 / 1$, UTS S vs. US ( 86 vs. $23 \mathrm{MPa})$, DTS S vs. US (51 vs. $23 \mathrm{MPa}$ ). 
After sixty days of water immersion at $37^{\circ} \mathrm{C}$, UTS (but not DTS) showed a significant decrease. For the flawed composites, DTS and CS showed slight decreases from the unmixed controls, but UTS was significantly lower.

For silanized microfilled composites the UTS values are significantly greater than the DTS values and the UTS technique of mechanical testing is a more sensitive indicator of the effects of silanization. The UTS test also shows greater sensitivity than the DTS test to the potentially deleterious effects of water immersion, and, compared to both the DTS and CS methods of testing, shows significantly greater sensitivity to the presence of flaws. 
Table 1 Composition of Composite Resins

\begin{tabular}{llc}
\hline RESIN & \multicolumn{1}{c}{ BIS-GMA/TEGDMA $(w / w)$} & $1 / 1$ OR $7 / 3$ \\
FILLER (wt $q)$ & $\begin{array}{l}\text { MACROSIZED BARIUM OXIDE } \\
\text { GLASS }\end{array}$ & 83.3 \\
FILLER SURFACE & SILANIZED* AND UNSILANIZED & 0.5 \\
TREATMENT (wt $q)$ & & \\
PHOTOINITIATOR & CAMPHORQUINONE & 0.2 \\
COMPONENTS (wt $q)$ & ETHYL 4-N,N-DIMETHYLBENZOATE & 0.8 \\
\hline \hline
\end{tabular}

*SILANIZED WITH 0.5 wt? 3-METHACRYOXYPROPYITRIMETHOXYSILANE

Table 2 comparison of UTS and DTS

\begin{tabular}{||c|c|c|c||}
\hline $\begin{array}{l}\text { Resin } \\
\text { BIS-GMA/TEGDMA }\end{array}$ & $\begin{array}{c}\text { Filler } \\
\text { Surface }\end{array}$ & $\begin{array}{c}\text { UTS } \\
\text { (MPa) }\end{array}$ & $\begin{array}{c}\text { DTS } \\
\text { (MPa) }\end{array}$ \\
\hline $7 / 3$ & S & $77.9(2.2)$ & $52.9(1.1)$ \\
\hline $1 / 1$ & US & $22.7(3.6)$ & $24.0(1.8)$ \\
\hline & S & $85.9(3.9)$ & $51.4(5.4)$ \\
\hline
\end{tabular}

Table 3 UTS and DTS after water immersion

\begin{tabular}{||c|c|c|}
\hline & $\begin{array}{c}\text { UTS } \\
\text { (MPa) }\end{array}$ & $\begin{array}{c}\text { DTS } \\
(\mathrm{MPa})\end{array}$ \\
\hline 1 day & $77.9(2.2)$ & $52.9(1.1)$ \\
\hline 1 week & $70.0(6.3)$ & $56.2(2.2)$ \\
\hline 1 month & $68.7(7.0)$ & $57.4(2.5)$ \\
\hline 2 months & $65.1(4.0)$ & $54.6(1.4)$ \\
\hline BIS-GMA/TEGDMA $=7 / 3$ & $($ ):Standard deviation \\
\hline
\end{tabular}

BIS-GMA/TEGDMA $=7 / 3$ ( ):Standard deviation

Table 4 Effect of flaws on strength

\begin{tabular}{||l|c|c|c||}
\hline & $\begin{array}{c}\text { UTS } \\
\text { (MPa) }\end{array}$ & $\begin{array}{c}\text { DTS } \\
\text { (MPa) }\end{array}$ & $\begin{array}{c}\text { CS } \\
(\mathrm{MPa})\end{array}$ \\
\hline Control & $85.9(3.9)$ & $51.4 \quad(5.4)$ & $276.3 \quad(9.5)$ \\
\hline 1 min. mixing & $62.3(1.8)$ & $48.9(2.4)$ & $264.3 \quad(16.8)$ \\
\hline 3 min. mixing & $57.7(6.1)$ & $46.9 \quad(3.3)$ & $258.2 \quad(16.6)$ \\
\hline 1 min. mixing + injection & $73.1(3.2)$ & $47.8 \quad(0.7)$ & $269.0 \quad(16.8)$ \\
\hline
\end{tabular}

BIS-GMA/TEGDMA $=1 / 1$ 
B. Improvement of Filler systems for composites and cements

\section{PROGRES8 REPORT}

\section{Background}

Considerable effort has been given to improving the properties (especially wear resistance and polishability) of dental composites through modification of their filler systems. In addition to a wide variety of macrofilled and microfilled composites, submicron macrofilled, hybrid filled and megafilled insert-containing composites have been developed. There also has been a trend toward somewhat softer fillers that would not abrade opposing enamel or accelerate the wear process. Modifications in the surface porosity of fillers as a means of enhancing interfacial bonding and wear resistance is another significant development.

The basic approach of this proposal is to optimize the properties of composites by controlling the type, size, shape, distribution and volume percent of the dispersed phase. In addition to the traditional siliceous fillers (radiopaque glasses, fused quartz, silicates, mica, microfine silicas) emphasis is given to other softer, more ductile filler types such as various phosphates, metaphosphates, polymers, etc. as candidates for use in the filler phase of these materials.

Although section B is no longer a part of our proposal it is necessary to consider the effects of different types of fillers, size effects, etc. on the formation of the critical interphase in composites which is relevant to section A.7. Therefore, some parts of section B relating to how filler types and characteristics affect the degree and durability of the interfacial phase of composites are now incorporated into Section A.7. (Synthesis, Characterization and Evaluation of Multifunctional Silane Agents).

D. New Resin systems and Pretreatment Techniques for Bonding to Dentin

\section{Background}

Current dental composites, in contrast to polycarboxylate and glass ionomer cements, are not inherently adhesive to enamel or dentin. The discovery of the acid etch pretreatment technique by Buonocore, however, provided an effective means of bonding composites to enamel $[26,27]$. 
The generation of surface microporosities in enamel by acid treatments involving both inorganic $\left(\mathrm{H}_{3} \mathrm{PO}_{4}, \mathrm{HNO}_{3}\right)$ and organic acids (citric, pyruvic) permits infiltration of the resin into this substrate which by polymerization then forms a micromechanical, interlocking, tag-like structure with the enamel. Although an element of chemical bonding also may exist with certain bonding resins that contain acid (e.g., 1,4-di [2-(2-methy 1-2-propenoate) ethyl]-phthalate-2,5dicarboxylic acid (para-PMDM), anhydride (e.g. (2-methyl-2propenoate) -phthalate-3,4-dicarboxylic acid (4-META), chelating (e.g. NPG-GMA (the reaction product of $\mathrm{N}$ phenylglycine and glycidyl methacrylate), or other types of surface-active groups, the primary mode of adhesion to enamel is considered to be by micromechanical retention. However, superior tag formation and perhaps some chemical interaction may develop when certain types of surface-active components are used in the resin bonding system.

Because of the vital and heterogeneous nature of dentin, bonding to it has been a more challenging problem. on a weight basis dentin consists of $69 \%$ apatitic mineral (mainly hydroxyapatite), $18 \%$ organic matter (mainly collagen) and $13 \%$ water. Factors that can adversely affect bonding to dentin include an inherently wet, tubular surface structure that provides a variable area of peritubular and intertubular dentin. In addition, other complications that can adversely effect bonding include an ill-defined smear layer, which contains damaged dentin having denatured collagen and an altered mineral phase, and the potential for intertubular dentinal fluid flow to the bonded interface which may compromise the durability of the original bond to dentinal tissue.

Although many bonding systems for dentin are predicated on chemical reactions involving the mineral and/or organic components of dentin with surface-active agents (e.g. monomer, polymer, components of the initiator system, etc.), the prevailing assessment indicates that a strong micromechanical, interlocking mode of bonding is definitely involved [28-38]. In addition, in some systems, the polymerization mechanism, e.g., by initiation primarily from the dentinal substrate, may play an important role, especially in those systems (e.g., PMDM, etc.) that involve some sort of spontaneous polymerization and/or efficient oxygen scavenging reactions. A major objective of our studies has been to obtain a better understanding of all phases of the mechanisms for bonding to dentin which would aid in the design of more effective, durable bonding systems. Other objectives are to synthesize new types of surface active monomers, initiator systems or other agents 
for improving interaction with dentin and to assess the efficacy of new modes of pretreating dentin.

\section{PROGRESS REPORT}

Phase I Functional Monomers for Adhesion to Dentin

(a) Synthesis of aldehyde monomers for dentin bonding.

The synthesis and characterization of several acrylic benzaldehyde derivatives was accomplished in this reporting period. The synthesis method is shown below.

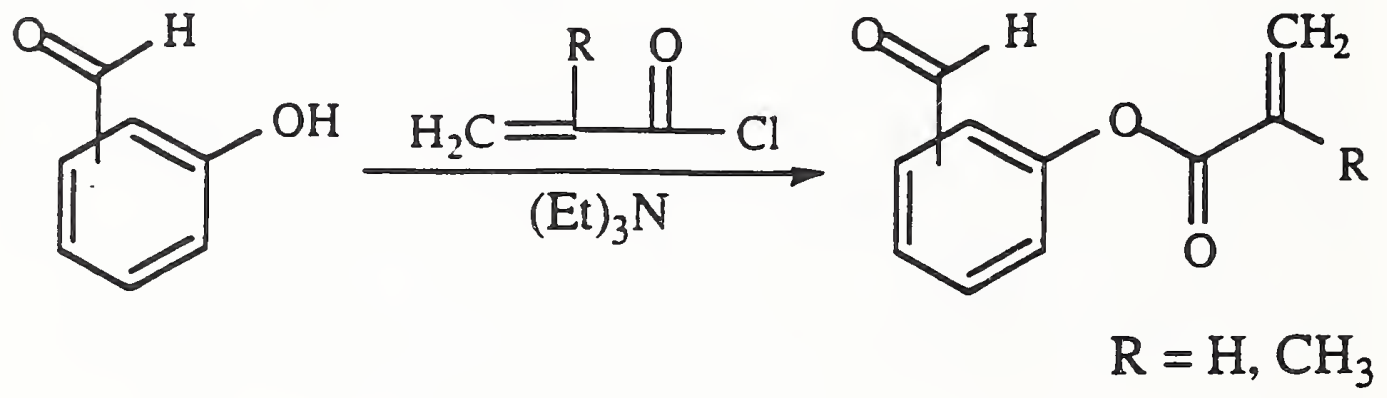

Figure 6. Synthesis of Acryloxy- and Methacryloxybenzaldehydes.

These monomers, by virtue of their aldehyde functionality, may have adhesion-promoting potential. In addition, the presence of the carbonyl group also makes these monomers photoactive towards polymerization. This was especially noteworthy in the case of 2-methacryloxybenzaldehyde which spontaneously polymerized under ambient conditions. Surprisingly, 2-acryloxybenzaldehyde showed greater stability under the same laboratory conditions. The polymers derived from these acrylic aldehydes, using chemical or photoinitiation in their bulk or solution polymerization, were partially crosslinked. A free radical mechanism involving chain transfer reactions of the aldehydic hydrogens either of the monomer or growing polymer is a likely explanation of these results (see Fig. 2A). Similar results were observed in the polymerization of methacryloxyethoxybenzaldehydes (see Fig. 2B). Chain transfer monomers such as these aldehydic monomers, in addition to their potential as adhesion agents, also have the potential for delaying gelation, enhancing vinyl 
conversion and increasing the crosslink density of resin based dental materials. 


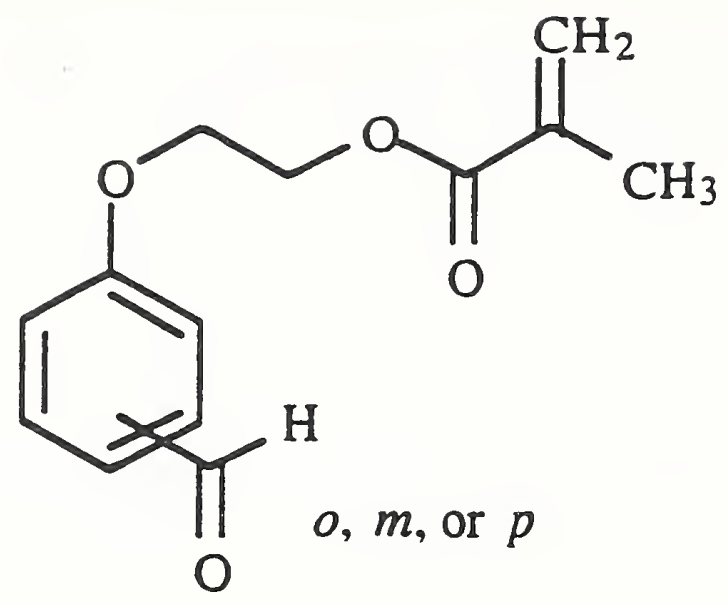

Figure 7B . Aldehyde Methacrylates Derived from Isomeric Hydroxybenzaldehydes
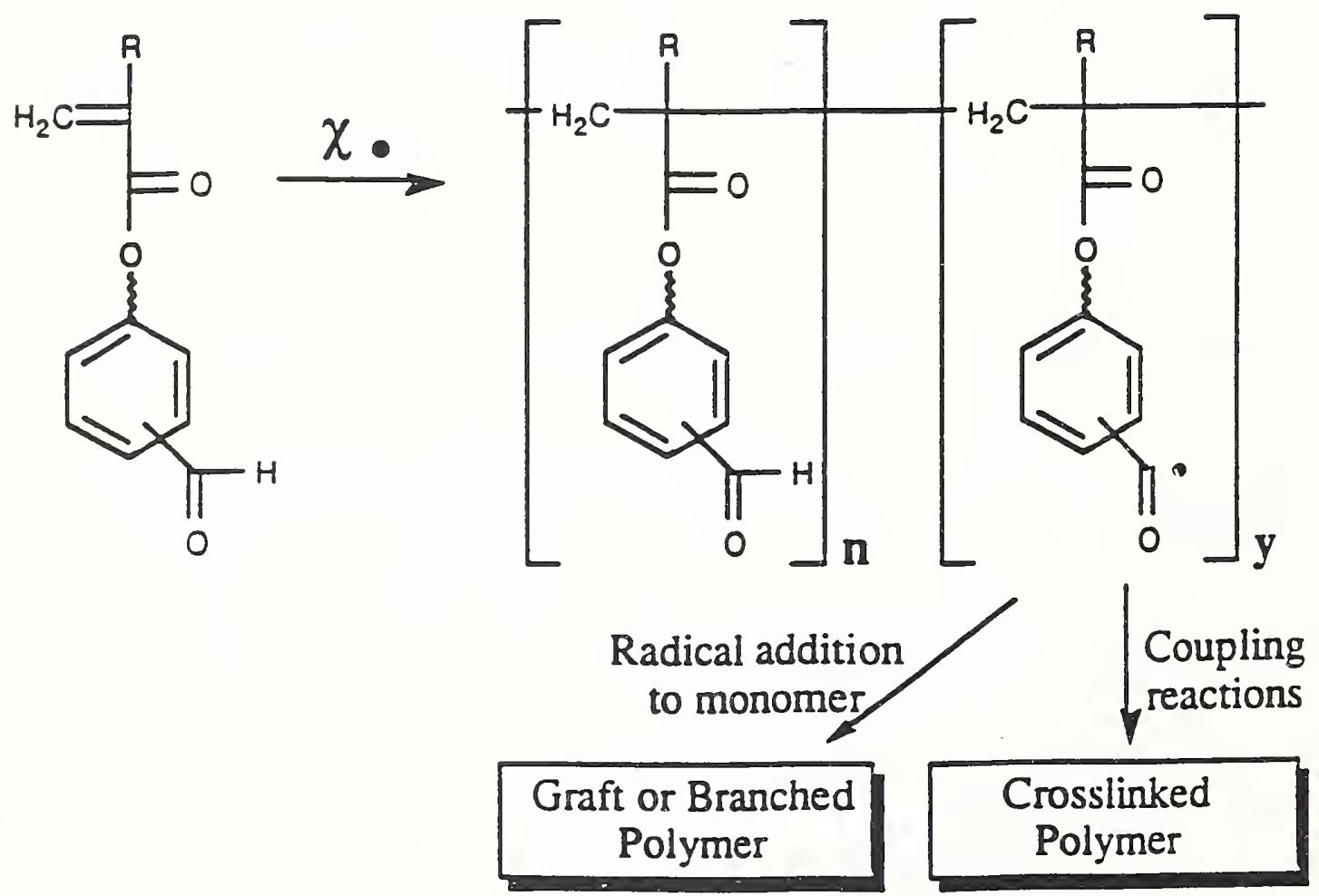

Figure 7A. Possible Mechanistic Pathways for the Formation of Graft (Branched) Polymer and/or Crosslinked Polymer from the Homopolymerization of Acrylic Aldehyde Monomers. 
To examine the potential utility of aldehydic monomers and non-vinyl aldehydes in composite formulations, a study of their effect on the mechanical properties of composites was initiated. These results were presented at the 1992 IADR meeting and are summarized below.

Monofunctional aldehydic methacrylates were shown to form crosslinked polymers probably because their aldehyde groups undergo chain transfer reactions during free radical

polymerization (Antonucci, 1978). Nonvinyl aldehydes, e.g., benzaldehyde (BA), also undergo chain transfer reactions. This study evaluates the effect of several aldehyde additives on the strength of composites. Photoactivated, macrofilled ( 83.3 wt $\%$ ) composites were prepared from BISGMA/TEGDMA ( $1: 1)$ containing varying amounts of $B A$. Composites with 11.5 wto 2-ABA (2-acryloyloxybenzaldehyde) and 10.0 wto DMABA (the dimethyl acetal of $\mathrm{BA}$ ) were prepared as positive and negative controls, respectively. Diametral tensile strength (DTS) and flexural strength (FS) specimens $(n=6)$ were photocured, stored in distilled water at $37^{\circ} \mathrm{C}$ and tested after 24 hours. Compared to either the control $(0 \%$ $B A)$ or a negative control (10.0\% DMABA), composites with BA or 2-ABA had significantly higher FSs (ANOVA and NewmanKeuls multiple comparison test, $\mathrm{p}<0.05)$. Trends were similar for DTS and FS but FS seems to be the more sensitive indicator of changes in the polymeric matrices. Other aldehydes, e.g., phthaldehydes, had similar positive effects on DTS and FS. These results suggest that both vinylic and nonvinylic aldehydes can interact with vinyl monomers to enhance the properties of resin-based dental materials.

\begin{tabular}{||l|c|c|c|c|c|c|}
\hline \hline wt \% & 0, & 3.3, & 7.0, & 14.0, & 11.5, & 10.0 \\
\hline DTS, MPa (S.D.) & $58.6(2.5)$ & $60.3(1.8)$ & $64.9(3.0)$ & $60.9(1.2)$ & $61.8(2.8)$ & $52.1(1.6)$ \\
\hline FS, MPa (S.D.) & $99.5(5.8)$ & $110.5(2.5)$ & $121.6(8.2)$ & $123.6(4.0)$ & $117.4(3.7)$ & $83.9(3.2)$ \\
\hline
\end{tabular}

Future plans involve evaluation of these acrylic aldehyde monomers in dentin adhesive systems.

The following $(b, c, d, e)$ represent collaboration involving Drs. Schumacher and Code of the Commisioned officers Dental Clinic at NIH. The work to date is summarized below.

(b) Synthesis of Zirconyl Monomers for Dentin Bonding

Effective composite-to-dentin bonding systems that utilized NTG-GMA (the adduct of N-tolylglycine and glycidyl methacrylate) or its sodium salt and carboxylic acid monomers (e.g. PMDM) have been developed. The aim of this study was to synthesize, characterize and evaluate the bonding potential of the zirconyl (ZrO) salt of NTG-GMA. 
The salt Zro(NTG-GMA) 2 was prepared by the reaction of NaNTG-GMA with $\mathrm{ZrOCl}_{2}$ in an aqueous solution. Zro(NTG-GMA) 2 was characterized by $I R$ and ${ }^{1} \mathrm{H}$ NMR analysis. In contrast to NaNTG-GMA, ZrO(NTG-GMA) 2 is insoluble in water but quite soluble in a wide range of organic solvents and monomers. In monomeric solutions ZrO(NTG-GMA) 2 has excellent stability in contrast to NTG-GMA or its sodium salt. A three step bonding protocol that consisted of sequential applications of $2.8 \mathrm{w} / \mathrm{w} \%$ ferric oxalate in $1.9 \mathrm{w} / \mathrm{w} \% \mathrm{HNO}_{3}$, an acetone solution of the NTG-GMA salt and a $10 \mathrm{w} / \mathrm{w} \%$ acetone solution of PMDM was used. IA and IB are at equivalent concentrations. The following mean tensile bond strengths (TBS) were obtained after storage for 24 hours in $\mathrm{H}_{2} \mathrm{O}$ at $23^{\circ} \mathrm{C}(\mathrm{n}=10)$ :

\begin{tabular}{|rrrrc|}
\hline Salt of NTG-GMA & $w / w \%$ in Acetone & TBS (MPa) & S.D. (MPa) \\
\hline IA & $\mathrm{Na}$ & 0.91 & 11.4 & 5.2 \\
\hline IB & ZrO & 1.00 & 8.7 & 3.5 \\
\hline$I 1$ & ZrO & 2.50 & 11.3 & 3.1 \\
\hline$I 11$ & ZrO & 5.00 & 12.1 & 3.7 \\
\hline IV & ZrO & 10.00 & 8.1 & 2.5 \\
\hline
\end{tabular}

These results indicate that $\left.\mathrm{ZrO}_{(\mathrm{NTG}-G M A}\right)_{2}$, and perhaps other zirconates, could be effective as agents in dentin adhesive systems. An abstract has been submitted for the 1993 IADR meeting.

(c) Evaluation of Pretreated Dentin Using Aliphatic and Aromatic Carboxylic Acid Monomers.

The objective of this study was to compare the tensile bond strengths (TBS) of composites to ferric oxalatepreconditioned dentin when aliphatic or aromatic carboxylic acid monomers were used as intermediary surface active monomers. The chemical structures and acronyms of the two types of carboxylic acid methacrylates are shown in Figures 1 and 2. The results of the bond experiments are summarized in Tables 1 and 2 . In Table 1 the surface-active monomers were applied from acetone solutions while in Table 2 solutions III-VI employed monomer or resin solutions. The results indicate that the aliphatic carboxylic acid monomers gave TBSs that were significantly lower than those obtained with the aromatic carboxylic acid monomers. MMEP, a monofunctional carboxylic acid monomer, appeared to give lower TBS than difunctional aromatic carboxylic acid monomers when applied from acetone (Table 1). The results of this study were presented at the 1992 AADR. 

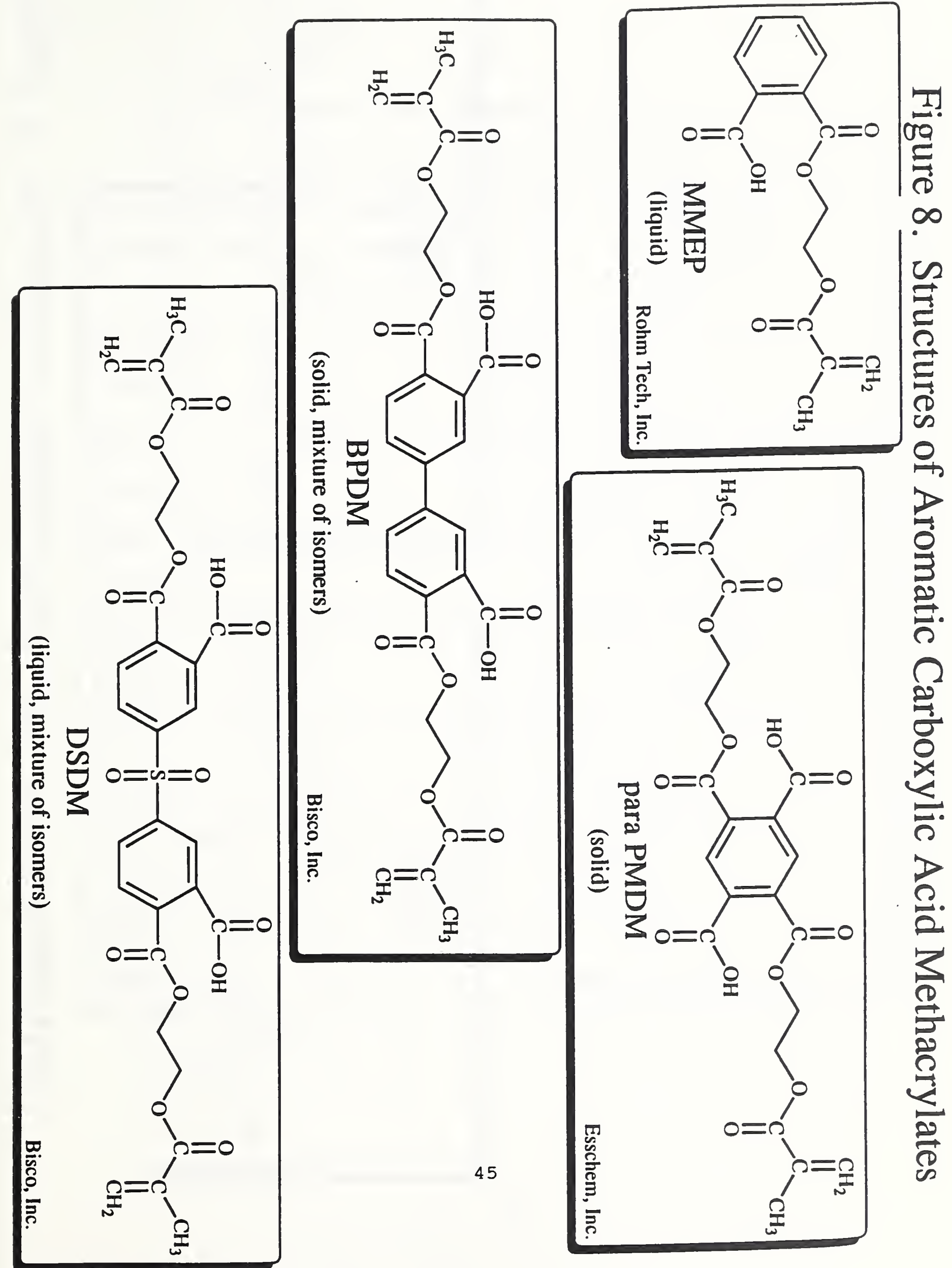

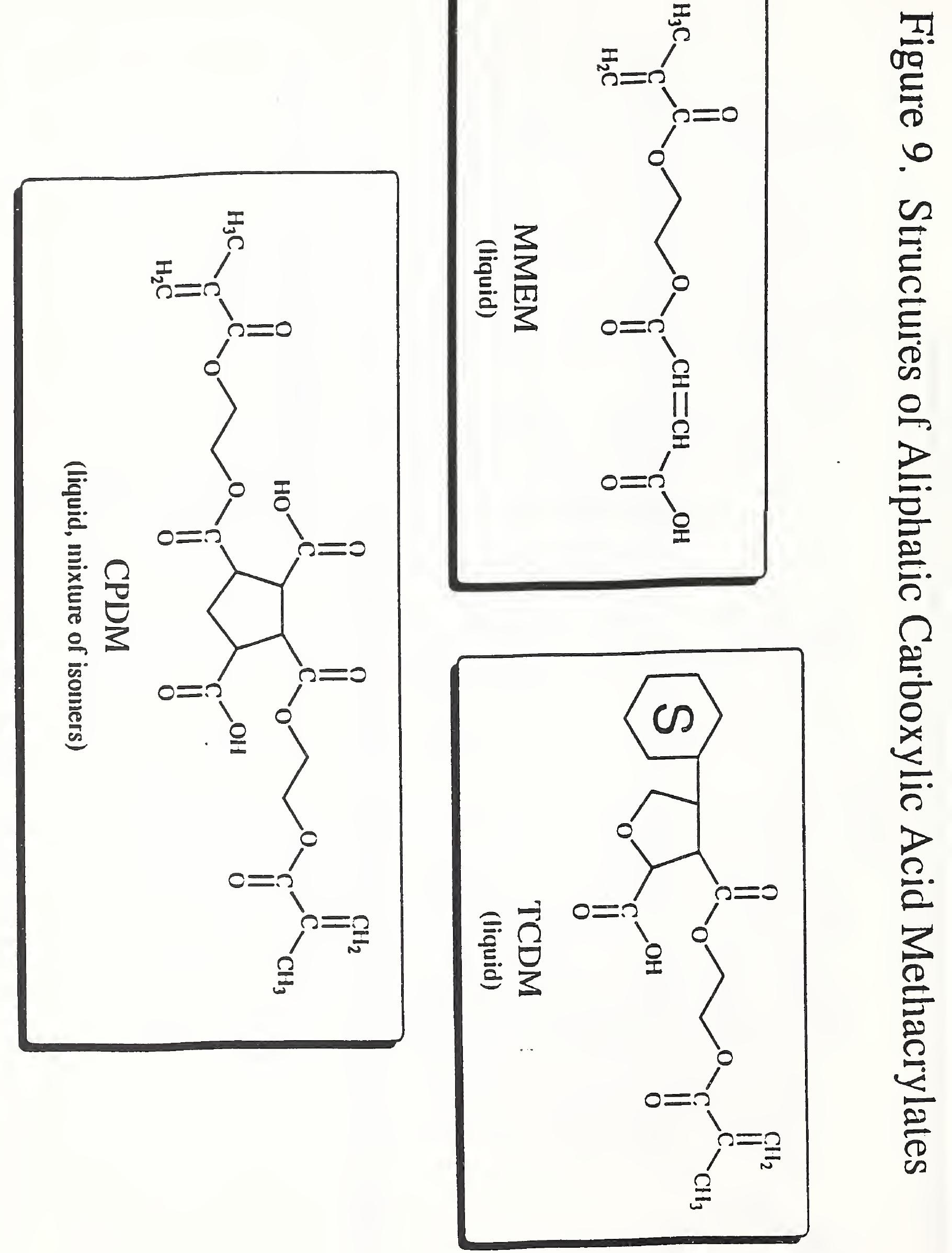

है

足 
Table 5

Tensile Bond Strengths to Dentin

Using Bonding Monomers in Acetone

\begin{tabular}{|c|c|c|}
\hline $\begin{array}{l}\text { BONDING MONOMER IN } \\
\text { ACETONE, wt\% }\end{array}$ & $\begin{array}{l}\text { MEAN TENSILE BOND } \\
\text { STRENGTH IN MPa } \\
\text { (STD. DEV.) }\end{array}$ & $\begin{array}{l}\text { NUMBER OF } \\
\text { MEASUREMENTS, n }\end{array}$ \\
\hline $\begin{array}{l}\text { para-PMDM, } \\
\text { aromatic }\end{array}$ & $11.2(2.7)$ & 8 \\
\hline $\begin{array}{l}\text { MMEP, } \\
\text { aromatic }\end{array}$ & $8.7 \quad(2.2)$ & 10 \\
\hline $\begin{array}{l}\text { MMEM, } \\
\text { aliphatic }\end{array}$ & $1.0 \quad(2.3)$ & 10 \\
\hline $\begin{array}{l}\text { DSDM, } \\
\text { aromatic }\end{array}$ & $10.0(1.9)$ & 10 \\
\hline $\begin{array}{l}\text { BPDM, } \\
\text { aromatic }\end{array}$ & $10.6(3.1)$ & 10 \\
\hline $\begin{array}{l}\text { TCDM, } \\
\text { aliphatic }\end{array}$ & $6.3 \quad(2.6)$ & 10 \\
\hline $\begin{array}{l}\text { CPDM, } \\
\text { aliphatic }\end{array}$ & $6.3 \quad(2.7)$ & 10 \\
\hline
\end{tabular}


Table 6

Tensile Bond Strengths to Dentin Using Bonding Resins

\begin{tabular}{|c|c|c|c|c|}
\hline $\begin{array}{l}\text { BONDING } \\
\text { SOLUTION }\end{array}$ & $\begin{array}{r}\text { COMPOSI } \\
\text { wt }\end{array}$ & ION, & $\begin{array}{l}\text { MEAN TENSILE } \\
\text { BOND STRENGTH } \\
\text { MPa (STD. DEV) }\end{array}$ & $\begin{array}{c}\text { NUMBER OF } \\
\text { MEASUREMENTS, } \\
\mathrm{n}\end{array}$ \\
\hline I & MMEP & 20.7 & $8.7 \quad(2.2)$ & 10 \\
\hline II & MMEM & 30.0 & $1.0 \quad(2.3)$ & 10 \\
\hline III & $\begin{array}{l}\text { MMEP } \\
\text { HEMA } \\
\text { BIS-GMA }\end{array}$ & $\begin{array}{l}38.2 \\
16.9 \\
45.8\end{array}$ & $9.4(3.0)$ & 10 \\
\hline IV & $\begin{array}{l}\text { MMEM } \\
\text { HEMA } \\
\text { BIS-GMA }\end{array}$ & $\begin{array}{l}39.9 \\
20.6 \\
39.5\end{array}$ & $5.8 \quad(2.8)$ & 10 \\
\hline v & $\begin{array}{l}\text { PMDM } \\
\text { HEMA } \\
\text { MMEP }\end{array}$ & $\begin{array}{r}7.2 \\
59.4 \\
33.4\end{array}$ & $10.5(3.7)$ & 1.0 \\
\hline VI & $\begin{array}{l}\text { PMDM } \\
\text { HEMA } \\
\text { MMEM }\end{array}$ & $\begin{array}{r}5.6 \\
50.0 \\
44.4\end{array}$ & $0.6(1.9)$ & 10 \\
\hline
\end{tabular}


Several aqueous solutions $(0.5-1.0 \mathrm{w} / \mathrm{w} \%)$ of zirconium tetrafluoride, $\mathrm{ZrF}_{4}$, were prepared at $23^{\circ} \mathrm{C}$. The $\mathrm{pH}$ of the $1.0 \%$ solution was 2.0 . Unfortunately, these solutions proved to be unstable and formed precipitates, presumably from the hydrolysis of $\mathrm{ZrF}_{4}$. However, several solutions of L-ascorbic acid ( $A A$ ) with $\mathrm{ZrF}_{2}$ appear to inhibit precipitation of the zirconium salt and yield solutions of relatively low $\mathrm{pH}$. The table below summarizes these results.

\begin{tabular}{|c|c|c|c|}
\hline Solution & $\begin{array}{c}\text { conc. in } \mathrm{W} / \mathrm{W} \% \\
\text { of } \mathrm{AA}\end{array}$ & $\begin{array}{c}\text { Conc. in } \mathrm{W} / \mathrm{W} \% \\
\mathrm{ZrF}_{4}\end{array}$ & $\mathrm{pH}$ \\
\hline $\mathrm{A}$ & 10.0 & 0 & 2.20 \\
\hline $\mathrm{B}$ & 10.0 & 0.82 & 1.70 \\
\hline C & 20.0 & 0 & 1.90 \\
\hline $\mathrm{D}$ & 20.0 & 0.72 & 1.53 \\
\hline
\end{tabular}

Solutions of these types will be examined for their efficacy in pretreating dentin for composite bonding.

(e) L-ascorbic acid as an etchant/conditioner for bonding to dentin

Previously L-ascorbic acid ( $A A)$, was evaluated as an etchant/conditioner for dentin bonding using sequential applications of acetone solutions of $\mathrm{N}$-phenylglycine (NPG) and carboxylic acid monomers. In subsequent studies the feasibility of substituting 2-hydroxyethyl methacrylate (HEMA) based solutions of several carboxylic acid monomers (BPDM, DSDM, PMGDM) for the usual acetone solutions of the same monomers in this bonding protocol was evaluated. Tensile bond strengths (TBS) were measured after dentin surfaces were treated sequentially with a solution of aqueous AA ( 60 secs), NPG in acetone (60 secs), various carboxylic monomers in HEMA (60 secs), and finally with a chemically cured composite. Mean TBS were determined after storage in distilled $\mathrm{H}_{2} \mathrm{O}$ at $23^{\circ} \mathrm{C}$.

\begin{tabular}{|c|c|c|c|c|c|}
\hline & $\left(\frac{\circ}{W} / W\right)$ & NPG $\left(\frac{\circ}{6} \mathrm{~W} / \mathrm{W}\right)$ & RESIN $(\% W / W)$ & TBS (MPa) & $\underline{S D}$ \\
\hline A & 20 & 10 & $\mathrm{BPDM} 16.6$ & 10.3 & $\overline{3.7}$ \\
\hline$B$ & 20 & 10 & DSDM & 10.0 & 1.6 \\
\hline c & 20 & 10 & PMGDM 19.8 & 7.9 & 3.4 \\
\hline D & 20 & 10 & PMGDM 50.0 & 5.8 & 2.6 \\
\hline & 20 & 10 & PMGDM 40.5 & 5.1 & 1.6 \\
\hline
\end{tabular}


TBS results demonstrate that HEMA based carboxylic monomers applied to AA conditioned dentin containing infused NPG can yield significant composite-to-dentin bond strengths.

Phase VIII

Adhesion of Dental Resins via Acid-Base Free Radical Mechanisms

Since understanding the chemical aspects of the mechanism of bonding to dentin via the PMDM and related systems can aid in the design of improved dentin adhesive systems, we have decided to make this study part of our Phase I effort. Dr. Farahani of the ADAHF/PRC is collaborating in this endeavor, especially with respect to radical detection and

characterization using electron spin resonance (ESR)

spectroscopy.

A significant breakthrough in dental adhesion occurred with the discovery that the application of para-PMDM (a diadduct of 2-hydroxyethyl methacrylate and pyromellitic anhydride) to tooth structure that had been preconditioned with acidic agents and a surface active amine resulted in strong bonding of dentin and enamel to resin based dental materials. An intriguing feature of this and similar bonding systems is the spontaneous polymerization or copolymerization of paraPMDM. A plausible mechanism for this surface-initiated polymerization involves the interaction of the carboxylic acid groups $\left(-\mathrm{CO}_{2} \mathrm{H}\right)$ of para-PMDM and similar acidic monomers with the amine component of the bonding system to yield an unstable salt or complex which then breaks down to initiating radicals.

To test this hypothesis dental resin formulations with monomer systems containing $-\mathrm{CO}_{2} \mathrm{H}$ groups (A), e.g. acidic monomers, simple aliphatic and aromatic acids, anhydrides, phenols, etc. were prepared and mixed with monomer systems containing various types of amines (B). The concentration of the $-\mathrm{CO}_{2} \mathrm{H}$ and the amine components of resin $\mathrm{A}$ and resin $\mathrm{B}$ were varied. Rotational hardening times (RHTs) at $23^{\circ} \mathrm{C}$, $37^{\circ} \mathrm{C}$ and $60^{\circ} \mathrm{C}$ were determined by mixing equal parts of the $\mathrm{A}$ and B components between crossed glass slides (see Figure 4) and noting the time to immobilization. Time to immobilization as determined by RHTs varied inversely with temperature and with the concentrations of amine and acid component. Acid strength of the $-\mathrm{CO}_{2} \mathrm{H}(\mathrm{pKa})$ was a factor with the stronger acids generally giving shorter RHTs. The basicity (pKb) of tertiary aryl amines also was a factor, with the more basic amines giving shorter $\operatorname{RHTs} ;$ air $\left(\mathrm{O}_{2}\right)$ and weakly phenolic compounds (BHT) inhibited the polymerization. 
The polymerization of dental resins activated with acid-base components (see Figure 5) was monitored using IR

spectroscopy; ESR experiments indicate the formation of radical species. ${ }^{1} \mathrm{H}$ NMR spectroscopy of acid-aryl amine mixtures in deuterated chloroform indicated initial ammonium salt formation followed by transformations which may be due to subsequent charge-transfer reactions. Similar acidaliphatic amine mixtures only showed ammonium salt formation (Figs. $6 \& 7$ ). Strong dental composites were prepared using several of these acid-amine initiator systems, e.g. a BISGMA/TEGDMA (7/3) resin containing 83.3 wt: silanized glass filler and 3.1 wt: $\mathrm{BF}_{3} \cdot \mathrm{DMPT}$ yielded a composite which had a diametral tensile strength of $51.2(1.6) \mathrm{MPa}$ as well as excellent esthetic.

In dentin bonding experiments surface-active aromatic amines were more effective than surface-active aliphatic amines (Table 3 ). These results suggest radical polymerization mechanisms involving acid-amine complexation and electron transfer (Figure 6). Understanding the mechanism(s) of these self-initiated polymerizations will aid in designing optimal dental adhesive and multi-cure initiator systems. 


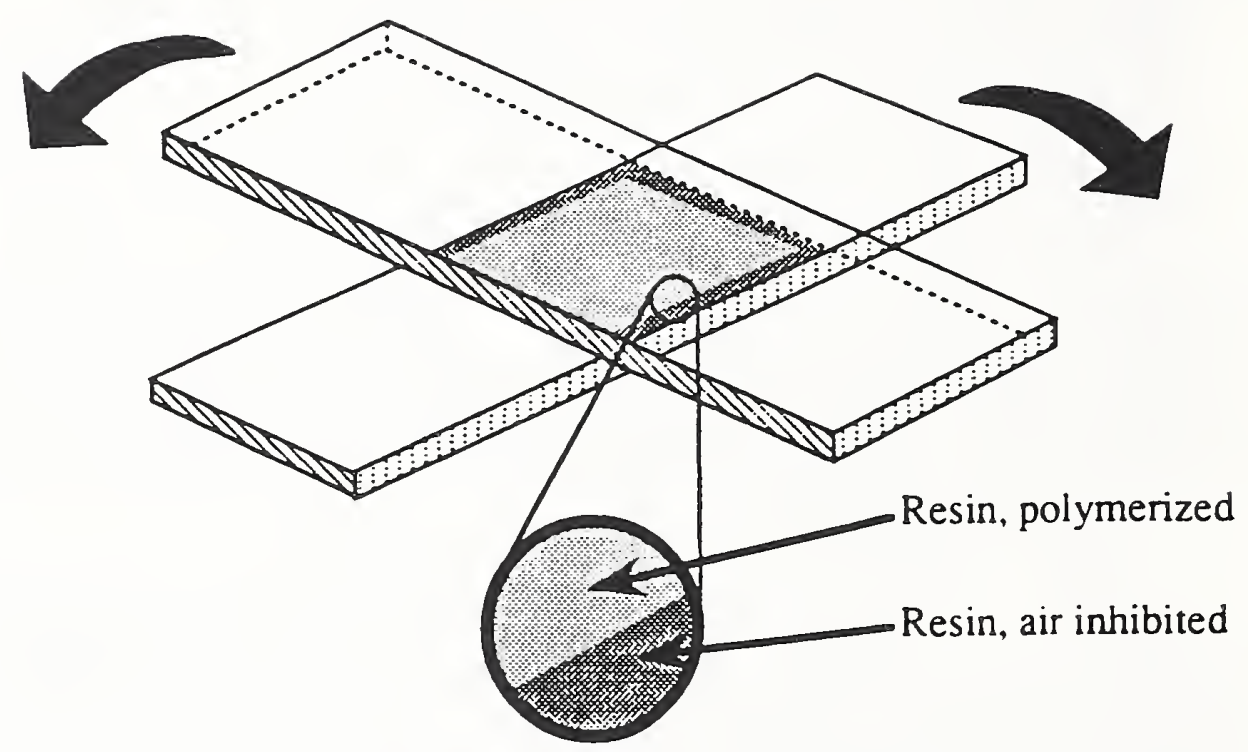

Figure 10
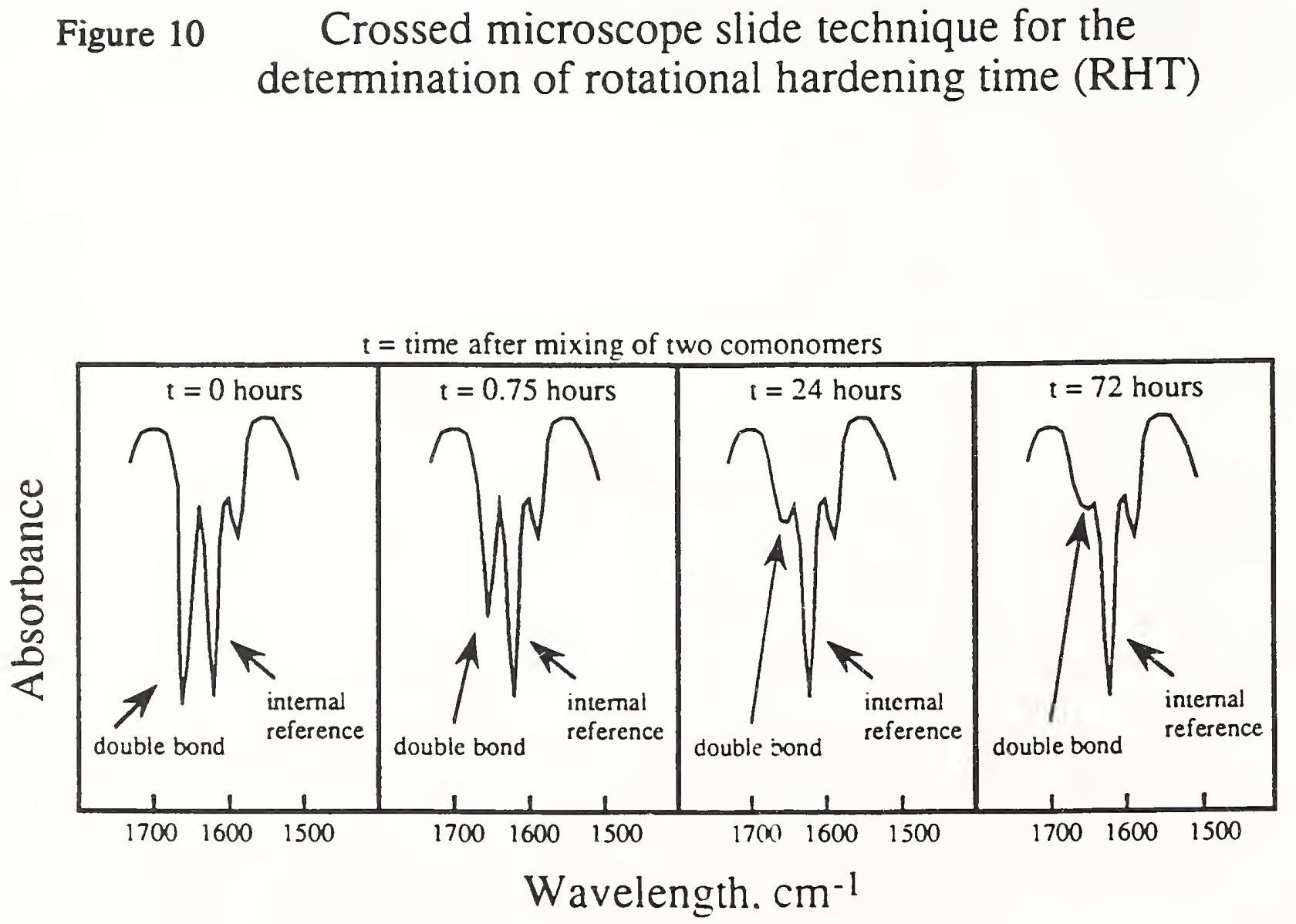

Figure 11 Time dependent conversion by IR spectroscopy of BIS-GMA/TEGDMA (7/3) activated with $2.7 \% \mathrm{w} / \mathrm{w}$ D:MPT and $4.0 \% \mathrm{w} / \mathrm{w}$ PFP. 


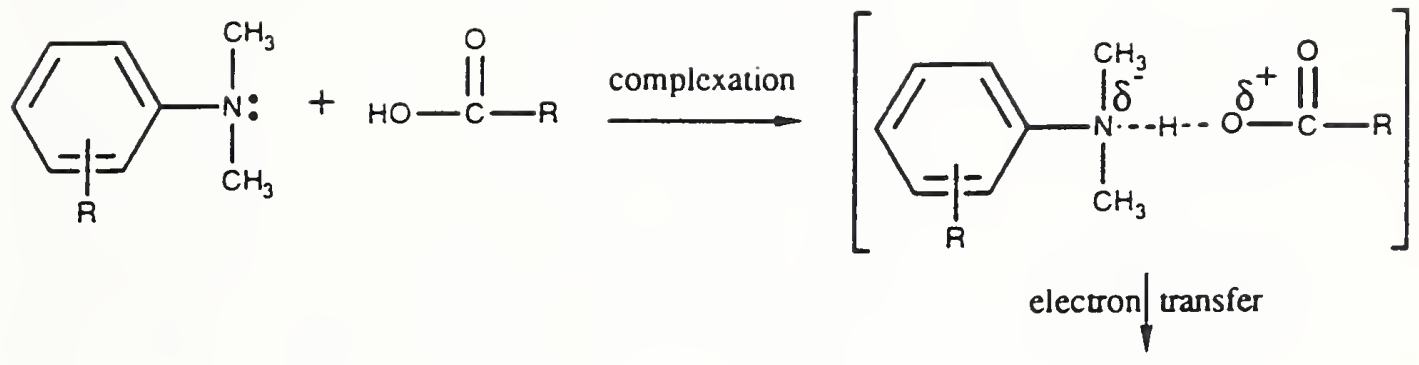

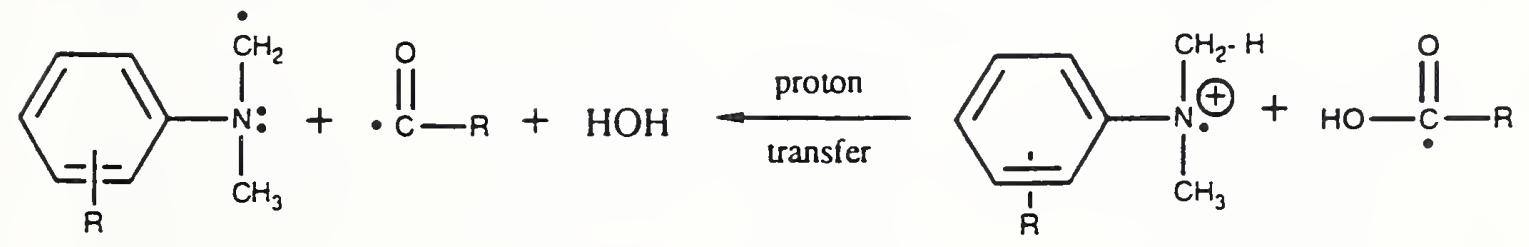

Figure 12 Initiation Mechanism Via Aryl Amine-Acid Complex 
Table 7

Composite/Dentin Tensile Bond Strength (TBS) in $\mathrm{MPa}^{*}$ Aryl Amino Acids (I) vs. Aliphatic Amino Acids (II)

\begin{tabular}{||c|l|c|l||}
\multicolumn{1}{c}{ Amino Acid } & \multicolumn{1}{c}{ Acronym } & \multicolumn{1}{c|}{ Protocol } & \multicolumn{1}{c|}{ TBS (std dev) } \\
\hline \hline N-Methyl, N-Phenylglycine & NMNPG I & a & $14.3(4.9)$ \\
\hline N-Methyl, N-Phenylalanine & NMNPA I & a & $13.2(2.0)$ \\
\hline N-Tolylglycine & NTG I & a & $12.9(2.0)$ \\
\hline N-Phenylglycine & NTG I & a & $12.4(3.6)$ \\
\hline Glycine & G II & a & $6.1(5.9)$ \\
\hline N-Methylglycine & NMG II & a & $5.9(5.5)$ \\
\hline N-Tolylglycine & & & \\
\hline N-Phenylglycine & NTG I & b & $15.6(4.0)$ \\
\hline$\alpha$-Phenylglycine & NPG I & b & $11.5(3.4)$ \\
\hline N-Methylglycine & APG II & b & $2.4(1.6)$ \\
\hline N,N-Bis(2-hydroxyethyl)-glycine & NNHEG II & b & $0.9(0.9)$ \\
\hline \hline
\end{tabular}

a: 3-step bonding protocol i) $\mathrm{Fe}_{2}(\mathrm{Ox})_{3}+\mathrm{HNO}_{3}$ ii) amine iii) PMDM

b: 2-step bonding protocol i) $\mathrm{HNO}_{3}+$ amine ii) PMDM

•from A.D. Johnston et al. J Dent Res 681337 (1989) 
E. Improvement of Dental Cements

Background

Dental cements also can be considered as composite materials and because of their heterogenous nature, exhibit many of the same problems, i.e. relatively weak matrices, fillers and interfaces that are vulnerable to mechanical, physical or chemical modes of degradation [71-83]. Dental cements are especially weak in their resistance to acidic conditions and the tensile and shear forces that are commonly generated by masticatory activities and stresses.

Dental cements can be divided into two broad categories: (1) those that are largely aqueous based (e.g. zinc phosphate, zinc polycarboxylate and glass ionomer cements) and (2) those that are relatively nonaqueous in nature, although small amounts of water or other protic agents are considered essential to their setting and hardening process (e.g. ZOE, ZOE-EBA, hexyl vanillate-EBA, and dimer acid cements). Dental cements that combine optimal strength, adhesion, durability and biocompatibility are still lacking.

The overall goal is to develop tough, durable cements by reducing their propensity to brittle failure and hydrolytic degradation, especially in acidic environments. BY appropriate modification of the structure achieved by compositional changes in existing cements and/or by the development of improved types of composite structures, cements having these properties as well as enhanced biocompatibility and adhesiveness are expected.

\section{PROGRESS REPORT}

Phase I

Develop new types of hybrid cement-composites based on polyelectrolyte cements and water soluble monomers capable of cyclopolymerization. The synthesis of the requisite monomers is progressing (see I A.4 part i) but is not at a stage to be applied to this study.

Phase II

Develop new types of hybrid cement-composites based on modified water soluble polymers.

In this study the feasibility of achieving stronger, more adhesive cements by incorporating into a water setting glass ionomer cement, water soluble salts of PMDM (the reaction product of 2-hydroxyethyl methacrylate and pyromellitic anhydride) was investigated. The sodium and potassium salts 
of PMDM were prepared by neutralization of PMDM with the alkali carbonates as shown below:

$$
\begin{aligned}
& \mathrm{PMDM}+\mathrm{M}_{2} \mathrm{CO}_{3} \\
& \mathrm{M}=\mathrm{Na}, \mathrm{K}
\end{aligned} \stackrel{\mathrm{H}_{2} \mathrm{O}}{\rightarrow} \mathrm{M}_{2} \mathrm{PMDM}
$$

The water setting glass ionomer used in this study was Chemfil II. The powder component was a mixture of ionleachable glass and poly(acrylic acid) blended with $0.3 \mathrm{w} / \mathrm{w} \%$ benzoyl peroxide (BPO). The liquid component (distilled water) was formulated into a solution consisting of $\mathrm{M}_{2}$ PMDM and an accelerator such as 3-N,N-dimethylaminobenzoic acid (3-DMAB) or 3-DMAB plus sodium p-toluene sulfinate (NapTs).

\begin{tabular}{|c|c|c|c|}
\hline \multicolumn{2}{|c|}{ Formulation A } & \multicolumn{2}{|c|}{ Formulation B } \\
\hline $\begin{array}{lll}30 \mathrm{w} / \mathrm{w} & \mathrm{K}_{2} & \text { PMDM } \\
0.7 \mathrm{w} / \mathrm{w} \% & 3-D M A B\end{array}$ & $\begin{array}{c}\text { Chemfil II Powder } \\
0.3 \mathrm{w} / \mathrm{w} \% \mathrm{BPO} \\
\mathrm{DTS}=21.0(3.2) \mathrm{MPa} \\
\mathrm{n}=5\end{array}$ & $\begin{array}{l}11.3 \mathrm{w} / \mathrm{w} \mathrm{Na}_{2} \text { PMDM } \\
0.6 \% 3-\mathrm{DMAB} \\
\mathrm{MPa} 0.6 \% \text { NapTs }\end{array}$ & $\begin{array}{c}\text { Chemfil II Powder } \\
0.3 \mathrm{w} / \mathrm{w} \% \text { BPO } \\
\text { DTS }=18.5 \quad(1.7) \mathrm{MPa} \\
n=5\end{array}$ \\
\hline
\end{tabular}

These preliminary results suggest that soluble salts of PMDM and similar monomers can be used to formulate resin modified cement-composite.

Phase III

(a) Polymeric calcium phosphate cements based on poly(vinyl alcohol) and CPC powder.

In our efforts to develop improved types of polymeric calcium phosphate cements we initiated a collaborative study with Dr. McDowel1, Head of the Chemistry Department at the University of the District of Columbia, and Drs. Chow and Takagi of the ADAHF/PRC which involves the reaction of $C P C$, a stoichiometric mixture of tetracalcium phosphate (TTCP) and anhydrous dicalcium phosphate (DCPA), in aqueous solutions of poly(vinyl alcohol), PVA. setting times and diametral tensile strengths (DTS) were determined for several formulations using PVA with a molecular weight of 14,000. Using the Gilmore needle test approximate setting times were determined and DTS measurements were conducted using formulations with CPC powder to liquid ratios of 4. The setting times of CPC cement (formulated with only distilled water) was $30-60 \mathrm{~min}$ at $37^{\circ} \mathrm{C}$ in $100 \%$ relative humidity. Cements prepared using 4-10\% w/W aqueous solutions of PVA gave similar setting times. The addition of $\mathrm{H}_{3} \mathrm{PO}_{4}$ to the PVA formulations $\left(5.7 \mathrm{w} / \mathrm{w}^{2} \mathrm{H}_{3} \mathrm{PO}_{4}\right.$ in $8 \mathrm{w} / \mathrm{w} \%$ PVA and $2.9 \% \mathrm{H}_{3} \mathrm{PO}_{4}$ in $4 \mathrm{w} / \mathrm{W} \% \mathrm{PVA}$ ) reduced the setting time significantly, to 15-20 minutes. The DTS values of PVA 
cements formulated with $\mathrm{H}_{3} \mathrm{PO}_{4}$ were virtually the same as those containing no $\mathrm{H}_{3} \mathrm{PO}_{4}$, i.e. $4 \% \mathrm{PVA}-\mathrm{CPC} \sim 6.4 \mathrm{MPa}$ and $8 \%$ PVA-CPC $5.8 \mathrm{MPa}$. X-ray diffraction analysis showed that hydroxyapatite formation occurred in the PVA-CPC cements.

(b) Polymeric calcium phosphate cements based on amorphous calcium phosphate (ACP)

In a recent collaborative effort with Dr. Eanes of NIDR and Dr. Skrtic (Ruder Boskovic/Istitute, Zagreb, Croatia), a visiting associate at the Bone Research of NIDR, a study of the feasibility of forming polymeric calcium phosphate cements from water soluble polymers and amorphous calcium phosphate has been initiated. Preliminary results have shown that ambient setting cements can be formed using aqueous PVA and ACP. X-ray analysis shows the formation of hydroxyapatite. Studies also are planned to prepare ACP composites and sealants based on monomer systems of different hydrophilicity.

A paper based on new calcium phosphate cements derived from the polyacid, PMVE-Ma (an alternating copolymer of methyl vinyl ether and maleic acid), and CPC powder (a stoichiometric mixture of tetracalcium phosphate and dicalcium phosphate) and other calcium phosphate mixtures was prepared for submission to Dental Materials. This work was presented at the 1992 AADR meeting.

F. Fluorescent Probes for Assessing the Cure of Dental Composites and the Effectiveness and Durability of Coupling Agents

\section{PROGRESS REPORT}

\section{Objective}

The primary objectives of this proposal are to explore the use of fluorescent dye technology for improvement of the properties of dental composite resins and resin-based cements through: 1) monitoring of the degree of cure and 2) assessing the quality of the filler-matrix interfacial bond within composites.

The first application involves the use of cure sensitive fluorescent dyes for making definitive measurements of the degree of cure in resins, composites, and cements, thereby leading to improved resin formulations and initiator systems. It can be foreseen that this technology could be useful for both research and product quality assurance. 
The second application is the use of fluorescent dyes for quantifying the effectiveness of various methods of applying coupling agents to filler substrates and for determining the degradation resistance of the coupling agent-to-filler interfacial bond. This work also holds the potential for the evaluation of the durability of the interfacial bond between the resin matrix and the coupling agent-filler system.

\section{Background}

Fluorescent probes, in the form of relatively low molecular weight organic dyes (usually with substituted aromatic structures), absorb light energy (UV and/or visible) at characteristic wavelengths and emit a spectrum of light at longer wavelengths. Some fluorescent molecules exhibit sensitivity to viscosity and to the chemical environment, such as polarity, solvation, and $\mathrm{pH}$, at the molecular site [102-106]. Thus since the microviscosity of a resin based system changes with degree of cure, fluorescent probes hold the potential as a real time indicator of how well the system has cured. Fluorescent probes also might be useful as tracer molecules to indicate the extent of the silanization of filler particles.

These fluorescent probes can be uniformly dispersed in the resin or attached to various functional molecules (through double bonds or amino groups). The spectral characteristics of the fluorescent probe can change in several ways (depending on the microenvironment in which the probe resides) including: wavelength (color) shifts in peaks of the emission spectra, changes in the fluorescent intensities (i.e. changes in peak heights), and/or changes in the shape of the emission spectra.

The selection of suitable fluorescent probe molecules for degree of cure studies is governed by the following considerations: (1) chemical stability in the cure environment (e.g. how are results affected by chemical reactions involving the probe, e.g. reactions with the photo-oxidant), (2) sensitivity of the fluorescence intensity to a wide range of microviscosities, (3) excitation and fluorescence frequencies in relation to the internal photochemical effects of the resin systems, (4) solubility in the resin, and (5) the excitation and fluorescence frequencies of any internal, non-viscosity dependent, fluorescent intensity standard. The selection of probes for efficacy of silanization requires that the probe be easily attached chemically to the silane molecule and that the new bond be chemically stable. To assess the quality of the silanated interface requires that the fluorescent probe exhibit sensitivity to the viscosity of the microenvironment created by solvation of the surface 
modified filler (similar to the probes used in the degree of cure studies).

One difficulty encountered with the use of fluorescent dyes for the assessment of degree of cure or effectiveness of silanization in glass filled composites is the phenomena of light scattering. The presence of the fine particulates adds scattering peaks to the fluorescence spectra of composite samples. These scattering peaks can be subtracted out from a reference spectrum, but more work remains to be done to assess the reproducibility of such spectrum subtraction techniques. An additional note should be made here that the original intent to use fiber waveguides for fluorescence monitoring has not been pursued as yet because the basic analytical technique requires further development before this application can be considered.

Phase I

\section{CURING TECHNOLOGY}

This section presents the results of progress from the one year pilot study on fluorescent cure technology and serves as the basis for a request for an extension of the work through FY's 92 and 93. This work represents a $70 \%$ man year effort (mistakenly identified as a $20 \%$ man year effort in the previous report) and required substantial infusion of NIST support ( $35 \%$ man year), to achieve these results.

\section{overview}

Fluorescent probes that were identified for sensitivity to changes in the microviscosity fell into two classes: 1) the excimer type, and 2) combination of a viscosity sensitive dye and an insensitive dye, the latter of which serves as an internal intensity standard. Probes of the excimer type exhibit dual fluorescence with emissions arising from monomeric units and from an excimer formation which results when two chromophors are situated such that the electronic excitation of one chromophor is shared with the other through dipole coupling. [107] Emission from the excimer state occurs at a lower frequency than that from the excited monomer. Excimer type probes exhibit a decrease in excimer fluorescence due to the decreasing diffusion coefficient with cure. [108]

The other class of fluorescent probes to monitor cure are those that show sensitivity of the fluorescence spectra to the local viscosity, or as it is sometimes called, microviscosity, due to the dependence of the internal modes of rotation of molecular bonds on microviscosity [106,109113]; these are the type of fluorescent probes utilized in 
this report. An electronically excited molecule returns to the ground state either by giving off radiation (fluorescence) or by transferring the electronic excitation into vibrational or rotational degrees of freedom (nonradiative). Non-radiative transition probabilities depend on molecular mobility, in particular internal rotations. Thus fluorescent probes that are sensitive to local environmental conditions exhibit fluorescent spectral changes that arise because of the competition between radiative and nonradiative processes for de-excitation of the electronically excited states, a change which occurs as the cure proceeds. [107] A probe molecule constrained by its environment so as to limit internal rotations, as would occur during gelation and continuing through the polymerization process, would exhibit increased fluorescence since non-radiative pathways become more restricted.

\section{Accomplishments}

Phase I The results of this pilot study were given in the last reporting period.

During this reporting period a paper was prepared for

Polymer Preprints and was presented at the American Chemical Society meeting in Washington, D.C. at a symposium on

Polymers of Biological and Biomedical significance [116].

\section{References}

[1] Bowen, R.L. Use of epoxy resins in restorative materials. J. Dent. Res. 35: 360-369, 1956.

[2] Bowen, R.L. Dental filling materials comprising vinyl silane treated fused silica and a binder consisting of the reaction products of bisphenol and glycidyl methacrylate, U.S. Patent 3,066,012, 1962 .

[3] Bowen, R.L. Properties of a silica-reinforced polymer for dental restorations, J. Am. Dent. Assoc. 66:57-64, 1963.

[4] Bowen, R.L. Effect of particle shape and size distribution in a reinforced polymer, J. Am. Dent. 69:481495,1964 .

[5] Antonucci, J.M. New monomers for use in dentistry. In: Biomed. and Dental Applications of Polymers eds., Gebelein, C.G. and Koblitz, F.F. Plenum Press, NY, NY, $357-371,1981$. 
[6] Jorgensen, K.D. and Asmussen, E. Occlusal abrasion of a composite restorative material with ultra-fine filler - An initial study. Quintessence Int. 9:73-78, 1978.

[7] Dennison, J.B. Status report on microfilled composite restorative resins. J. Am. Dent. Assoc. 105:488-492, 1982.

[8] Glenn, J.F. Composition and properties of unfilled and composite resin restorative materials. In: Biocompatibility of Dental Materials Vol. 3, Smith, D.C. and Williams, D.F. eds, CRC Press, Boca Raton, FL pp. 97130,1982 .

[9] Lutz, F. and Phillips, R.W. A classification and evaluation of composite resin system. J. Prosth. Dent. $50: 480-488,1983$.

[10] Cook, W.D., Beech, D.R., and Tyas, M.J. Structure and properties of methacrylate based restorative materials. Biomaterials $6: 362-368,1985$.

[11] Draughn, R.A., Bowen, R.L. and Moffa, J.P. Composite restorative materials. In: Restorative Dental Materials An Overview, Vol. 1, J.A. Reese and T. Valega, eds., Londone: Quintessence Publishing Co. Ltd., pp. 75-107, 1985 .

[12] Antonucci, J.M. Resin Based Dental Composites-An overview. In: Polymers in Medicine II, Chiellini, E., Giusti, P., Migliaresi, C. and Nicolais, L. eds., New York: Plenum Publishing Corp., pp. 277-303, 1986.

[13] Draughn, R.A. Fatigue and fracture mechanics of composite resins. In: Posterior Composite Resin Dental Restorative Materials, VanHerle, G. and D.C. Smith, eds., Peter Szulc Publishing Co., The Netherlands, pp. 29-307, 1985.

[14] Mccabe, J.F. In vitro wear testing of composite resins ibid. pp. 319-330, 1985 .

[15] McKinney, J.E. Enivronmental damage and wear of dental composite restoratives. ibid pp. 331-347.

[16] Ruyter, I.E. Monomer systems and polymerization ibid pp. $109-135,1985$.

[17] Soderholm, K-J. Filler systems and resin interface ibid pp. 139-159, 1985 .

[18] Cook, W.P. Polymerization defects in composite resins ibid pp. 273-286, (1985). 
[19] Fan, P.L. Polymerization defects ibid pp. 287-298.

[20] Davidson, C.L. Conflicting interests with posterior use of composite materials. ibid pp. 61-65, 1985.

[21] Bowen, R.L., Menis, D.L., Setz, L.E., and Jennings, K.A. Theory of Polymer Composites ibid pp. 95-1051, 1985.

[22] Craig, R.G. Overview of posterior composite resins for use in clinical practice ibid pp. 199-211, 1985.

[23] Erickson, R.L. Closing remarks ibid pp. 555-557, 1985.

[24] Leinfelder, K.F. Current developments in posterior composite resins. In: Advances in Dental Research 2(1) International state-of-the-Art Conference on Restorative Dental Materials 1986, NIDR 15-121, 1988.

[25] Ruyter, I.E. Composites-characterization of composite filling materials: Reactor response, ibid, 122-129, 1988.

[26] Buonocore, M.G. A simple method of increasing the adhesion of acrylic filling materials to enamel surfaces. J. Dent. Res. 34:849-853, 1955.

[27] Buonocore, M.G., Wileman, W. and Brudevold, F. A report on a resin composition capable of bonding to human dentin surfaces. J. Dent. Res. 35:846-851, 1956.

[28] Bowen, R.L., Cobb, E.N. and Rapson, J.E. Adhesive bonding of various materials to hard tooth tissues: Improvement in bond strength to dentin. J. Dent. Res. 61:1070-1076, 1982 .

[29] Asmussen, E. and Munksgaard, E.C. Bonding of restorative resins to dentin promoted by aqueous mixtures of aldehydes and active monomers. Int. Dent. J. 35:160-165, 1985.

[30] Nakabayashi, N., Kojima, K., Masuhara, E. The promotion of adhesion by the infiltration of monomers into tooth substrates. J. Biomed. Mater. Res. 16:265-273, 1982 .

[31] Phillips, R.W. Bonding agents and adhesives. In: Advances in Dental Research 291 International State-ofthe-Art Conference on Restorative Dental Materials (1986, NIDR) 150-154, 1988 .

[32] Bowen, R.I. Bonding agents and adhesives; Reactor Response ibid 150-157, 1988.

[33] Fusayama, T. The problems preventing progress in adhesive restorative dentistry, ibid 158-161, 1988 . 
[34] Asmussen, E., DeAraujo, P.A., and Peutzfeld, A. In-vitro bonding of resins to enamel and dentin. An Update, Trans. Acad. Dent. Materials 2(2) pp. 36-63, 1989.

[35] Erickson, R.I. Adhesive dental materials, Trans.

International Congress of Dental Materials (Acad. of Dent. Materials and the Japanese Soc. for Dental Materials and Devices) Okabe, T. and Takahashi, S. eds. pp. 55-69, 1989.

[36] Nakabayashi, N. Adhesive Dental Materials, ibid pp. 70$79,1989$.

[37] Johnston, A.D., Asmussen, E., and Bowen, R.L. Substitutes for $\mathrm{N}$-phenylglycine in adhesive bonding to dentin. $\mathrm{J}$. Dent. Res. 68:1337-1344, 1989.

[38] Schumacher, G.E., Eichmiller, F.C., and Antonucci, J.M. Effects of surface-active resins on dentin/composite bonds. J. Dent. Res. 70 Abstr. 1044, 1991.

[39] Asmussen, E. Composite restorative resins. Composition versus wall-to-wall polymerization contraction, Acta. odont. Scand. 33:337-344, 1975.

[40] Dermann, K., Rupp, N.W., and Brauer, G.M. Effect of hydrophilic diluents on the properties of cured composites, J. Dent. Res. 61:1250-1254, 1982.

[41] Brauer, G.M., Dulik, D.M., Hughes, H.N., Dermann, K., and Rupp, N.W. Marginal adaptation of BIS-GMA-based composites containg various diluents, J. Dent. Res. $60: 1966-1971$, 1981 .

[42] Bowen, R.L., Rapson, J.E., and Dickson, G. Hardening shrinkage and hygroscopic expansion of composite resins. J. Dent. Res. 61, 654-658, 1982.

[43] Endo, T. and Bailey, W.J. Synthesis and radical ringopening polymerization of spiro o-carbonates, J. Polym. Sci.: Polym. Chem. Ed. 13:2525-2530, 1975.

[44] Thompson, V.P., williams, E.F., and Bailey, W.J. Dental resins with reduced shrinkage during hardening, J. Dent. Res. 58:1522-1532, 1979 .

[45] Stansbury, J.W. and Bailey, W.J. Synthesis of monomers that polymerize with expansion in volume. J. Dent. Res. 65:219, Abstr. No. 452, 1986.

[46] Bailey, W.J., No, K., Pan, C.-Y., Saigo, K., Stansbury, J., Tan, S.-R. and Zhou, J. Recent advances in ionic 
polymerization with expansion in volume. Polym. Prepr. (Am. Chem. Soc., Div. Polym. Chem.) 26:50-51, 1985.

[47] Bailey, W.J., Amone, M.J. and Issari, B. Recent advances in matrices that expand during polymerization. Am. Chem. Soc. Div. Polym. Mater. Sci. Eng. 59:825-829, 1988 .

[48] Stansbury, J.W. and Bailey, W.J. Evaluation of spiro orthocarbonate monomers capable of polymerization with expansion as ingredients in dental composite materials. In: Progress in Biomedical Polymers, C.G. Gebelein and R.I. Dunn, eds., Plenum Pub. Corp., New York, pp. 133-139, 1990.

[49] Bausch, J.R., De Lange, K., Davidson, C.L., Peters, A., and De Gee A.J. Clinical significance of polymerization shrinkage of composite resins. J. Prosthet. Dent. 48, 5967,1982 .

[50] Bowen, R.L., Nemoto, K., and Rapson, J.E. Adhesive bonding of various materials to hard tooth tissues; forces developing in composite materials during hardening. J. Am. Dent. Assoc. 106, 475-477, 1983.

[51] Kidd, E.A.M. Polymerization shrinkage and microleakage. In: Posterior Composite Resin Dental Restorative Materials, G. VanHerle and D.C. Smith, eds., Peter szulc Pub. Co., The Netherlands pp. 263-268, 1985.

[52] Gross, J.D., Retief, D.H. and Bradley, E.L. Microleakage of posterior composite restorations. Dent. Mater. 1:7-10, 1985.

[53] Patel, M.P., Braden, M., and Davy, K.W.M. Polymerization shrinkage of methacrylate esters, Biomaterials 8:53-56, 1987.

[54] Rees, J.S. and Jacobsen, P.H. The polymerization shrinkage of composite resins, Dent. Mater. 5:41-44, 1989.

[55] Feilzer, A.J., DeGee, A.J., and Davidson, C.L. Setting stress in composite resin in relation to configuration of the restoration, J. Dent. Res. 66:1636-1639, 1987.

[56] Feilzer, A.J., DeGee, A.J. and Davidson, C.L. Increased wall-to-wall curing contraction in thin bonded resin layers. J. Dent. Res. 68:48-50, 1989 .

[57] Antonucci, J.M., Stansbury, J.W., and Dudderar, D.J. Dental resin and initiator systems based on polythiols. J. Dent. Res. 61270 , Abst. 824, 1982 . 
[58] Venz, S. and Antonucci, J.M. Effect of a polythiol on the degree of polymerization of resins. J. Dent. Res. 63 199, Abst. 257, 1984 .

[59] Antonucci, J.M. Dental Composite Formulation from acrylate monomer and monomer polythiol accelerator. U.S. Patent 4,536,523, 1985 .

[60] Asmussen, E. Restorative resins: hardness and strength vs. quantity of remaining double bonds, Scand. J. Dent. Res. 90:484-489, 1982 .

[61] Ferracane, J.L. and Greener, E.H. The effect of resin formulation on the degree of conversion and mechanical properties of dental restorative resins, J. Biomed. Mater. Res. 20:121-131, 1986.

[62] McKinney, J.E. and Wu, W.L. Effect of degree of cure on hardness and wear of three commercial dental composites, J. Dent. Res. 62:285, Abstr. No. 1047, 1983.

[63] Asmussen, E. Factors affecting the color stability of restorative resins, Acta. Odont. Scand. 41:11-18, 1983.

[64] De Rijk, W.G., Conner, M.L., Jennings, K.A., and Wu, W. The in vivo wear resistance of dental composites with enhanced polymerization. J. Dent. Res. 63:286 Abst 951, 1983 .

[65] Antonucci, J.M., Stansbury, J.W. and Venz, S. Synthesis and properties of a polyfluorinated prepolymer multifunctional urethane methacrylate. Poly. Mater. Sci. Eng., Proceeding of the ACS Division of Polymeric Materials Vol. 59, pp. 388-396, 1988.

[66] Antonucci, J.M., Venz, S., Stansbury, J.W. and Dudderar, D.J. Low surface energy dental composites from a polyfluorinated prepolymer multifunctional methacrylate. Proceedings of the 1st Medical Plastic Conference of the Society of the Plastic Industry, Inc. New Brunswick, NJ, 1983 .

[67] Ferracane, J.L. In vitro evaluation of composite resins. Trans. Acad. Dent. Materials 2(2) 6-35, 1989.

[68] Cross, M., Douglas, W.H. and Fields, R.P. The relationship between filler loading and particle size distribution in composite resin technology. J. Dent. Res. $62,850,1983$.

[69] Nemcek, J., Roberts, T.A., and sherliker, F.R. U.S. Patent $4,374,937$. 
[70] Donly, K.J., Wild, T.W., Bowen, R.L. and Jensen, M.E. An in vitro investigation of the effects of glass inserts on the effective composite resin polymerization shrinkage. J. Dent. Res. 68, 1234-1237, 1989 .

[71] Wilson, A.D. Dental cements - general. In: Scientific Aspects of Dental Materials von Fraunhofer, J.A. and Bradlaw, R. eds., Boston Buttersworth pp. 131-158, 1975.

[72] Wilson, A.D. The chemistry of dental cements. Chem. Soc. Rev. 7265, 1978 .

[73] Smith D.C., Norman, R.D. and Swartz, M.L. Dental cements: Current status and future prospects. In: Restorative Dental Materials An Overview Vol. 1 Reese, J.A. and Valega, T.M. eds., Quintessence Publ. Co., pp. 33-74, 1985 .

[74] Smith, D.C. Dental cements In: Advances in Dental Research 2(1) International state-of-the-Art Conference on Restorative Dental Materials (1986, NIDR) pp. 134-141, 1988 .

[75] Swartz, M.L. Dental cements: Reactor response, ibid pp. $142-146,1988$.

[76] Smith, D.C. In-vitro performance of glass ionomer cements. Trans. Acad. Dent. Materials 2(2), pp. 106-125, 1989.

[77] Antonucci, J.M., McKinney, J.E. and Stansbury, J.W. Formulation and evaluation of resin-modified glass ionomer cements. Trans. 13th Ann. Meeting Soc. Biomater. p. 225, 1987 .

[78] Antonucci, J.M. and Stansbury, J.W. Polymer-modified glass ionomer cements. J. Dent. Res. 68:251 Abstr. 555, 1989.

[79] Rusz, J., Antonucci, J.M., Eichmiller, F. and Anderson, M. Adhesive properties of polymer-and resin-modified glass ionomer cements. J. Dent. Res. 69:366 Abstr. 2058, 1990 .

[80] Brown, W.E. and Chow, L.C. A new calcium phosphate, water-setting cement. In: Cements Research Progress 1986, ed. Brown, P.W., Waterville, OH, American Ceramic Society, pp. 352-379, 1986.

[81] Sugawara, A., Antonucci, J.M., Takagi, S., Chow, L.C. and ohashi, M. Formation of hydroxyapatite in hydrogels from tetracalcium phosphate/dicalcium phosphate mixtures. J. Nihon Univ. 31:372-381, 1989. 
[82] Miyazaki, K., Takagi, S., Chow, L.C. and Antonucci, J.M. Polymeric calcium phosphate cements. J. Dent. Res. 69:367 Abstr. 2068, 1990.

[83] Prosser, H.J., Brant, P.J., Scott, R.P., and Wilson, A.D. The cement-forming properties of phytic acid. J. Dent. Res. 62:598-600, 1983 .

[84] Mathias, L.J. and Kusfoglu, S.H. A new nonhydrolyzable ether crosslinking agent containing two methacrylate units linked through the $\alpha$-methyl carbons. J. Polym. Sci., Polym. Lett. Ed. 25:451-453, 1987.

[85] Mathias, L.J., Kusefoglu, S.H. and Ingram, J.E. Cyclopolymerization of the ether of methyl $\alpha-$

(hydroxymethyl) acrylate, Macromolecules 21:545-546, 1988.

[86] Stansbury, J.W. Difunctional and multifunctional monomers capable of cyclopolymerization, Macromolecules 24:20292035, 1991 .

[87] Stansbury, J.W. Evaluation of a new multifunctional oligomer for dental composites. J. Dent. Res. 69:208, Abstr. No. $794,1990$.

[88] Stansbury, J.W. Cyclopolymerizable monomers for use in dental resin composites. J. Dent. Res. 69:844-848, 1990.

[89] Antonucci, J.M., Stansbury, J.W. and Cheng, G.W. A facile synthesis of novel fluorinated multifunctional acrylates. Polymer Preprints 31(1) 320-321, 1990.

[90] Mathias, L.J., Kusefoglu, S.H. and Kress, A.O. Functional methacrylate monomers. Simple synthesis of alkyl $\alpha^{-}$ (hydroxymethyl)acrylates. Macromolecules 20:2326-2328, 1987.

[91] Kress, A.O., Mathias, L.J. and Cei, G. Copolymers of styrene and methyl $\alpha$-(hydroxymethyl)acrylate: Reactivity ratios, physical behavior, and spectral properties. Macromolecules 22:537-546, 1989.

[92] Raney, M.W., Berger, S.E. and Marsden, J.G. Silane coupling agents in particulate mineral filled composites. Interfaces in polymer matrix composites In: Composite Materials 6, Plueddemann, E.P., ed. Academic Press, New York, N.Y., 1974 .

[93] Antonucci, J.M., Stansbury, J.W., and Venz, S. Synthesis of silyl ether derivatives of BIS-GMA. J. Dent. Res. $65: 219$, Abst. No. 451, 1986. 
[94] Venz, S. and Antonucci, J.M. Silanization and modification of fillers for dental composites. J. Dent. Res. 65 Abst. No. 191, 1986.

[95] Penn, R.W., Craig, R.G., Tesk, J.A. Diametral tensile strength and dental composites. J. Dent. Materials, 3: $46-48,1987$.

[96] Zidan, O., Asmussen, E., Jorgensen, K.D. Tensile strength of restorative resins. Scand. J. Dent. Res. 88:285-289, 1980 .

[97] Hannah, C.M., Combe, E.C. Mechanical properties of composite restorative materials. Br. Dent. J. 140:167-173, 1976 .

[98] Lautenschlager, E.P. and Harcourt, J.K. Photoelastic observations in diametral compression testing. J. Dent. Res. 49:175, 1970 .

[99] Hetzer, H., Dhurv, V., Brantley, W., and Prey, J. Tensile strength of composite restorative material as determined by two methods. J. Dent. Res. 67 Abstr. 1182, 1988.

[100] Spencer, H.G. A note on the dissociation constants of polycarboxylic acids. J. Poly. Sci. 56:S25-S28, 1962.

[101] GAF Technical Bulletin: Gantrez An copolymer, poly(methylvinylether/maleic anhydride, GAF Corporation, 1983.

[102] Guilbault, G.G Practical Fluorescence. Marcel Dekker, New York, 1973.

[103] Itagaki, H. et al. Iuminescent probe studies of the microstructure and mobility of solid polymers. Prog. Polym. Sci. 15:361-424, 1990 .

[104] Horawetz, H. Fluorescent Phenomena Useful for the Study of Polymers. In: Photophysical and Photochemical Tools in Polymer Science, M. A. Winnick (ed.) D. Reidel Publishing Co. 1986.

[105] Farid, S. Selected aspects of photochemistry in polymer media. Pure and Appl. Chem. 51:241-259, 1979.

[106] Loutfy, R.O. Fluorescent probes for polymer free volume. Pure and Appl. Chem. 58:1239-1248, 1986.

[107] Fanconi, B.M. Optical and spectroscopic techniques in process monitoring sensors for polymer composites. NISTIR 4514,1991 . 
[108] Wang, F.W., Lowry, R.E., Fanconi, B.M. Novel fluorescence method for cure monitoring of epoxy resins. Polymer $27: 1529-1532$, 1986 .

[109] Ledwith, A. Polymer chain effects on ground state and excited state charge transfer processes. Makromol. Chem., Supp. 5:42-57, 1981 .

[110] Loutfy, R.O. Fluorescence probes for polymerization reactions. J. Polym. Sci. 20:825-835, 1982 .

[111] Loutfy, R.O. and Arnold, B.A. Effect of viscosity and temperature on torsional relaxation of molecular rotors. J. Phys. Chem. 86:4205-4211, 1982 .

[112] Hayashi, R., Tazuke, S., Frank, C. Twisted intramolecular charge-transfer phenomena as a fluorescence probe of microenvironment. Macromolecules 20:983-988, 1987.

[113] Safarzadeh-Amir, A. Effect of solvent polarity and viscosity on the decay dynamics on an intramolecular charge transfer complex. Chem. Phys. 125:145-154, 1988.

[114] Grambowski, Z.R., et al. Acta. Phys. Pol., A54: 767, 1978. 
PART II. Wear Resistance and Durability Assessment of Dental Composite Restoratives and Related Materials

\section{Overview}

The general objective of conducting wear studies is to evaluate the durability of dental composite restoratives and related materials as an aid in the development of new resin formulations and model composite systems. For this work two classical pin and disc wear apparatuses can be employed: (1) a first generation unit, (NIST-1), which bathes specimens with flowing water and; (2) a second generation unit, (NIST-2), for which the bathing medium can be chosen from a variety of food simulating liquids (including water) with the capability for providing constant exposure of the specimen. A complete description of the mechanical aspects of the (NIST-1) wear machine has been previously described. [1] A description of the variables thought to be important in wear tribology, including the effects of pre-conditioning in solvents and acidic conditions, has been summarized in previous reports. $[2,3,4]$ This project consists of the following phase:

Phase V This phase has one component:

(A) Round-Robin Wear and Chemical Degradation study of Posterior Composites

Phases I, II, III, IV, and VI which had been part of the three year proposal have been incorporated into part 1 of the proposal. They are no longer distinct projects but those activities on wear are conducted solely as needed in support of the work in Part 1.

(A) Round-Robin Wear and Chemical Degradation study of Posterior composites.

\section{Background}

The majority of our efforts in this reporting period continued to involve participation in an ADA sponsored "round robin" wear and chemical degradation study designed to evaluate the wear of several commercial posterior composites on different types of wear machines at participating laboratories. Other mechanical tests that were performed were flexural strength, flexural modulus, polymerization shrinkage and solubility in water and in a $75 \%$ solution of ethanol in water. Participation in this study had three primary objectives: 1) to provide researchers with an expanded data base which may be useful in the design and evaluation of future wear and 
degradation studies, and 2) to help NIST researchers understand how NIST wear and other related results compare with those from other laboratories, and (3) to attempt to correlate our pin-on-disk wear results with other mechanical properties.

\section{PROGRESS REPORT}

The four commercial materials used in this study were FulFil, Herculite XR, Heliomolar RO, and Silux Plus. The first three materials are accepted for posterior applications. In addition an unsilanized material with a Ful-Fil type formulation was supplied by the manufacturer as a negative control. A machinable glass-ceramic material, Macor (Corning Glass) was also tested for use as a possible low-wear control material. The materials used with their compositions from McLundie (1985) are given below.

Table 1: Composition of Commercial Composite Materials

\begin{tabular}{|c|c|c|c|c|c|c|}
\hline Material & Company & $\begin{array}{l}\text { Batch \# } \\
\text { Shade }\end{array}$ & Resin & $\begin{array}{l}\text { Classification } \\
\text { Filler Type }\end{array}$ & $\begin{array}{l}\text { Filler } \\
\text { size weigh }\end{array}$ & \\
\hline Ful-Fil & $\begin{array}{l}\text { Caulk/ } \\
\text { Dentsply }\end{array}$ & $\begin{array}{l}070390 \\
U-B-62\end{array}$ & $\begin{array}{l}\text { Bis-GMA"/ } \\
\text { TEGDMA }\end{array}$ & $\begin{array}{l}\text { Fine-particle hybrid } \\
\text { Barium glass } \\
+ \text { colloidal silica }\end{array}$ & $\stackrel{\mu \mathrm{m}}{2.0-5.0}$ & $\begin{array}{l}8 \\
77\end{array}$ \\
\hline $\begin{array}{l}\text { Herculite } \\
\mathrm{XR}\end{array}$ & Kerr & $\begin{array}{l}02338 \\
U-66\end{array}$ & Bis-GMA & $\begin{array}{l}\text { Submicron hybrid } \\
\text { Barium glass } \\
+ \text { Pyrogenic silica }\end{array}$ & $0.5-0.8$ & 79 \\
\hline $\begin{array}{c}\text { Heliomolar } \\
\text { RO }\end{array}$ & Vivadent & $\begin{array}{l}260425 \\
G-36\end{array}$ & $\begin{array}{l}\text { UDMA + } \\
\text { Bis-GMA }\end{array}$ & $\begin{array}{l}\text { Microfilled with } \\
\text { prepolymerized partic } \\
\text { colloidal silica }\end{array}$ & $\operatorname{les}^{0.04}$ & 68 \\
\hline Silux Plus & $3 M$ & $\begin{array}{l}\text { OBM1 } \\
5703 \text { UO }\end{array}$ & $\begin{array}{l}\text { Bis-GMA/ } \\
\text { TEGDMA }\end{array}$ & $\begin{array}{l}\text { Microfilled with } \\
\text { prepolymerized partic } \\
\text { colloidal silica }\end{array}$ & $\operatorname{les}^{0.04}$ & 52 \\
\hline $\begin{array}{l}\text { unsilanized } \\
\text { control }\end{array}$ & $3 M$ & $\begin{array}{l}26990 \\
\text { none }\end{array}$ & $\begin{array}{l}\text { Bis-GMA / } \\
\text { TEGDMA }\end{array}$ & $\begin{array}{l}\text { Unsilanized filler } \\
\text { Barium glass }\end{array}$ & $2-5$ & 77 \\
\hline
\end{tabular}

The major portion of the results from our efforts in the ADA sponsored "round-robin" study of wear and other 
properties of posterior composites were given in the last reporting period.

In this reporting period we devoted our efforts to establishing a correlation, if any, between our pin-ondisk wear data and varous mechanical properties of the composites.

The results of the wear tests for 9,600 and 40,000 revolutions are given in Table II. Note that the test times for the Macor samples are one-tenth as long as for the composite samples. In this high contact wear test (10 MPa) it is clear that the Macor cannot be considered as a positive control, i.e., a low wear material. The catastrophic wear observed in this test indicates that Macor wears at least 100 times as fast as the commercial composite materials, furthermore, caused extensive wear on the stainless steel pin. The unsilanized composite with the Ful-Fil type formulation exhibited the next highest wear with a average loss of $152 \mu \mathrm{m}$ after 40,000 revolutions.

Bartlett's M test was used to compare the magnitudes of the standard deviations and this test showed that the unsilanized material had a significantly higher standard deviation than the other materials, indicating that it comes from a different population distribution, as might be expected due to the large number of air voids that were present in the experimental material which was supplied for the tests. Comparing the wear values after 40,000 revolutions of the commercial composites only, the ranking is given below in the order of increasing wear.

$$
\text { Ful-Fil < Heliomolar RO < Herculite XR = Silux Plus }
$$

Materials with statistically similar wear values in Table II are connected by brackets $(P<0.05)$.

The opposing wear values of the stainless steel pin after completion of the wear tests $(40,000$ revolutions) are also given in Table II. Pin wear after the Macor tests was difficult to measure due to pin damage but was greater than $1 \mathrm{~mm}$ after 4000 revolutions. Ful-Fil and the unsilanized control material had the greatest pin wear $(380 \& 340 \mu \mathrm{m})$, followed by Herculite $(180 \mu \mathrm{m})$. The microfilled materials Heliomolar and silux, showed the least pin wear $(105 \& 100 \mu \mathrm{m})$. 


\begin{tabular}{|c|c|c|c|}
\hline Wear Test Material & $\begin{array}{l}\text { Initial Mean } \\
\text { Wear }(\mu \mathrm{m})\end{array}$ & $\begin{array}{l}\text { Final Mean } \\
\text { Wear }(\mu \mathrm{m})\end{array}$ & $\begin{array}{c}\text { Final Pin } \\
\text { Wear }(\mu \mathrm{m})\end{array}$ \\
\hline Unsilanized & $56.6(25.1)$ & 152 (47) & $340 \quad(60)$ \\
\hline Silux Plus & $16.0 \quad(2.4)$ & $67.9 \quad(10.3)$ & $105(25)$ \\
\hline Herculite XR & $15.7 \quad(5.9)$ & $60.5(10.7)$ & $180(30)$ \\
\hline Heliomolar RO & $10.6(2.5)$ & $45.1(4.1)$ & $105(25)$ \\
\hline Ful-Fil & $8.9(2.8)$ & $24.5 \quad(7.5)$ & $380 \quad(50)$ \\
\hline Macor & 174 (165) & $888 \quad(335)$ & $1 \mathrm{~mm}$ \\
\hline
\end{tabular}

* Initial and final measurements at 9,600 and 40,000 revolutions

** Measurements for Macor are at $1 / 10$ the time (ie 960 and 4000 revs)

Flexural strength, modulus, stored energy at fracture, and Knoop hardness for the materials are given in Table III, with values that are statistically the same connected by brackets. The ranking of the flexural strengths for the samples stored for 24 hours in distilled water at $37^{\circ} \mathrm{C}$ using the Newman-Keuls multiple comparison test was:

Herculite $=$ Ful-Fil $>$ Heliomolar > Silux > Unsilanized control

TABLE III MECHANICAL PROPERTIES OF COMPOSITE MATERIALS I

\begin{tabular}{||c|c|c|c|c||}
\hline \hline MATERIAL & $\begin{array}{c}\text { Flexural } \\
\text { Strength } \\
\sigma(\mathrm{MPa})\end{array}$ & $\begin{array}{c}\text { Flexural } \\
\text { Modulus } \\
\text { E (GPa) }\end{array}$ & $\begin{array}{c}\text { Flexural } \\
\text { Fracture } \\
\text { Energy (N*mm) }\end{array}$ & $\begin{array}{c}\text { Knoop } \\
\text { Hardness }\end{array}$ \\
\hline Unsilanized & $31.4(3.0)$ & $6.6(0.2)$ & $0.9(0.2)$ & $52.1(2.6)$ \\
\hline SILUX & $61.7(2.3)$ & $6.6(0.2)$ & $3.5(0.5)$ & $50.8(2.3)$ \\
\hline HELIOMOLAR & $90.2(3.6)$ & $6.6(0.2)$ & $\theta .9(0.2)$ & $54.3(1.5)$ \\
\hline HERCULITE & $130(20.1)$ & $12.0(0.4)$ & $11.2(2.8)$ & $73.3(1.6)$ \\
\hline FUL-FIL & $132(9.9)$ & $10.3(0.4)$ & $13.9(2.2)$ & $71.4(4.5)$ \\
\hline Macor & 65 & 30 & 0.6 & $95(8.0)$ \\
\hline
\end{tabular}

The correlation between the average wear rate and average flexural strength is shown in Figure 1 (note that the wear rate for Ful-Fil and the unsilanized composite show a decreasing trend with time). A linear regression fit showed a $r^{2}$ value of 0.56 and this relationship predicts negative wear values for high strengths. A more sensible relationship between the wear rate and flexural strength would be a hyperbolic function (i.e., the wear rate is proportional to the reciprocal of 
strength), as shown in the solid line in Figure 1. When linear regression analysis is performed on the data with the strength variable transformed to a reciprocal, the $r^{2}$ values is 0.86 . However, a pair-wise comparison of Ful-Fil and Herculite as seen in Figure 1 suggests that the wear rate is independent of flexural strength and a similar comparison of Herculite and silux indicates that flexural strength is not a very sensitive predictor of in vivo pin-on-disk wear.

Values for the compressive strength, modulus, and yield stress are given in Table IV. Fracture toughness values, $K_{I C}$, in Table IV were obtained from Mueller, (1991 ADA communication, ASC MD156 Task Group on Posterior Composites), and were determined by the short-rod, plane strain fracture toughness method described by Mueller (1990). Fracture toughness is a measure of the energy the material is capable of absorbing prior to fracture; the ranking of the fracture toughness according to Mueller was as follows:

Ful-Fil > Herculite $=$ silux > Heliomolar > unsilanized control

TABLE IV

\begin{tabular}{||c|c|c|c|c|}
\hline MATERIAL & $\begin{array}{c}\text { Compressive } \\
\text { Strength } \\
\sigma(\mathrm{MPa})\end{array}$ & $\begin{array}{c}\text { Compressive } \\
\text { Modulus } \\
\text { E (GPa) }\end{array}$ & $\begin{array}{c}\text { Compressive } \\
\text { Yield stress } \\
\sigma_{\mathrm{y}}(\mathrm{MPa})\end{array}$ & $\begin{array}{c}\text { Fracture } \\
\text { Toughness } \\
\mathrm{K}_{\mathrm{IC}}\end{array}$ \\
\hline unsilanized & $250(10)$ & $6.0(0.3)$ & 1.20 & $0.61(0.05)$ \\
\hline Silux & $290(15)$ & $6.5(0.3)$ & 1.44 & $1.10(0.06)$ \\
\hline Heliomolar & $340(20)$ & $6.3(0.3)$ & 2.27 & $0.87(0.07)$ \\
\hline Herculite & $380(20)$ & $11.5(0.6)$ & 1.47 & $1.14(0.02)$ \\
\hline Ful-Fil & $370(15)$ & $9.7(0.5)$ & 1.61 & $1.61(0.15)$ \\
\hline
\end{tabular}

The compressive resilience, $R_{\sigma, y}$ is a measure of the stored energy in a sample before permanent deformation and is calculated by the expression (Solderholm, 1985):

$$
R_{\sigma, y}=\sigma_{y}^{2} / 2 E
$$

where $\sigma_{y}$ is the compressive yield stress and $E$ is the compressive Young's modulus. Determination of the yield stress is difficult for composite resins due to the time and history dependence of the compressive creep at constant load (Bapna et al., 1985) and stress regeneration when the load is removed (especially for microfilled materials); therefore, a more useful indicator of the compressive $y i e l d$ stress was defined as $R_{\sigma, 1 / 2}$ where the resilience is now defined by one-half of the compressive fracture stress, $\sigma_{1 / 2}$, instead of the yield stress. Another measurement, which is similar to the compressive 
resilience, is stored compressive energy per unit volume at fracture, $E_{f}$, and is defined as the total integrated area under the stress-strain curve. Values for the three different measurements of stored energy are given in Table $\mathrm{V}$.

TABLE V

Measurements of Stored Compressive Energy

\begin{tabular}{|c|c|c|c||}
\hline MATERIAL & $\begin{array}{c}\text { Compressive } \\
\text { Resilience I } \\
\mathrm{R}_{\sigma, y}(\mathrm{MPa})\end{array}$ & $\begin{array}{c}\text { Compressive } \\
\text { Resilience II } \\
\mathrm{R}_{\sigma, 1 / 2}(\mathrm{MPa})\end{array}$ & $\begin{array}{c}\text { Compressive } \\
\text { Energy at Fracture } \\
\mathrm{E}_{(} \text {(MPa) }\end{array}$ \\
\hline unsilanized & $1.50(.15)$ & $1.12(.1)$ & $13(1)$ \\
\hline Silux & $1.62(.15)$ & $1.51(.15)$ & $16(1.5)$ \\
\hline Heliomolar & $1.90(.2)$ & $2.29(.2)$ & $23(2.5)$ \\
\hline Herculite & $1.41(.15)$ & $1.49(.15)$ & $17(1.5)$ \\
\hline Ful-Fil & $1.57(.15)$ & $1.67(.15)$ & $16(1.5)$ \\
\hline \hline $\begin{array}{c}\text { Correlation } \\
\text { Coefficient: } \mathrm{r}^{2}\end{array}$ & .86 & .98 & .96 \\
\hline
\end{tabular}

The ranking of the compressive energy at fracture was as follows:

Heliomolar > Silux $=$ Herculite $=$ Ful-Fil > unsilanized control

Abrasive wear theories (Routbort and Matzke, 1983; Evans, 1979; Rabinowitz, 1965) generally propose that the wear (volume of material removed from the surface) is proportional to time or distance traveled and inversely proportional to the mechanical properties affecting wear raised to some empirically determined power. The mechanical properties usually employed are flexural or tensile fracture stress, surface hardness, Young's modulus, and fracture toughness. However, since the principal stresses in the pin-on-disk configuration are primarily compressive and surface shear stresses, this would indicate that compressive resilience or compressive energy at fracture may be an important parameter, especially for polymer composites which exhibit considerably more plasticity than brittle ceramic materials and which demonstrate shear failure in compressive tests. Therefore, a relationship between the wear volume (or depth) and the product of the fracture toughness with various measures of the stored compressive energy (each raised to a power) was investigated. Table $\mathrm{V}$ shows the correlation coefficients obtained using an expression of the form:

Wear $\propto$ revolutions/( $\mathrm{K}_{\mathrm{IC}}$ stored compressive energy $)^{1.5}$ 
This relationship using $R_{\sigma, 1 / 2}$ as the measure of the stored compressive energy is shown in Figure 2 (the wear of unsilanized material at 40,000 revolutions was not included in the linear regression here due to the wear rate dependance with time which cannot be accounted for with such a two parameter model). The correlation coefficient was $r^{2}=.98$ and did produce a proper ranking for the in vitro pin-on-disk wear test. Inclusion of additional mechanical terms in the above wear equation did not increase the correlation coefficient. Routbort and Matzke (1983) have reported a similar expression for the wear of silicon carbide using hardness and fracture toughness. Their findings indicated that the power exponent for hardness could be either positive or negative and that the exponent for fracture toughness was between -1.3 and -1.9 , which is in good agreement with the findings here of -1.5 .

The results from the opposing wear of the stainless steel pin are in good agreement with existing wear theories, i.e., that larger harder fillers are expected to abrade the counterface more severely. Thus, Ful-Fil and the unsilanized control had the highest abrasion, followed by Herculite and the two microfilled materials. Furthermore, the extent of surface staining from the wear debris from the stainless steel pin (qualitative visual observation) is positively related to the amount of pin loss (and likewise filler size). The worn surface of Ful-Fil had extensive imbedding of metallic wear debris, Herculite was intermediate and the two microfilled materials had no visible debris imbedded in the surface and appeared to be polished by the pin. The lack of linearity of the wear depth with time for the unsilanized control (and to a lesser extent Ful-Fil) is probably due to the protective effects of the metal wear debris transferred to the surface from the wear pin, thus causing a decrease in the wear rate as seen in Figure 1.

The mechanical tests investigated indicated that flexural strength does not correlate with the other mechanical tests (i.e., the material rankings changed for most of the tests). Thus, Ful-Fil and Herculite had high flexural strengths but Herculite had a relatively low fracture toughness. Likewise, Heliomolar had the greatest compressive energy at fracture, moderate flexural strength, and low fracture toughness. The unsilanized material was the poorest material in all tests except the knoop hardness test which ranked it with the microfilled materials (Knoop hardness appears to be closely related to the Young's modulus). The flexural strength and flexural energy at fracture, in particular, appear to be the most sensitive indicators of the lack of silanization. The pin-on-disk wear results can be predicted with relationship of the product of the stored compressive energy times the fracture toughness raised to the minus 1.5 power. It must be noted, 
that although rankings of properties indicating wear behavior are given here, that no implications of the superior or inferior capabilities of any of the materials in clinical applications can or should be drawn frhom these results. The correlations between clinical wear and pin-on-disk wear studies have not been established. The objective was to seek a correlation between wear and mechanical properties for the pinon-disk in vitro experiments conducted and in that sense the investigation was successful.

During this reporting period an abstract and manuscript entitled "In vitro Pin-on-Disk Wear Testing of Dental Composites" was prepared for the 1992 AADR meeting. A slightly modified version of that paper is being prepared for submission to Dental Materials. A summary of the major findings reported on in the preceding is given below.

\section{SUMMARY}

The objective of this study was to measure the in vitro wear of several commercial dental composites using a three station pinon-disk wear machine and compare the results with their flexural strengths and other mechanical properties. The composites used were Ful-Fil, Herculite XR, Heliomolar RO, Silux Plus, and an unsilanized material with a Ful-Fil type formulation. The composite disks were well-cured and stored in water for two weeks before testing. The wear pin was a $2 \mathrm{~mm}$ diameter stainless steel rod with an average applied contact stress of $10 \mathrm{MPa}$. The wear results were made by measuring the depth of the wear track with an LVDT after 40,000 revolutions. The wear results were analyzed using Bartlett's test of homogeneity of variances which showed that the unsilanized material had a statistically higher standard deviation than the other materials $(p<0.05)$. A modified t-test showed that it also had significantly higher wear than the commercial materials. The means of the wear of the commercial materials were analyzed using a Newman-Keuls Multiple Comparison test $(p<0.05)$, which ranked the in vitro pin-on-disk wear results as follows:

Ful-Fil < Heliomolar RO < Herculite XR = Silux Plus.

No general correlation could be made between the pin-on-disk wear values and flexural strengths for all the materials. A good correlation $\left(r^{2}>.95\right)$ was found for in vitro wear by the following relationship: Wear depth $\propto$ revolutions/ ( $\mathrm{K}_{\mathrm{IC}}$ *stored compressive energy) ${ }^{1.5}$. It must be noted, that although rankings of properties indicating wear behavior are given here, that no implications of the superior or inferior capabilities of any of the materials in clinical applications can or should 
be drawn from these results. The correlations between clinical wear and pin-on-disk wear studies have not been established. 
[1] Bapna, M.S., Mueller, H.J., Knoeppel, R. Compressive creep of dental composites. J. Dent. Res. 64, 1179-1184, 1985.

[2] Mckinney, J.E. Apparatus for measuring wear of dental restorative materials. Wear $76,337-347,1982$.

[3] Mckinney, J.E., Wu, W. Relationship between subsurface damage and wear of dental restorative materials. J. Dent. Res. 61, 1083-1088, 1982 .

[4] Mckinney, J.E. Wu, W. Chemical softening and wear of dental composites. J. Dent. Res. 64, 1326-1331, 1985.

[5] Mclundie, A.C., Patterson, C.J.W., Stirrups, D.R. Comparison of the abrasive wear in vitro of a number of visible-light cured composite resins. Br. Dent. J. 159, 182-185, 1985.

[6] Montes, M.G., Draughn, R.A. In vitro surface degradation of composites by water and thermal cycling. Dent. Mater. 2, 193$197,1986$.

[7] Mueller, H.J. ADA communication from round-robin testing meeting (ASC MD156 Task Group on Posterior Composites, Chicago Feb. 14, 1991).

[8] Mueller, H.J. Fracture toughness and fractography of dental cements, lining, build-up, and filling materials. Scanning Microscopy 4, 297-307 1990 .

[9] Powers, J.M., Fan, P.L. Erosion of composite resins. J. Dent. Res. 59, 815-819, 1980 .

[10] Rabonowicz, E. Friction and wear of materials, New York: John wiley \& Sons, Inc., 1965.

[11] Routbort, J.L., Matzke, H. On the correlation between solidparticle erosion and fracture parameters in SiC. J. Mater. Sci. 18, 1491-1496, 1983.

[12] Sarrett, D.C., Söderholm, K.M., Batich, C.D. Water and abrasive effects on three-body wear of composites. J. Dent. Res. 70, 1074-1081, 1990.

[13] Söderholm, K.M., Zigan, M. , Ragan, M., Fischlschweiger, W., Bergman, M. Hydrolytic degradation of dental composites. J. Dent. Res. 63, 1248-1254, 1984.

[14] Sulong, M.Z.A.M., Aziz, R.A.A. Wear of materials in dentistry: a review of the literature. J. Prosthet Dent. 63, 342-349, 1990 . 
[15] Wu, W. , McKinney, J.E. Influence of chemicals on wear of dental composites. J. Dent. Res. 61, 1083-1088, 1982.

[16] McKinney, J.E. Apparatus for measuring wear of dental composites. Wear 76, 337-347, 1982 .

[17] Tesk, J.A., Antonucci, J.M., Chiang, M.Y.M., de Rijk, W.E., Keeny, S.M., McKinney, J.E., Stansbury, J.W., Asaoka, K., Cheng, G.W., Matthews, T., Miyazaki, K., Tang, J. Properties and interactions of oral structures and restorative materials. NISTIR 4566.

[18] Wu, W. and McKinney, J.E. Influence of chemical on wear of dental composites. J. Dent. Res. 61, 1180-1183, 1982 .

[19] McKinney, J.E. and Wu, W. Chemical softening and wear of dental composites. J. Dent. Res. 64, 1326-1331, 1985.

[20] Keeny, S.M., Antonucci, J.M. In vitro pin-on-disk wear testing of dental composites. J. Dent. Res. 71, 280 Abst No. 1397, 1992. 


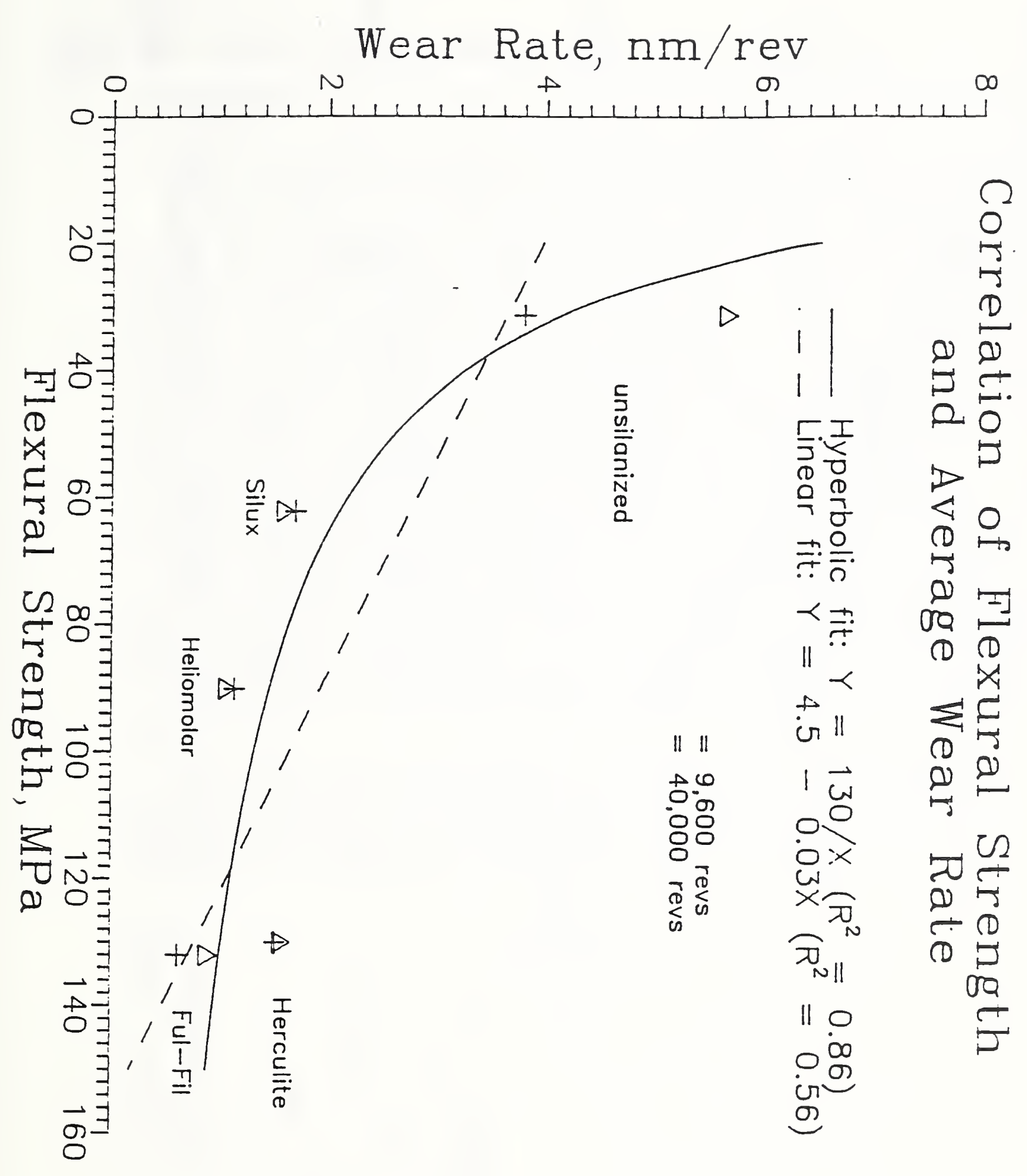




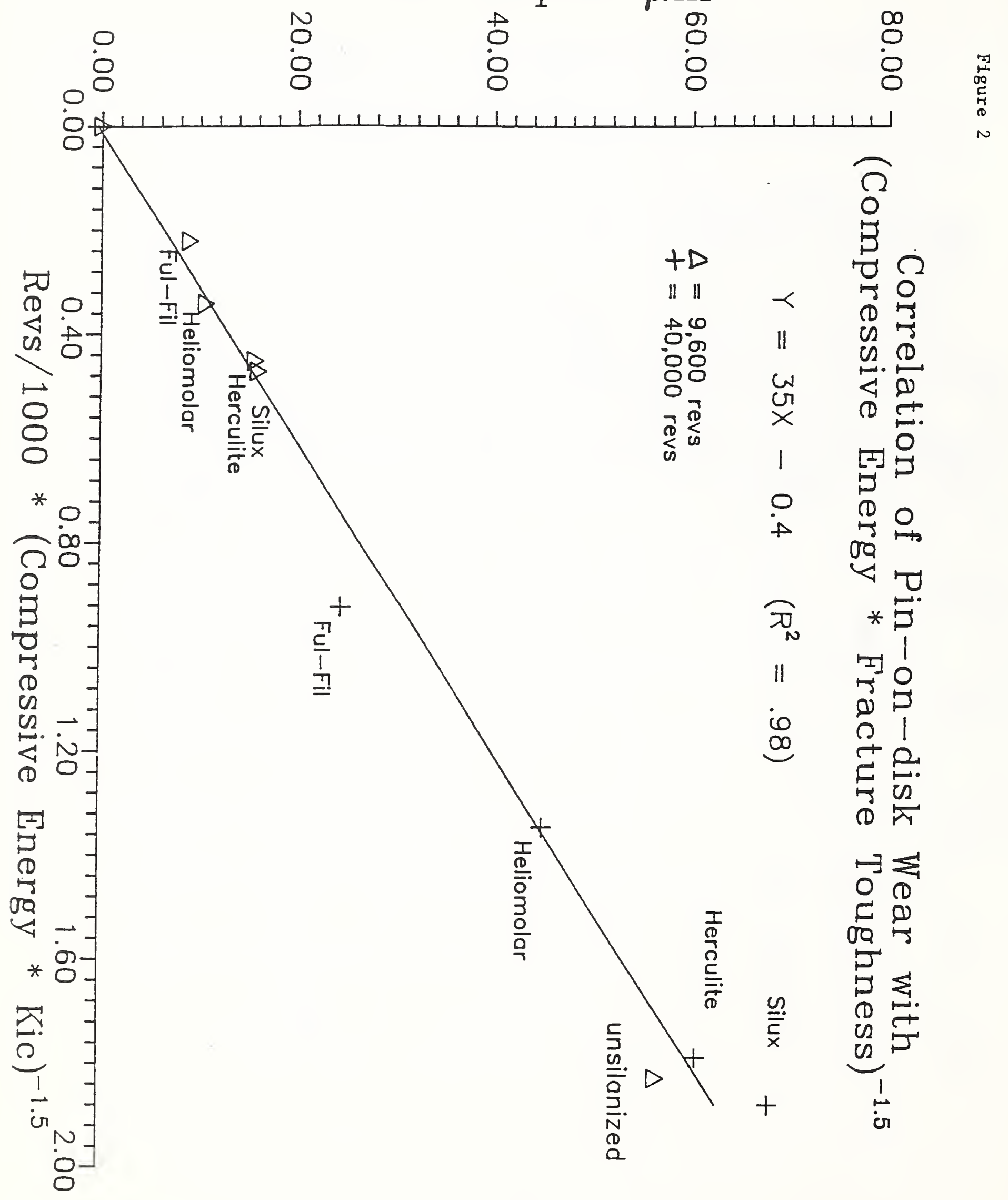


PART III. Dental Alloys, Ceramics, Metrology and Analyses

\section{overview}

Porcelain fused-to-metal (PFM) restorations constitute a major type of dental prosthesis. At the same time new materials for fabrication of non-metallic restorations have been introduced as have alloys of various kinds for cast metal restorations. The new materials can vary considerably in their fabrication characteristics and clinical performance. Although failure rates of PFM restorations are generally reported to be low, $1-2 \%$ in the first year [1] and $2-3 \%$ over 7 to 10 years $[1,2]$, the costs associated with each failure are high. Further, a recent study reported on by Anderson et al. [3] shows "unsatisfactory" veneer/metal integrity and porcelain crazing as high as ca $30 \%$ in some systems after eight years. More reliable methods than now exist are needed to evaluate properties and develop methods to aid in improvement of material systems with a view toward clinical performance. For porcelain fused-to-metal alloys the prime factors include thermal-stress compatibility, porcelain-metal system strength, alloy castability and the attendant capability of producing good fitting castings. Metrology plays an important role as the significance and relevance of materials properties needs to be more fully addressed in terms of relationships to clinical performance, reliability and predictability. Any measurement technique or process that can affect material properties or interpretation of clinical data rightfully belongs in this category.

Currently, this part focuses on dental alloy and ceramic systems and the use of Weibull statistics and finite element stress analysis for the determination of the strengths and origins of failure in dental ceramic and ceramic-metal restorative systems. 
A. stress in Prosthetic and Restorative systems, (Porcelain-Metal Thermo-mechanical Compatibility)

\section{PROGRE88 REPORT}

\section{Background}

Residual and transient stresses in porcelain metal and allceramic systems are considered to be major factors which influence their fabrication and service reliability. Compressive surface stresses may make restorations less prone to failure; tensile surface stresses and large interfacial stresses (for example body-opaque, opaque-metal) are considered less desirable. The geometries of porcelain-metal restorations are complex and influence the stresses developed from fabrication and/or mastication etc.

New material systems, fabrication techniques, and restorative designs continue to be introduced. As the introduction of new materials and designs proceeds, it is desirable to have clearer understandings of how transient and residual stresses are developed, and how major material and fabrication factors can affect their magnitudes. Thus, the design of systems and fabrication methods can be more effectively guided by engineering principles and, when failures occur, they can be more readily interpreted. This study was undertaken to delineate effects of material properties, geometry (thickness) and fabrication (cooling-heating) variables on the development of thermo-mechanical stresses.

\section{Accomplishments}

The viscoelastic and elastic properties of a dental porcelain and alloy were used in viscoelastic models of porcelain-metal beams to calculate the development of both transient and residual stresses. The emphasis on the work during this reporting period has been on:

a) calculation of stresses under shell-like conditions and comparison of those stresses with those for flexible substrates.

b) an evaluation of the tempering method on the residual stress in dental porcelain.

c) an investigation into the size of the effects of analysis methods on calculated indentation fracture toughnesses and residual stresses in dental porcelain and porcelain-metal slabs.

d) an evaluation of an in vitro test method for comparison of the origin of failure of ceramic and ceramic-metal systems and expected stresses within the systems. 


\section{PROGRESS REPORT}

a) The collaborative work with Dr. Kenzo Asaoka (Tokushima U.), has resulted in calculation of stresses for the shell-like porcelain-metal systems and revealed some interesting effects. In short, residual stresses in the outermost fibers of the porcelain body layer become more positive (tensile) as the glass transition temperature sharpens. This is considered to be the result of a shift to lower temperatures of the temperatures at which viscous relaxation can occur, hence, transient residual stresses can relax less with the result that the surface cannot be put into as high a state of compressive stress.

Results for two cooling regimens are presented in the following figures (Figs. 1-8). Within each figure is shown the trend for the residual stresses as the sharpness of the glass transition temperature range is varied. Comparisons between figures can be made to reveal the effects of shell-like (rigid) substrate on residual stress as opposed to a flexible substrate. Before proceeding further it must be pointed out that the results only hold strictly for small pertabations around the inherent values of $C_{3}$ (defined in the Table); the simulations were conducted over a rather wide range of values of $c_{3}$ to provide a clear sense of the effects. The changing of $c_{3}$, which affects the glass transition temperature range while holding the activation energy for the shear viscosity constant must be artificial and the results should be viewed with this in mind; these

parameters are interrelated. However, the interrelationship is complex and not explicitly known, hence, this exercise can be considered as presenting a first approximation variation to gain insight as to how such changes might affect the residual stresses in a system. The variations about $c_{3}$ straddle those obtained from expermental measurements, i.e., $c_{3} \simeq 75-100 \times 10^{-}$ $9{ }^{\circ} \mathrm{C}^{-2}$ for both body and opaque porcelain.

For the shell-like substrate (14.5 $\mathrm{mm}$ thick) the stress in the surface of the body porcelain is virtually unaffected, for all values of $\mathrm{C}_{3}$ for the body porcelain, by the cooling rate (Figs. 5 and 6). For these simulations, the cooling is well approximated by Newton cooling with the temperature, T, represented by :

$$
T-T_{a}=\left(T_{0}-T_{a}\right) \exp \{-m t\}
$$

where; $\mathrm{T}=$ temperature,

$\mathrm{T}_{\mathrm{o}}=$ the initial temperature,

$\mathrm{T}_{\mathrm{a}}=$ ambient temperature,

$t=$ time,

and $\mathrm{m}$ is a cooling rate exponent constant. 


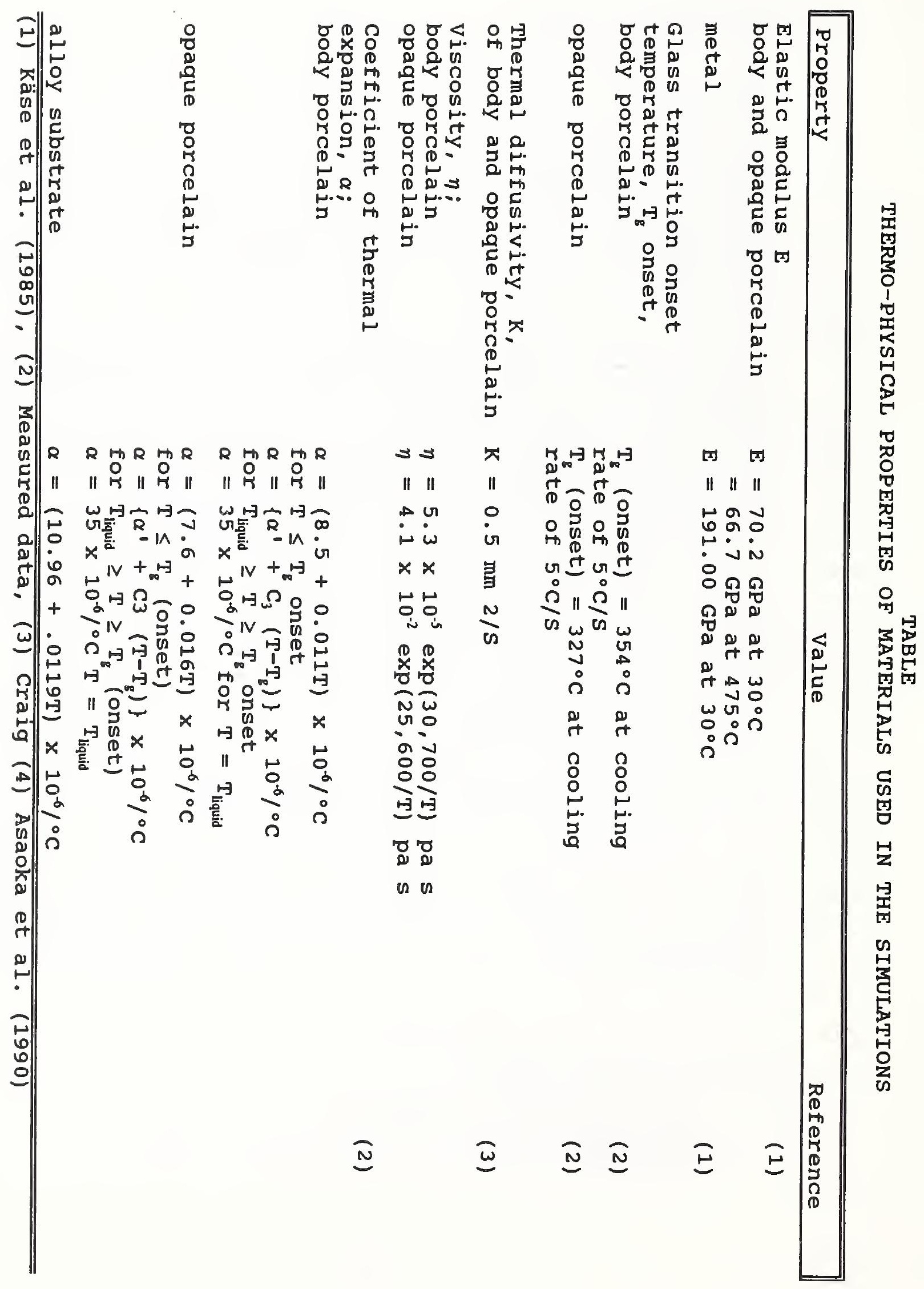


The higher cooling rate, $m=0.083$, produces stresses that are - $5 \mathrm{MPa}$ less compressive in the body porcelain at the opaque interface and about $5 \mathrm{MPa}$ more tensile in the opaque at the body interface with virtually no change in the stress in the opaque at the metal interface. The thick substrate specimen stresses are also virtually the same as the thin $(0.5 \mathrm{~mm})$ flexible substrate for $C_{3}$ body $\approx 100 \times 10^{-9}{ }^{\circ} \mathrm{C}^{-2}$ for fast cooling (Fig. 2), but slow cooling of the flexible substrate (Fig. 1) results in less compression in the porcelain body surface. Similar results are seen for the stresses in the opaque porcelain throughout the corresponding Figures $3,4,7,8$. These results indicate a much lower sensitivity of porcelain-metal restorations to cooling than is indicated by simple tempering of all glass-ceramic restorations. They indicate some rather unexpectedly strong effects of the porcelain substrate metal on controlling the stress within a system. 


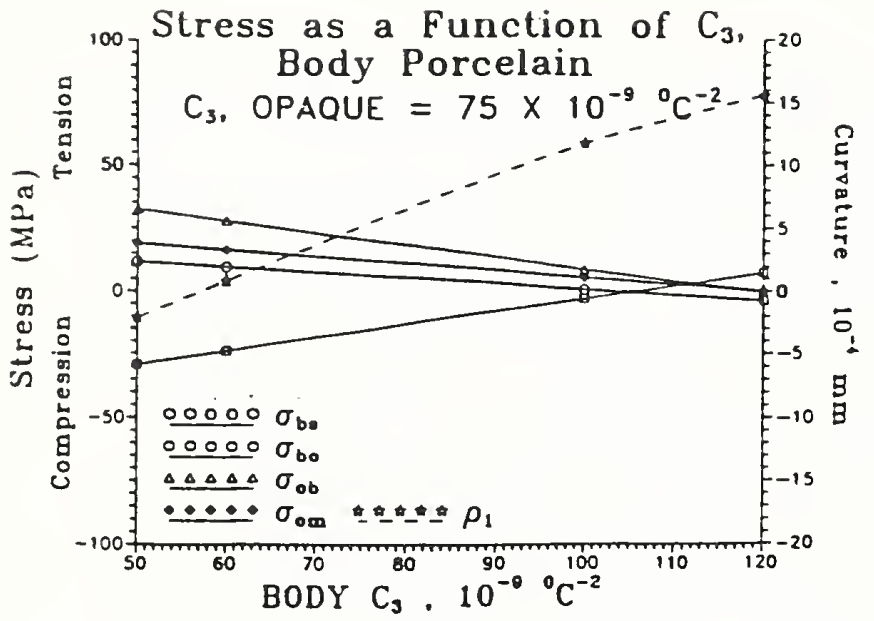

Fig. I Residual stress as a function of $\mathrm{C}_{3}$ for body porcelain, substrate thickness $=0.5 \mathrm{~mm}$ cooling rate exponent constant $\mathrm{m}=$ $0.030 \mathrm{~s}^{-1}$.

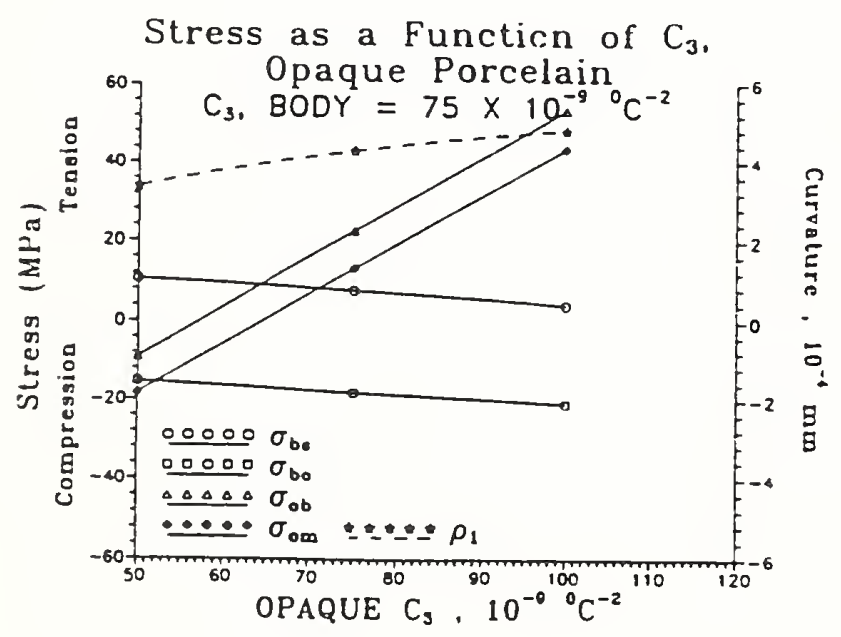

Fig. 3 Residual stress as a function of $\mathrm{C}_{3}$ for opaque porcelain, substrate thickness = $0.5 \mathrm{~mm}$, cooling rate exponent constant, $m=0.30 \mathrm{~s}^{-1}$.

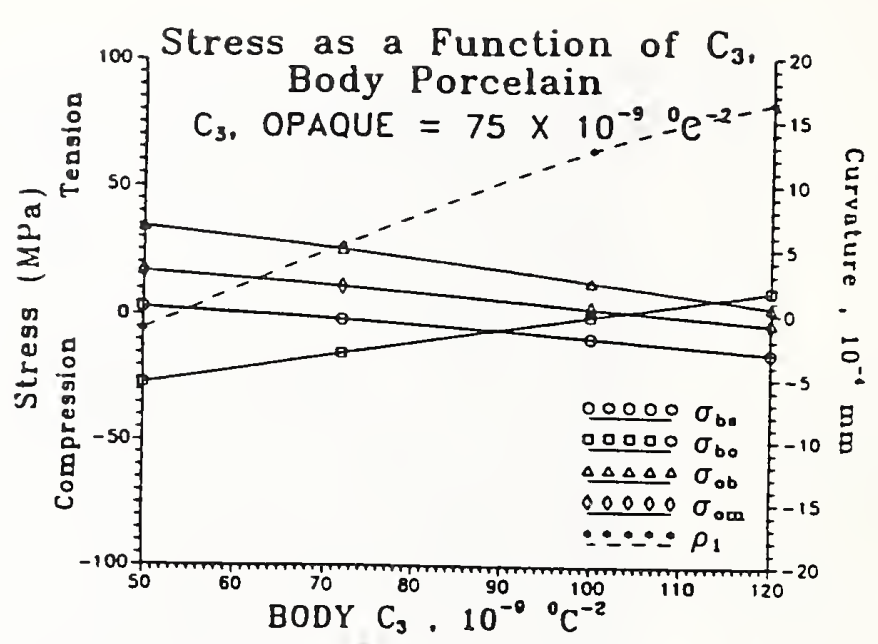

Fig. 2 Residual stress as a function of $\mathrm{C}_{3}$ for body porcelain, substrate thickness $=0.5 \mathrm{~mm}$, cooling rate exponent constant, $\mathrm{m}=$ $0.083 \mathrm{~s}^{-1}$.

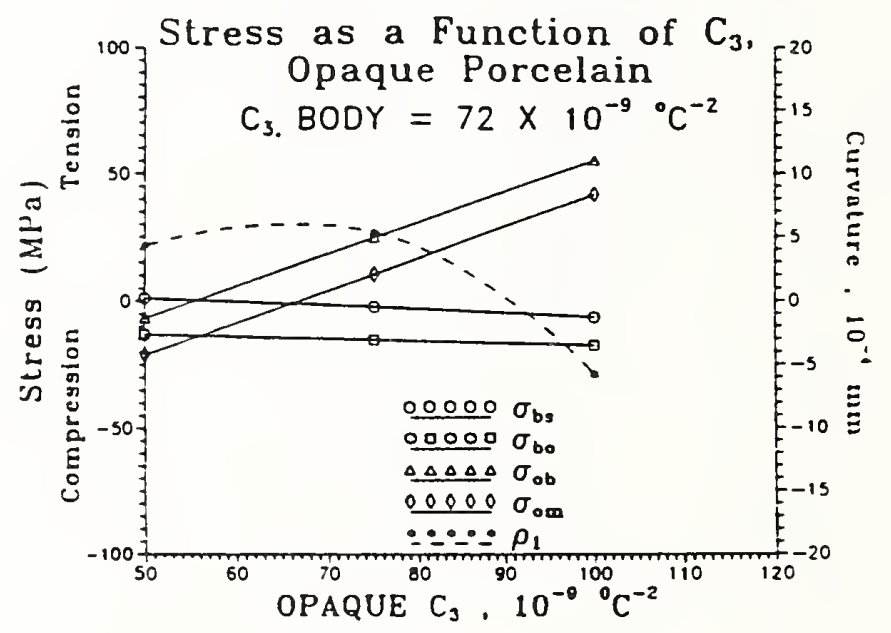

Fig. 4 Residual stress as a function of $C_{3}$ for opaque porcelain, substrate thickness = $0.5 \mathrm{~mm}$, cooling rate exponent constant, $m=0.083 \mathrm{~s}^{-1}$. 


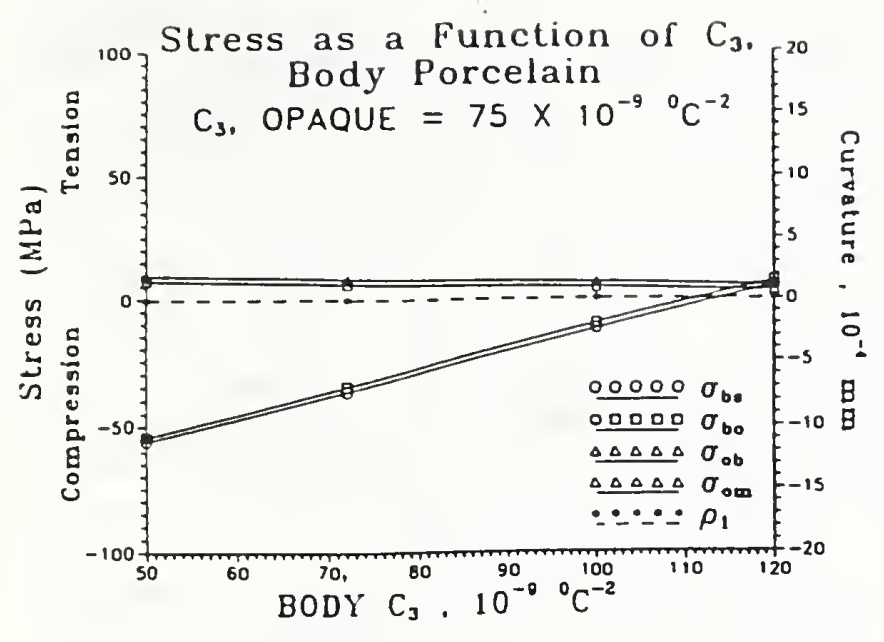

Fig. 5 Residual stress as a function of $C_{3}$ for body porcelain, substrate thickness $=14.5 \mathrm{~mm}$, cooling rate exponent $=0.021 \mathrm{~s}^{-1}$.

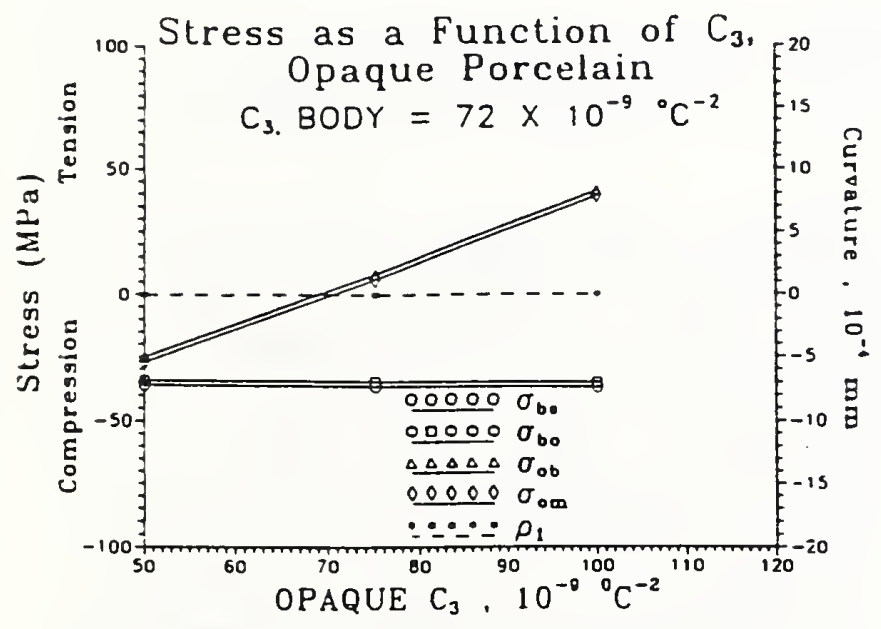

Fig. 7 Residual stress as a function of $\mathrm{C}_{3}$ for opaque porcelain, substrate thickness = $14.5 \mathrm{~mm}$, cooling rate exponent = $0.021 \mathrm{~s}_{.1}$.

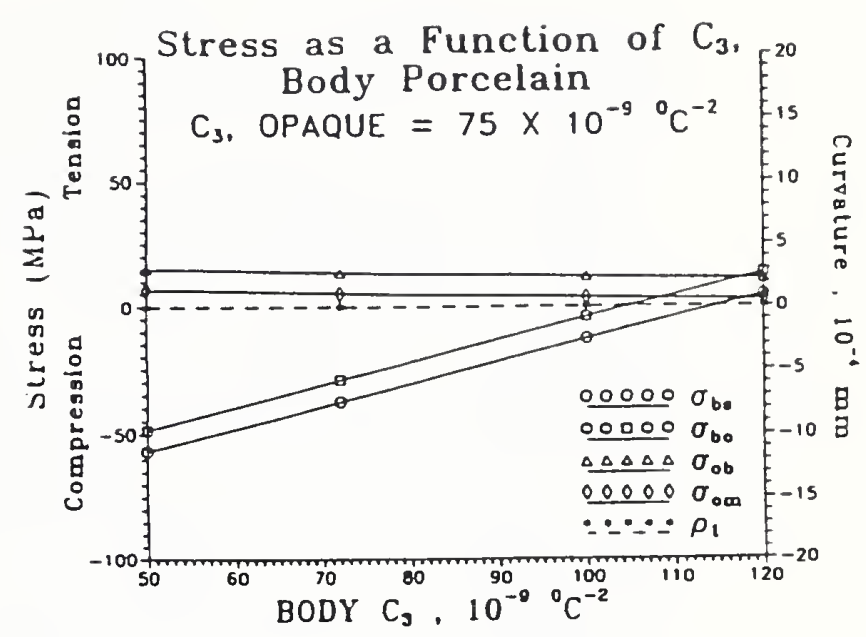

Fig. 6 Residual stress as a function of $\mathrm{C}_{3}$ for body porcelain, substrate thickness $=14.5 \mathrm{~mm}$, cooling rate exponent $=0.083 \mathrm{~s}^{-1}$.

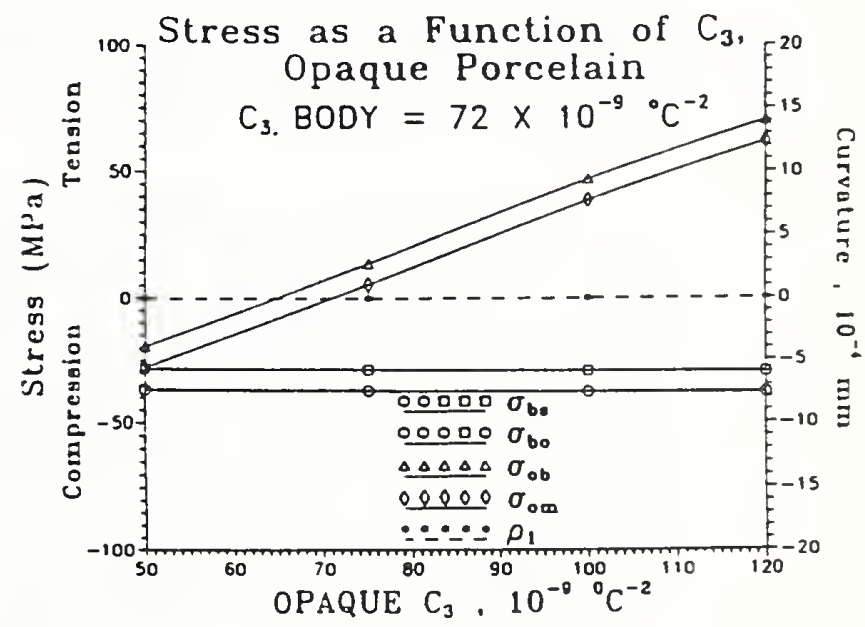

Fig. 8 Residual stress as a function of $\mathrm{C}_{3}$ for opaque porcelain, substrate thickness $=$ $14.5 \mathrm{~mm}$ cooling rate exponent $=$ $0.083 \mathrm{~s}_{-1}$ 
b) The effects of tempering methods on residual stresses were calculated by computer simulation of $2 \mathrm{~mm}$ thick porcelain disks that were either slow or fast cooled. The measured stresses were in reasonable agreement with those measured by Vicker's indentation fracture methods, thereby confirming the validity of the simulations under the conditions evaluated. The simulated surface stresses ( -21 and $-86 \mathrm{MPa})$ are higher than those reported by De Hoff and Anusavice ( -8 and $-26 \mathrm{MPa})$ [4] for slow and fast cooled conditions. Their lower values are thought to be partly due to the use of lower average heattransfer coefficients during heat tempering ( we estimated our value of the heat transfer coefficient, $U=210 \mathrm{~W} / \mathrm{m}^{2} \cdot{ }^{\circ} \mathrm{C}$ for fast cooling; they selected values of 56 and $170.3 \mathrm{~W} / \mathrm{m}^{2} \cdot{ }^{\circ} \mathrm{C}$ for $\mathrm{s} l o w$ and fast cooling respectively). Also, differences in coefficients of thermal expansion for the liquid and the use of a changing coefficient of thermal expansion throughout a glass transition temperature range (this study), as opposed to a sharp glass transition temperature, can be expected to produce differences as well. In our study, the the measured cooling rate was used for the calculation of the temperature distribution in the porcelain and did not require assumptions for a choice of a convective heat-transfer coefficient. This work was in collaboration with Dr. Kenzo Asaoka of Tokushima University.

A manuscript entitled "Influence of Tempering Method on Residual stress in Dental Porcelain" was submitted to The Journal of Dental Research.

c-1) In order to compare the computer simulation calculations of residual stress with those actually developed in dental ceramic and ceramic-metal systems, the indentation fracture method as described by Marshall and Lawn [5] is being employed. This method has been used by Anusavice et al. in their estimates of the residual stress in porcelain disks that have been submitted to tempering treatments. This method is sensitive as to how well the fracture toughness of the system can be determined. Before undertaking any study of fracture toughness and residual stress it was decided, in collaboration with the U.S. Navy (USN), to investigate the method of analysis commonly employed. The indentation fracture toughness, $\mathrm{K}_{\mathrm{Ic}}$, is related to the crack length, $C$, developed from an applied load $\mathrm{P}$ through the equation $\mathrm{K}_{\mathrm{Ic}}=\chi \mathrm{PC}^{-3 / 2}$.

$\mathrm{K}_{\mathrm{Ic}}$ has frequently been evaluated by the use of the mean value of individual determinations of $\mathrm{PC}^{-3 / 2}$ and a theoretical calculation of $\chi$. By Monte-Carlo calculation we have found that more reliable calculations of $K_{I c}$ can be made from the inverse slope of a regression analysis of $C^{-3 / 2}$ vs $P$, with the line forced through the origin. This work is being extended to analysis of the residual stress and to examination of the 
apparent fracture toughness of ceramic and ceramic-metal systems, i.e., how resistant an overall system is to crack propagation (see c-2, following).

A manuscript entitled "Error Propagation Biases in the Calculation of Indentation Fracture Toughness" will be published in the NIST Journal of Research.

c-2) Work was initiated on looking into the use of indentation load vs crack length as a method of analysis for comparing the overall fracture resistance of ceramic/ceramic-metal systems as factors such as material properties, processing methods and relative material-component thicknesses are changed. The indentation fracture toughness is $\mathrm{K}_{\mathrm{Ic}}=\chi \mathrm{PC}^{-3 / 2}$. A plot of $\mathrm{P}$ vs $\mathrm{C}^{-3 / 2}$ should yield a straight line through the origin. For different combinations of variables, the initial slope and deviation from linearity of $\mathrm{P}$ vs $\mathrm{C}^{-3 / 2}$ should allow comparisons of the abilities of systems to resist crack development; hence an apparent fracture toughness, Ka, at any load $\mathrm{P}$ can be determined from the plot of $\mathrm{P}$ vs $\mathrm{C}^{-3 / 2}$. This work is just in its early stages and was the driving force for the investigation into the methods of analysis mentioned in the preceding (part c-1).

An abstract entitled "Apparent Fracture Toughness as a Method for the Evaluation of Dental Ceramic/Ceramic-Metal systems" was prepared for submission for the Biomaterials Society Meeting in Birmingham, Alabama, in April of 1993.

d) The overall question of the effects of material parameters and processing on residual stresses, their influence on the survivability of chemical restorations and how in vitro testing might be used to verify overall system behavior has led to further collaboration with the USN on the evaluation of one type of in vitro test that is commonly employed; incisal loading of ceramic and ceramic-metal restorations. The results showed that loads much higher than commonly expected clinically are necessary for fracture. Interestingly, a Weibull analysis of the failure data was consistent with the development of catastrophic failure from the interface between the opaque porcelain and the metal.

A manuscript entitled " Fracture Behavior of In-Ceram ${ }^{R}$ Ceramic and Metal-Ceramic Restorations" was presented at the IADR Meeting in Boston Ma, 1992 and a manuscript has been prepared for submission to an archival journal. 
[1] Coornaert, J., Adriaens, P. and De Boever, J. Long-term study of porcelain-fused-to gold restorations. J. Prosthel. Dent. $51: 338-342$, 1984 .

[2] Kerschbaum, T. and Voss, R. Guss-und metallkeramisch Verblendkrone im Vergleich-Ergebnisse einer Nachuntersuchung bei Teilprothesenträgern, Dtsch Zahnaerztal Z 32:200-206, 1977.

[3] Anderson, R.J., Janes, G.R., Sabella, L.R. and Morris, H.F. Comparison of the performance on prosthetic criteria of several alternative alloys used for fixed crown and partial denture restorations: Department of Verterans Affairs Cooperative Studies Project 147, accepted for publication in J. Prosthet Dent.

[4] DeHoff, P.H., and Anusavice, K.J. Tempering stress in feldspatheic porcelain. J. Dent. Res. 68:134-138, 1989.

[5] Marshall, D.B. and Lawn, B.R. An indentation technique for measuring stresses in tempered glass surface. J. Am. Ceram. Soc. 60:86-87, 1977 . 


\section{ADDENDUM}

\section{Publications}

\section{Archival publications}

Antonucci, J.M.; Rusz, J.E.; Eichmiller, F.; Anderson, M.H. Adhesive properties of modified glass-ionomer cements. Dental Materials 8:3136 (1992).

Antonucci, J.M.; Stansbury, J.W. Polymers and elastomers for extraoral maxillofacial prosthetics (EMFP). Proceedings of Conference on Materials Research in Maxillofacial Prosthetics Transactions of the Academy of Dental Materials. 5(1):136-154 (1992).

Stansbury, J.W.; Antonucci, J.A. Evaluation of methylene lactone monomers in dental resins. Dental Materials 8:270-273 (1992).

Antonucci, J.M.; Miyazaki, K.; Akiyama, Y.; Motokowa, W.; Horibe, T.; Takagi, S. and Chow, L.C. An infrared spectroscopic study of cement formation of polymeric calcium phosphate cements. J. Japan Soc. Dent. Mater. and Dev. 11(2):278-284 (1992).

Antonucci, J.M.; Miyazaki, K.; Akiyama, Y.; Motokowa, W.; Takagi, S. and Chow, L.C. Chemical change of hardened PCA/CPC cements in various storing solutions. J. Japan Soc. Dent. Mater. and Dev. 11(2):324-330 (1992).

Stansbury, J.W. Chapter entitled "Free radical polymerization of expandable oxaspiro monomers" in Expanding Monomers: Synthesis, Characterization and Applications, CRC Press, R.K. Sadhir and R.M. Luck, Eds., pp 153-185. July 1992. Invited

Stansbury, J.W. Synthesis and evaluation of novel multifunctional oligomers for dentistry. J. Dent. Res. 71:434-437, 1992 .

Stansbury, J.W. Synthesis and evaluation of new oxaspiro monomers for double ring-opening polymerization. J. Dent. Res. 71:1408-1412, 1992.

Tesk, J.A. The National Institute of Standards and Technology and its Advanced Technology Program: A new model for government/industry innovation. Proceedings of a symposium at Forsyth Dental Center, Boston, MA, March 21-22, 1991. J. NIH Res., L.P. 3-,13-14 (1992).

\section{Preprints and Reports}

Antonucci, J.M.; Schumacher, G.E. and Code, J.E. Comparison of aliphatic and aromatic carboxylic monomers as dentin bonding resins. Microfilm Proc. of the DMG, Paper No. 1363, AADR meeting, Boston, MA, (1992). 
Antonucci, J.M.; Kikuchi, H. and Nishiyama, M. Assessing strength and durability of composites using uniaxial tension test. Microfilm Proc. of the DMG, Paper No. 1636, AADR meeting, Boston, MA, (1992).

Antonucci, J.M.; Code, J.E. and Schumacher, G.E. Ascorbic acid as an etchant conditioner for resin bonding to dentin. Polymer preprints $33(2): 505-506$ (1992).

Antonucci, J.M.; Keeny, III, S.M.; Tesk, J.A. and Wang, F.W. Fluorescent cure monitoring of dental resins. Polymer Preprint $33(2): 524-525$ (1992).

Antonucci, J.M.; Keeny, III, S.M. In vitro pin-on-disk wear testing of dental composites. Microfilm Proc. of the DMG, Paper No. 1397, AADR meeting, Boston, MA, (1992).

Tesk, J.A.; Asaoka, K. Residual stress in a porcelain-metal strip related to thermo-physical properties of materials. ICRS-3 Residual Stresses III H. Fujiwara, T. Abe and K. Tanaka, Eds., New York: Elsevier Applied Science, Vol. 1 pp. 146-150, (1992).

Asaoka, K.; Tesk, J.A. Effect of transformation of alloy on transient and residual stresses in a porcelain-metal strip. ICRS-3 Residual Stresses III H. Fujiwara, T. Abe and K. Tanaka, Eds., New York: Elsevier Applied Science, Vol. 1 pp. 626-631, (1992).

Tesk, J.A. and Asaoka, K. Residual stress in porcelain-metal systems: Effects of thermal expansion in the glass transition region. Microfilm Proc. of the DMG, Paper No. 1061, AADR meeting, Boston, MA, (1992)

Smith, T.B.; Kelly, J.R. and Tesk, J.A. Fracture behavior of InCeram and PFM crowns. Microfilm Proc. of the DMG, Paper No. 1722, AADR meeting, Boston, MA, (1992).

Stansbury, J.W. Ring-opening polymerization of a methacrylatesubstituted spiro orthocarbonate. ACS Polym. Prepr. 33(2):518-519, 1992 .

Antonucci, J.M.; Stansbury, J.W.; Farahani, M. Polymerization of dental resins via amine-acid interactions. Microfilm Proc. of the DMG, AADR, Boston, MA.

Stansbury, J.W. Spiro orthocarbonate-substituted methacrylates: New monomers for ring-opening polymerization. Microfilm Proc. of the DMG, AADR, Boston, MA.

Tesk, J.A. Dental biomaterials and engineering frontiers for the 90's. Proceedings of Third International Kyoto Symposium on Biomaterials Engineering, Nov. 20-21, (1990). Invited 


\section{Manuscripts in Press}

Schumacher, G.E.; Eichmiller, F.C. and Antonucci, J.M. Effects of surface-active resins on dentin/composite bonds. Approved for publication in Dental Materials.

Smith, T.B.; Kelly, J.R. and Tesk, J.A. Fracture behavior of InCeram and metal-ceramic restorations. Accepted for publication in $J$. Prosthodont.

Asaoka, K.; Kuwayama, N. and Tesk, J.A. Influence of tempering method on residual stress in dental porcelain. Accepted for publication in

J. Dent. Res.

\section{Submitted to Journal or Under Review}

Miyazaki, K.; Horibe, T.; Antonucci, J.M.; Takagi, S. and Chow, L.C. Polymeric calcium phosphate cements: Analysis of reaction products. Submitted to Dental Materials.

ibid.

Polymeric calcium phosphate cements: Setting reaction modifiers. Submitted to Dental Materials.

Kelly, J.R.; Cohen, M.E. and Tesk, J.A. Error propagation biases in the calculation of identations fracture toughness. Under review for the NIST J. of Res. Publications.

Stansbury, J.W. Observations related to the amine-catalyzed coupling reaction of aldehydes and acrylates, submitted to Macromolecules.

\section{Invited Talks}

Antonucci, J.M. Polymers and elastomers for extraoral maxillofacial prosthetics (EMFP). Conference on Materials Research in Maxillofacial Prosthetics. Academy of Dental Materials, Chicago, IL, Feb. 14, (1992).

Antonucci, J.M. Adhesion of dental resins via acid-base free radical mechanisms. Poster presentation at the 1992 Gordon Research Conference on the Science of Adhesion Aug. 11, (1992).

Antonucci, J.M.; Stansbury, J.W. and Cheng, G.W. Novel hydrophilic and hydrophobic acrylic monomers and oligomers for dental and medical applications. ACS Meeting, Washington, D.C. Symposium on Polymers of Biological and Biomedical Significance, Aug., (1992).

Stansbury, J.W. Ring-opening polymerization of a methacrylatesubstituted spiro orthocarbonate. Polymers of Biological and Biomedical significance symposium at ACS Polymer Chemistry Div., Washington, D.C. August 1992. 
Antonucci, J.M.; Code, J.E. and Schumacher, G.E. Ascorbic acid as an ethchant/conditioner for dentin bonding. AADR Meeting, Boston, MA, March, (1992).

Antonucci, J.M.; Matsuya, Y.; Matsuya, S.; Takagi, S. and Chow, L.C. Polymeric calcium phosphate cements derived from poly(methyl vinyl ether-maleic acid). AADR Meeting, Boston, MA, March (1992).

Antonucci, J.M.; Keeny, S.M. In vitro pin-on-disk wear testing of dental composites. AADR Meeting, Boston, MA, March (1992).

Antonucci, J.M.; Schumacher, G.E. and Code, J.E. Comparison of aliphatic and aromatic carboxylic monomers as dentis bonding resins. AADR Meeting, Boston, MA, March, (1992).

Antonucci, J.M.; stansbury, J.W. and Farahani, M. Polymerization of dental resins via acid-amine interactions. AADR Meeting, Boston, MA March, (1992).

Antonucci, J.M.; Stansbury, J.W.; Keeny, III, S.M. and Matsukawa, S. Effect of aldehydes on the mechanical strength of dental composites. IADR Meeting, Glasgow, Scotland July, 1992.

Antonucci, J.M.; Kikuchi, H. and Nishiyama, M. Assessing strength and durability of composites using uniaxial tension test. IADR Meeting, Glasgow, Scotland, July, (1992).

Antonucci, J.M.; Code, J.E. and Schumacher, G.E. Ascorbic acid as an etchant conditioner for resin bonding to dentin. ACS Meeting, Washington, D.C. Symposium on Polymers of Biological and Medical Significance Aug. (1992).

Antonucci, J.M.; Keeny, III, S.M.; Tesk, J.A. and Wang, F.W. Fluorescent cure monitoring of dental resins. ACs Meeting, Washington, D.C. Symposium on Polymers of Biological and Biomedical Significance. Aug., (1992).

Smith, T.B.; Kelly, J.R. and Tesk, J.A. Fracture behavior of InCeram and PFM crowns. Paper \#1722 AADR meeting, Boston, MA, (1992).

Stansbury, J.W. Spiro orthocarbonate-substituted methacrylates: New monomers for ring-opening polymerization. AADR, Boston, MA, March 1992 .

* (Contribution from our collaborative efforts with the ADA/PRC on a Center of Excellence Materials Science Research Project ("Resin Systems with Minimal Dimensional Changes")

AII AADR and IADR abstracts also include a WERB reviewed manuscript that are part of the microfiche proceedings of the Dental Materials Group of IADR/AADR. 
*Antonucci, J.M.; Stansbury, J.W. and Reed, B.B. Ring-opening dental resin systems based on cyclic acetals. Polymer Preprint 33(2):520-521 (1992).

*Antonucci, J.M.; Stansbury, J.W. and Reed, B.B. Ring-opening dental resin systems based on cyclic acetals. AADR Meeting, Boston, MA, March, (1992).

*Antonucci, J.M.; Stansbury, J.W. and Reed, B.B. Radical ring-opening efficiency of two aryl substituted cyclic ketene acetals. Composite applications. ACS Meeting, San Francisco, CA. Symposium on Advanced Composites. April, (1992).

*Antonucci, J.M.; Stansbury, J.W. and Reed, B.B. Ring-opening dental resin systems based on cyclic acetals. ACS Meeting, washington, D.C. symposium on polymers of Biological and Biomedical significance (1992).

*Reed, B.B.; Stansbury, J.W.; Antonucci, J.M. Ring-opening dental resin systems based on cyclic acetals. Microfilm Proc. of the DMG, AADR, Boston, MA.

*Reed, B.B.; Stansbury, J.W.; Antonucci, J.M. Ring-opening dental resin systems based on cyclic acetals. AADR, Boston, MA. March 1992.

\section{Patents}

Stansbury, J.W. U.S. Patent No. 5145374 Synthetic Dental Compositions and Bonding Methods, issued september 8, 1992. 


\section{Addenda}

The following publications and talks are those given by the rest of the Dental and Medical Materials group, which comprises research associates from the American Dental Association and the National Institute of Dental Research, as well as numerous guest scientists from the U.S. Public Health Services, the United States Naval Dental Corp. and other institutions. The NIDR IA with NIST makes possible the NIST dental research program, without which these ancillary outputs would not be possible.

American Dental Association Health Foundation/PRC Papers published in FY 92 .

Babic-Ivancic, V.; Furedi-Milhofer, H.; N. Brnicevic, N.; and Markovic, M. Precipitation and solubility of calcium hydrogenurate hexahydrate. J. Res. Natl. Inst. Stand. Technol. 97:365-372, (1992).

Bowen, R.L. Guest Editorial: What's in those wonder(ful) restorative materials? J. Dent. Res. 71(9):1640, 1992.

Bowen, R.L. and Marjenhoff, W.A. Dental composites/glass ionomers: The Materials. Adv. Dent. Res. 6:44-49, (1992).

Bowen, R.L.; Eichmiller, F.C. and Marjenhoff, W.A. Gazing into the future of esthetic restorative materials. J. Am. Dent. Assoc. 123:3339, May, (1992).

Chow, L.C.; Takagi, S. and Shih, S. Effect of a two-solution fluoride mouthrinse on remineralization of enamel lesions in vitro. J. Dent. Res. 71(3):443-447, March, (1992).

Eichmiller, F.C. Clinical use of beta-quartz glass-ceramic inserts. Compend. Contin. Educ. Dent. 13(7):568-576, (1992).

George, L.A.; Eichmiller, F.C. and Bowen, R.L. An intrinsically colored microcrystalline glass-ceramic for use in dental restorations. American Ceramic Bulletin 71(7):1073-1076, (1992).

Misra, D.N. Reaction of alizarin red $s$ with hydroxyapatite: a stoichiometry and surface effect. Colloids and Surf 66:181-187 (1992).

Miyazaki, K.; Akiyama, Y.; Motokawa, W.; Horibe, T.; Antonucci, J.M.; Takagi, S. and Chow, L.C. An infrared spectroscopic study of cement formation of polymeric calcium phosphate cement. J. Japan Soc. Dent. Mater. and Dev. 11(2):278-284, (1992).

Miyazaki, K.; Akiyama, Y.; Motokawa, W.; Horibe, T.; Antonucci, J.M.; Takagi, S. and Chow, L.C. Chemical change of hardened PCA/CPC cements 
in various storing solutions. J. Japan Soc. Dent. Mater. and Dev. $11(2): 324-330$, (1992).

Rusz, J.E.; Antonucci, J.M.; Eichmiller, F. and Anderson, M.H. Adhesive properties of modified glass-ionomer cements. Dent. Mater. $8: 31-36$, (1992).

Siew, C.; Gruninger, S.E.; Chow, L.C. and Brown, W.E. Procedure for the study of acidic calcium phosphate precursor phases in enamel mineral formation. Calcif. Tissue Int. 50:144-148, (1992).

Tung, M.S.; Tomazic, B. and Brown, W. E. The effects of magnesium and fluoride on the hydrolysis of octacalcium phosphate. Arch. Oral Biol. 37 (7): 585-591, (1992).

Vogel, G.L.; Mao, Y.; Carey, C.M.; Chow, L.C. and Takagi, S. In vivo fluoride concentrations measured for two hours after a NaF or a novel two-solution rinse. J. Dent. Res. 71(3):448-452, March, (1992).

Waterstrat, R.M.; Bendersky, L.A. and Kuentzler, R. Deformation twinning, slip, martensite formation and crack inhibition in the B2type $\mathrm{Zr}_{50} \mathrm{Pd}_{35} \mathrm{Ru}_{15}$ alloy, In: shape-Memory Materials and Phenomena Fundamental Aspects and Applications, C.T. Liu, H. Kunsmann, K. Otsuka, and M. Wuttig, Eds., Pittsburgh: Materials Research Society, 1992, pp. 115-120.

Submitted to Journal or Under Review.

Bowen, R.L. Adhesive bonding and glass-ceramic inserts for composite restorations.

Bowen, R.L. and Marjenhoff, W.A. Adhesion of composites to dentin and enamel.

Dickens-Venz, S.; Takagi, S.; Chow, L.C.; Bowen, R.L.; Johnston, A.D. and Dickens, B. Physical and chemical properties of resin-reinforced calcium phosphate cements.

Eichmiller, F.C. An overview of betz quartz glass-ceramic inserts.

Eichmiller, F.C. and Parry, E.E. Tapered X-pin attachments for fixed bridges.

Farahani, M.; Eichmiller, F.C.; and McLaughlin, W.L. New method for shielding electron beams used for head and neck cancer treatment.

Farahani, M.; Eichmiller, F.C. and McLaughlin, W.L. Shielding high energy beams in cancer treatment. 
Fowler, B.O.; Markovic, M. and Brown, W.E. Octacalcium phosphate. III. Infrared and Raman bibrational spectra.

Johnston, A.D.; Cellarosi, S.; Eichmiller, F.C. Effect of testing mode on bond strength.

Marjenhoff, W.A. and George, L.A. Paffenbarger Research Center: The cutting edge of dental science.

Markovic, M.; Fowler, B.O. and Brown, W.E. Kinetics of formation and solubility of octacalcium phosphate succinate.

Markovic, M.; Fowler, B.O. and Brown, W.E. Octacalcium phosphate carboxylates. I. Preparation and identification.

Mathew, M.; Schroeder, L.W. and Brown, W.E. Crystal structure of dicalcium potassium trihydrogen bis(pyrophosphate) trihydrate.

Mathew, M.; Takagi, S. and Ammon, H.L. The crystal structure of calcium adipate monohydrate.

Miniotis, N.M.; Bennett, P.B.; Johnston, A.D. Molar efficiency study of chlorinated NPG substitutes in dentin bonding.

Misra, D.N. Adhesion to hydroxyapatite: Coupling agents, hydrogen bonding and adsorption.

Misra, D.N. Adsorption of sodium polyacrylate on hydroxyapatite:

Effect of ionic charge.

Misra, D.N. Adsorption of zirconyl-(4-diethylamino) benzoate and acid on hydroxyapatite: solvent effect, reversibility and surface orientation.

Misra, D.N. Interaction of chlorhexidine digluconate with and Adsorption of chlorhexidine on hydroxyapatite.

Miyazaki, K.; Akiyama, Y.; Motokawa, W.; Horibe, T.; Antonucci, J.M.; Takagi, S. and Chow, L.C. An infrared spectroscopic study of cement formation of polymeric calcium phosphate cement.

Miyazaki, K.; Akiyama, Y.; Motokawa, W.; Horibe, T.; Antonucci, J.M.; Takagi, S. and Chow, L.C. Chemical change of hardened PCA/CPC cements in various storing solutions.

Nemoto, K.; Komatsu, K.; Horie, K.; Tomotune, K. and Bowen, R.L. Shrinkage stress of composite resins during hardening. I. Design of the apparatus and shrinkage stresses of chemically and light-cured resins.

Nieberlein, E.J. and Johnston, A.D. Steric effects on N-phenylglycine dentin bonding. 
Ratzker, M. and Lashmore, D.S. Electropolishing of titanium alloys.

Richards, N.D., Eichmiller, F.C., Dickens, S.V., and Simoni, F.V. The effect of initiators and stabilizers on the bond strength to nonprecious alloy.

Shearer, B.; Naleway, C.; Chow, L.C.; Ebisudani, K. and Chou, H. Dissolution behavior of apatites under bacterial acid challenge.

Simpson, M.D.; Horner, J.A.; Brewer, P.D.; Eichmiller, F.C.; and Pashley, D.H. Effects of aluminum oxalate/glycine pretreatment solutions on dentin permeability.

Tomazic, B.B.; Brown, W.E. and Eanes, E.D. A critical evaluation of the purification of biominerals by hypochlorite treatment.

Tung, M.S.; Bowen, H.J.; Derkson, G. and Pashley, D.H. The effects of calcium phosphate solutions on dentin permeability.

Tung, M.S. and O'Farrell, T.J. Effect of ethanol on the formation of calcium phosphates - A simple method for preparation of amorphous calcium phosphate.

Tung, M.S. and O'Farrell T.J. The effect of ethanol on the solubility of dicalcium phosphate dihydrate on the system $\mathrm{Ca}(\mathrm{OH})_{2}-\mathrm{H}_{2} \mathrm{PO}_{4} \cdot \mathrm{H}_{2} \mathrm{O}$ at $37^{\circ}$ c.

Tung, M.S. and Sung, P. Calcium phosphate type reference material: Development, preparation and characterization.

Waterstrat, R.M. New Zr-Pd-Ru alloys show extraordinary resistance to fracture and wear.

waterstrat, R.M., Bendersky, L.A., Kuentzler, R. Deformation twins and martensite in ductile B2 alloys of the $\mathrm{Zr}(\mathrm{PdRu})$ system.

Waterstrat, R.M. and Okabe, T. Dental amalgam.

\section{NIDR Research Associate Papers}

Skrtic, D.; Eanes, E.D. Effect of membrane cholesterol on calcium phosphate formation aqueous suspensions of anionic liposomes. Calcif. Tiss. Int. 50, 55-60, 1992 .

Skrtic, D.; Eanes, E.D. Effect of different phospholipid-cholesterol membrane compositions on liposome-mediated formation of calcium phosphates. Calcif. Tiss. Int. 50, 253-260, 1992 .

Eanes, E.D. Dynamics of calcium phosphate precipitation. In: (Bonucci E., ed.) Calcification in biological systems. Boca Raton: CRC Press pp. 1-17, 1992. 
Skrtic D., Eanes, E.D. Membrane-mediated precipitation of calcium phosphate in model liposomes with matrix vesicle-like lipid composition. Bone and Mineral 16, 109-119, 1992 .

Eanes, E.D. Mixed phospholipid liposome calcification. Bone and Mineral 17, 269-272. 

